\title{
Cholesteric liquid crystals in living matter
}

\section{Michel Mitov*}

Liquid crystals play an important role in biology because the combination of order and mobility is a basic requirement for self-organization and structure formation in living systems. Cholesteric liquid crystals are omnipresent in the living matter in both in vivo and in vitro conditions and address the major types of molecules essential to life. In animal and plant kingdoms, the cholesteric structure is a recurring design, suggesting a convergent evolution to an optimised left-handed helix. Herein, we review the recent advances in the cholesteric organisation of DNA, chromatin, chitin, cellulose, collagen, viruses, silk and cholesterol esters deposition in atherosclerosis. Cholesteric structures can be found in bacteriophages, archaea, eukaryotes, bacteria nucleoids, chromosomes of unicellular algae, sperm nuclei of many vertebrates, cuticles of crustaceans and insects, bone, tendon, cornea, fish scales and scutes, cuttlebone and squid pen, plant cell wall, virus suspensions, silk produced by spiders and silkworms, and arterial wall lesions. This article specifically aims at describing the consequences of the cholesteric geometry in living matter, which are far from being fully defined and understood, and discusses various perspectives. The roles and functions of biological cholesteric liquid crystals include maximisation of packing efficiency, morphogenesis, mechanical stability, optical information, radiation protection and evolution pressure.

\footnotetext{
${ }^{*}$ Centre d'Elaboration de Matériaux et d'Etudes Structurales (CEMES), CNRS, BP 94347, 29 rue Jeanne-Marvig, F-31055 Toulouse cedex 4. E-mail : mitov AT cemes.fr
} 


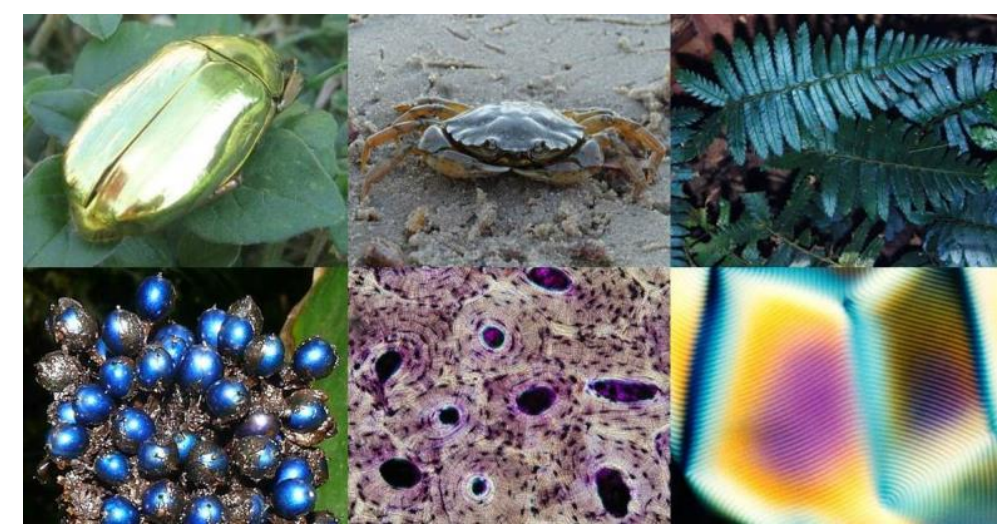

Cholesteric liquid crystals are ubiquitous in animal and plant kingdoms. We review the advances and open questions in the cholesteric organisation of DNA, chromatin, chitin, collagen, cellulose, viruses, silk fibroin and cholesterol esters.

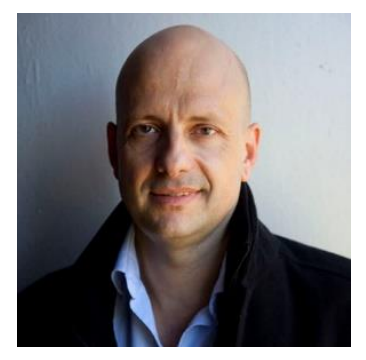

Michel Mitov graduated from the University of Nice-Sophia Antipolis (France), where he received his PhD in condensed matter physics. He is Director of Research at CNRS (National Center for Scientific Research) and leader of the Liquid Crystal Group at Centre d'Elaboration de Matériaux et d'Etudes Structurales (CEMES) in Toulouse. His current areas of interest are the design and optical response of complex cholesteric liquid crystal structures (pitch gradient, double helicity, spatially-variable helicoidal axis), and bio-inspired versions from insect carapaces. He is the inventor of patents related to smart reflective windows to control solar light and heat. He has published a science popularisation essay on soft matter ("Sensitive Matter-Foams, Gels, Liquid Crystals and Other Miracles", Harvard University Press, 2012). 


\section{Introduction}

\subsection{Historical background}

In 1957, Glenn H. Brown and Wilfrid G. Shaw from the University of Cincinnati, Ohio, published a notable 100-page long article reviewing the knowledge on the states of the matter once named as liquid crystals (LCs) [1]. During those times, LCs were neglected or even forgotten in textbooks. The first book on the structure and properties of LCs was published in 1962 by George Gray from the University of Hull, England [2]. In August 1965, the first meeting of the International Liquid Crystal Conference series was organised under the leadership of Brown at the Kent State University, Ohio. On 28 May 1968, a press conference was held in New York City at the 30 Rockefeller Center, where the RCA management revealed their LC research results and showed prototype displays. These displays included a numeric indicator, small electronic window, television test pattern and fully functional digital clock [3]. These devices were revolutionary and they marked the beginning of a new era for a novel industry. Therefore, the mid-1960s was considered as a period of the great revival of LC research, in the USA, after the pioneering work conducted in Germany and France between 1888 and 1920s.

The seminal book "Crystals that flow" primarily focused on compiling classical papers on the history of LC research with commentary [4]. The readers may refer to the book "Soap, science, \& flat-screen TVs" to understand the background behind the discoveries and the communications between the scientists, which also provides social and political contexts [5]. The milestones of the pioneering research on LCs from 1888 to 1922 have been summarised in a five-page report [6]

\subsection{Motivation of the Review}

From 1968 to around 1990s, much attention was focused on the chemistry, physics and technology of flat panel LC displays (LCDs) in both public and private sectors, and a huge amount of funding was available to solve fundamental problems and to develop the flourishing market of flat screens. The 
response time of cholesteric LCs (CLCs) was too slow to display video frame rate dynamic images, and the driving voltages were high. Therefore, these chiral phases probably could not gather the attraction they deserved with regard to the scientific questions they raise to gain fundamental knowledge and find innovative (non-display) applications.

Furthermore, compared with LCs for flat screens, biological LCs have received very less attention from the scientific community although they are highly important as no life is possible without them. LCs are commonly classified as thermotropic and lyotropic LCs. The most encountered LCs in nature are lyotropic [7], for which the organization is determined or changed by concentration, rather than temperature like in the case of thermotropic LCs [8] found in LCDs. For example, in the cell membrane, the LC phase forms from the dissolution of phospholipids in water. The phospholipid bilayer in the cell membrane is a smectic LC that is reduced to two layers [9]. Amylopectin side chains in starch-a glucose polymer of vast importance found in wheat, rice and potatoes-may adopt smectic structures [10]. Solanine, a glycoalkaloid found in small quantity in potatoes, tomatoes and eggplants, exhibits a smectic $A^{*}$ phase [11]. Muscles have been long considered as biological analogues of LCs [12]. Protein filaments (myosin and actin) in smooth and striated muscles have an organisation reminiscent from nematic and smectic structures [13]. The difference between crossstriated muscles (arthropods and vertebrates) and oblique-striated muscles (annelids and molluscs) corresponds to the difference between smectic $A$ and $C$ phases. The helicity observed in certain obliquely striated muscles has its counterpart with smectic $C^{*}$ phase [14]. Nevertheless, smectic phases were rarely found, probably due to polydispersity in the length of fibrils composed of biological macromolecules [15]. During this review, columnar phases (in DNA) or nematic phases (in chitin, collagen, cellulose, viruses and silk) will incidentally appear. However, the LC structure, which is ubiquitously present in living matter and whose chirality is one of the most important features, is a cholesteric structure found in almost all types of animals and plants. The unifying structure of biological CLCs is attributed to the helicoidal organisation of elementary bricks such as molecules, 
macromolecules, and microfibrils as anisotropic aggregates of macromolecules (chitin, collagen and cellulose)-with no positional order for these bricks. This is the basic structure of CLC phase.

Therefore, it is necessary to dedicate a review to the cholesteric organisation in living organisms, regardless of the nature of the constituent molecules or taxa. Due to the large bibliographic domains involved, there is a huge dispersion of data. One can be tempted to apply to biological CLCs the main concepts introduced by physicists in the field of synthetic LCs; however, reviewing and discussing these concepts is needed. This review may be of interest to a large audience in the fields of soft matter physics, LC science, biological material science and engineering, biophysics, developmental biology, plant and animal physiology and botany.

\subsection{Methods}

CLC phases are the most common LC phases formed by biopolymers; therefore, this article focuses on the cholesteric arrangements found in nucleic acids (e.g. DNA), chromatin (i.e. macromolecule complex consisting of DNA and proteins), polysaccharides (e.g. chitin and cellulose) and proteins (e.g. collagen, silk fibroin). In addition, virus and cholesterol ester depositions in atherosclerosis are addressed. The cholesteric structure found in the following organisms is discussed in this study: bacteriophages, archaea, eukaryotes, bacteria nucleoids, chromosomes of unicellular algae dinoflagellates, sperm nuclei of many vertebrates, exoskeleton of arthropods (such as crustaceans and insects), bone, dentin, tendon, cornea (such as that of fishes, amphibians, reptiles and birds), fish armour, coleoid cephalopods (such as cuttlebone and squid pen), molluscan nacre, plant cell wall (such as that from leaves of tropical ferns, berry-like fruits, wood or cotton pulp), virus suspensions, silk (such as that from spiders and silkworms) and arterial wall lesions.

The following questions were taken into consideration while analysing the recent advances:

- Which elementary bricks are responsible for the CLC organisation?

- In which living organisms are they found? 
- At what scale does the CLC organisation occur?

- What is the state-of-the-art before the 2000s?

- What kinds of cases are found in the literature over last 10 years?

- What are the current trends in the field?

- Does the CLC organisation differ from one organism to another and from animals to plants?

- What are the accepted or debatable biological functions?

- To what extent biological CLC structures may inspire artificial structures and for which applications?

- Which are the least investigated topics?

- Can fresh research directions be suggested and future directions be speculated?

\subsection{Article Content}

Section 2 gives a historical perspective on the early days of research in LC science and states the speculations on liquid-crystalline organisations in living matter as essential features for the realisation of processes inherent to life. Section 3 describes the following main features of the CLC phase: structural parameters, optical properties, applications and the twisted plywood model, which is of paramount importance for analysing different scale textures and the textures found in different organisms or tissues. All the sections are then organised around the main biological materials, and discuss and highlight the current progress and problems using a few studies from the literature that are of particular interest and significance. Sections 4 to 10 discuss the basic understanding of cholesteric organisation, its main features, functions and (when applied) evolutionary context in the DNA and chromatin, chitin (in vivo and in vitro), collagen (in situ and ex situ), cellulose, suspensions of rod-like viruses, silk fibroin, and cholesterol ester deposits in atherosclerosis. At the end of each section, conclusions are drawn or interesting questions are posed to make the readers aware of the future prospects. In the last, Section 11 summarises the previous findings and concludes with general perspectives. 


\section{Historical perspective}

Friedrich Reinitzer (1857-1927) was a botanist, known as a biochemist in the modern terms, at the Institute of Plant Physiology, German University of Prague, in 1888. His primary work focused on cholesterol derived crystals extracted from carrot roots [16] and he found that cholesteryl benzoate had 'two melting points', cited in Reinitzer's letter dated 14 March 1888. This letter was addressed to the crystallographer Otto Lehmann (1855-1922), a physicist at the Polytechnical School of Aachen (Germany) who specialised in the growth phenomena and phase transitions of crystalline materials. In his letter, Reinitzer explained that the small crystals lose their rigidity at $145.5^{\circ} \mathrm{C}$; this 'first' melting point is the temperature at which the solid turned into a milky fluid. The 'second' melting point was at $178.5^{\circ} \mathrm{C}$, later named the clearing point; at this temperature, the material became transparent. On cooling, the material exhibited violet and blue colours, which then disappeared, leaving the liquid substance cloudy. This is starkly different from the current knowledge on the crystalline matter, which believes that a crystal should lose both its colour and solidity at a single, unique temperature. In 1854, Rudolf Virchow [17] described similar unusual behaviour for myelin-the sheath that surrounds nerve fibres. Furthermore, Carl von Mettenheimer [18] showed that myelin is birefringent. Between 1861 and 1887, different chemists, like Julius Planer [19], reported strange colour effects in cholesterol esters, but the complexity of their observations and the difficulty of duplicating them did not encourage them to pursue their investigations. For this reason, science historians consider that LCs were discovered in 1888 by Reinitzer, who was the first to give a detailed description of his observations and to recognise that the strange behaviour of these 'crystals' was a significant, novel phenomenon and not an artefact.

Lehmann reproduced the phenomena observed by Reinitzer in a large number of substances and concluded that it was a general phenomenon. He was the main promoter of 'liquid crystals'; he promoted not only the term but also the research activities in this field. In addition to his use of heterodox terms, Lehmann's links with the ultra-Darwinist Ernst Haeckel (1834-1919) detracted him 
from a credibility. Haeckel was a zoologist whose view on the theory of evolution was more than controversial. He believed that matter, including inert one, was endowed with a soul. He spoke literally on 'crystal souls' [20]. He was convinced that Lehmann's LCs contained the essence of life itself, i.e. the vital force, that they linked the living and the dead; it was a link he was desperately seeking. Apart from the non-scientific claims of Lehmann and Haeckel, they were probably the first scientists to propound upon the idea that the LC state is responsible for many of the biological processes. The roots of research on LCs lie in living matter.

The liquid crystalline phases that Reinitzer observed were chiral phases, later named as cholesteric phases and blue phases. The term cholesteric was coined in 1922 by Georges Friedel (1865-1933) [21] as this state of matter was discovered in cholesterol esters by Reinitzer. However, post the discovery, cholesteric-liquid-crystalline states were found in other substances not connected with cholesterol. The CLC phase is also known as the chiral nematic phase, which stems from the fact that the phase is like the twisted version of the nematic phase. A small amount of a chiral (non-racemic) compound, dissolved in a nematic LC, may transform it into a CLC [21].

\section{Main features of the cholesteric liquid crystal phase}

\subsection{Structure}

The CLC phase exhibits a helicoidal structure with a twist axis perpendicular to the local director (Fig. 1.a), which comes in whole or in part from the molecular chirality (rod-like molecules here). If the structure is cut in a direction perpendicular to the helicoidal axis, local nematic order would appear. A nematic LC phase is an achiral phase that exhibits a purely orientational order of elongated molecules. The CLC structure is often drawn as a stack of layers with an orientational order of molecules in each plane and rotation by a constant angle of each plane with respect to its neighbours. However, this representation is only a guide for the observer and these layers do not 
have a physical reality because the CLC phase is not a layered system. When the CLC structure is modelled as a layered system, each layer behaves like a uniaxial anisotropic medium with the slow axis parallel to the rod-like molecules and the fast axis perpendicular to them. The two axes twist regularly without discontinuity from 'layer' to 'layer'.

The cholesteric phase is characterised by the following two structural parameters: the helical pitch and twist sense. The pitch gives the distance along the helicoidal axis that corresponds to a rotation of $360^{\circ}$ in the orientation of the rod-like molecules (Fig. 1.b). Due to the head-tail symmetry of the molecules, the periodicity of the cholesteric phase along the axis is given by half the pitch. The magnitude of the pitch can considerably vary from a few tens of nanometres to many micrometres. The twist sense determines a left- or right-handed helix. To date, there is no method to predict which chiral molecular configuration will give a certain helix handedness. Furthermore, quantitative prediction of the pitch based on molecular features is another unsolved problem. One of the greatest challenges in LC science is understanding and anticipating the connection between the molecular chirality and the structure chirality of LC phases.

Topological defects are key features in LCs, and the connection between symmetry and defects is a contemporary research subject in biology. The spatial confinement of the cholesteric structure in complex curved geometries, like in chromosomes, imposes restrictions on the configurations of the order parameter and requires the appearance of topological defects in the ground state [22]. It leads to a rich palette of defect structures such as focal conic domains and oily streaks. The complexity of twisted structures with defects makes the CLCs an important subject to investigate the relationship between the symmetry of molecular interactions and the mesoscopic organization. 


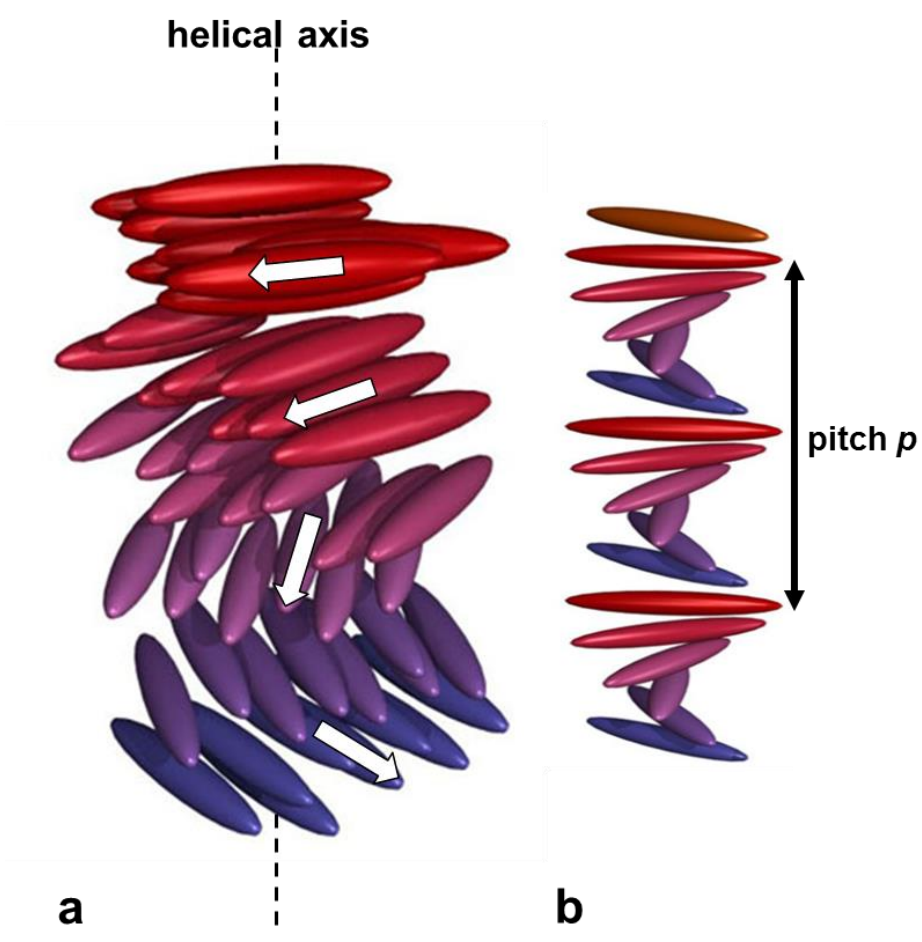

Fig. 1. The helicoidal structure of the cholesteric liquid crystal phase. (a) The twist in the arrangement of rod-like molecules is shown with the help of the rotating white arrow. A partial twist is represented. (b) A complete revolution of the arrow along the helicoidal axis occurs over a length equal to the pitch. Adapted with permission of authors from a figure by K. G. Yager (Brookhaven National Laboratory) and C. J. Barrett (McGill University).

\subsection{Main optical properties}

CLC material is multifunctional in a proper orientation (i.e. when it presents a planar Bragg texture, for which the helicoidal axis is perpendicular to the surfaces of the sandwich cell). At the same time, it is a reflector, a notch filter, a polariser and an optical rotator.

When light propagates through a CLC slab in the Bragg regime, the medium produces interference colours and gives rise to the fundamental property of selective light reflection. At the normal incidence (i.e. for light propagating along the helicoidal axis), the maximum selective reflection occurs at a wavelength of $\lambda_{0}$ which is directly related to $p$ by $\lambda_{0}=n p$, where $n$ is the average refractive index $\left[n=\left(n_{\mathrm{o}}+n_{\mathrm{e}}\right) / 2\right.$ and $n_{\mathrm{o}}$ and $n_{\mathrm{e}}$ are the ordinary and extraordinary indices or refraction, 
respectively, which are measured in directions perpendicular and parallel to the local (uniaxial) director, respectively].

The light reflected by a CLC is circularly polarised (CP). Consider the incident light as linearly polarised, which can be hypothesised to consisting of a left- and right-handed CP component. At $\lambda_{0}$ and normal incidence, one of these components is fully reflected by the CLC structure and the electric field pattern in the reflected wave is a helix that is identical in shape to the cholesteric helix, which strongly contrasts with the reflection from a common mirror that undergoes an $180^{\circ}$ phase shift upon reflection and changes handedness. The other component is simply transmitted. The fact that the reflected light is CP with the same handedness as that of the CLC structure constitutes the polarisation-selectivity rule, which is valid only at normal incidence. At oblique incidence, the reflected or transmitted light is elliptically polarised. Therefore, a CLC cannot reflect $>50 \%$ of normally incident unpolarised light and reflects $0 \%$ when the incident beam is CP with a handedness opposite that of the CLC.

The helicoidal structure of CLCs gives rise to an exceptionally large optical activity, occurring on each side of the reflection band. An optical rotation up to $10^{3}$ to $10^{5 \%} / \mathrm{mm}$ may occur in the visible spectrum compared with typical values between 0.01 and $100 \% / \mathrm{mm}$ for a chiral liquid (e.g. sugar water) or a crystal (e.g. quartz). The wavelength regions for optical activity are separated by the Bragg band and have opposite signs of rotation.

\subsection{Applications}

Applications which take advantage of the optical properties of the cholesteric phase in thermotropic LCs include temperature [23], gas [24], flow [25] and humidity [26] sensors based on colour changes; super-twisted nematic LCDs [27]; tunable bandpass filters and rewritable colour recordings [28]; thermal printable e-paper [29]; polariser-free reflective displays [30]; lasing applications [31] and reflective smart (field-switchable) window prototypes [32,33]. In lyotropic LCs, which are very widely 
used in beauty cares [34], CLC formulations might be chosen to screen UV light. In make-up cosmetics, CLC formulations can be used to obtain iridescent visual effects, depending on the angle of view or illumination. CLC-based applications are reviewed in Refs. [35,36]. Medical applications of (synthetic) CLCs, which are mainly in thermography [37], are out of the scope of the present review.

\section{4. The twisted plywood model}

A series of arced patterns are recurrently observed in the cuts of cells and tissues by optical or electron microscopy. The twisted plywood model, as introduced by Yves Bouligand (1935-2011) $[38,39]$, is of paramount importance for explaining how the cholesteric organisation of elementary bricks results in these patterns [40-42]. The term universal is often associated with the geometry of the twisted plywood because it is ubiquitously present in different phyla.

Bouligand showed that the arced patterns do not result from authentic curved filaments, as interpreted earlier, but they originate from oblique sections of a cholesteric arrangement. The geometry of the twisted plywood can be understood by a pyramidal model (Fig. 2.a), where the molecular orientations are represented by parallel and equidistant straight lines on a series of rectangles; the direction of the lines rotates from one rectangle to another by a small and constant angle. A periodicity is visible with each $180^{\circ}$ rotation of the molecular orientations and corresponds to the half-pitch $p / 2$. The helicoidal axis is normal to the stratification. The rotation, shown in Fig. 2.a, is chosen to be left handed as it is found in biological materials. A superposed series of parallel nested arcs appear to be directly visible on the oblique sides of the pyramid (Fig. 2.b, right). The concavities of the arcs are reversed on opposite sides of the pyramid, as shown in Fig. 2.a. Therefore, arcs are the visual artefacts of the cholesteric texture. If the section is strictly perpendicular to the rectangles, a network of parallel lines (Fig. 2b, left), appearing as periodically dark and bright under a microscope,-the so-called fingerprint texture-would appear. If the section is strictly parallel to the rectangles, no periodic pattern would be visible. Importantly, when the section of the biological 
material is not realised in the right direction, the arced patterns and the fingerprint texture as a consequence of the cholesteric geometry may be missed [43].

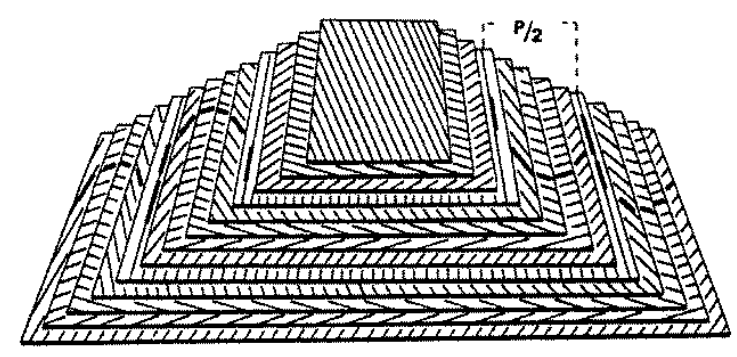

a

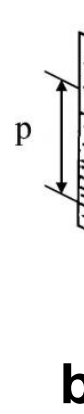

Fig. 2. The twisted plywood model. (a) Superimposed cards represent equidistant and parallel planes forming a pyramidal model. On each card the orientations of the molecules (or elementary bricks in general) are represented as parallel lines; their direction rotates by a small and constant angle from one plane to the other. An $180^{\circ}$ rotation of the line direction defines the helicoidal half-pitch. The superimposed series of nested arcs are visible on the oblique sides of the model [44]. Copyright $(C$ 1995 Academic Press. (b) When the section is perpendicular (left), the molecules appear as dots or parallel segments of different length as a consequence of the twist of the molecular orientation. When the section is oblique, the molecules appear as superposed series of nested arcs. [45] Copyright @ 2003, Springer-Verlag Berlin/Heidelberg.

The chitin, collagen or cellulosic fibres are organised by self-assembly outside the cells as a fluid LC phase, and many animals and plants would collapse without the control of fibre architecture [46]. A progressive loss of fluidity then occurs in the extracellular matrices due to molecular crosslinks and/or mineralisation. The most common organisations are orthogonal and helicoidal plywood, which may be imitated in vitro with molecules obtained by chemical synthesis or extracted from biomaterials. 
Architectures of different macromolecules or microfibrils as anisotropic aggregates of macromolecules show arced patterns, possibly extending over hundreds of micrometres in oblique sections of biological materials such as DNA in certain nuclei and chromosomes or fibrils in many extracellular matrices such as chitin, collagen or cellulose. During the morphogenesis, macromolecules and fibrils are at first in a fluid CLC phase, and then they self-assemble into a twisted state. In thermodynamic terms, self-assembly is a free energy minimisation process driven by entropy. The free energy of the system is lowered as the excluded volume between the molecules is reduced; reduction is favourably operated by twisted packing because most of the biological macromolecules are chiral. A model based on the Landau-de Gennes theory helps understand the structure formation process of the twisted plywood. Theoretical models based on soft matter physics employed to investigate biological LCs are reviewed in Refs. [47-49].

\section{DNA}

\subsection{Overview}

DNA (deoxyribonucleic acid) encodes the genetic instructions used in the development and functioning of living organisms and many viruses. Most DNA molecules are double-stranded forming a right-handed $(\mathrm{RH})$ double helix as a consequence of the chirality conformation of the sugarphosphate backbone. A few years after the discovery of the helical structure of DNA in 1953, liquid crystalline organisations in DNA concentrated solutions were discovered as columnar hexagonal in 1959 by Luzzati and Nicolaieff [50] and as cholesteric in 1961 by Robinson [51].

$\mathrm{RH}$ closely packed helices of linear DNA form a left-handed (LH) CLC phase in a range of DNA concentrations [52]. The mutual alignment of DNA molecules is affected by many factors such as salt composition, temperature, DNA length, DNA charge pattern, DNA-bound charged polymers and DNA 
supercoiling. Taking all these parameters into account within a single theoretical model is currently out of reach.

The two strands of the helix are complementary in their nucleotide sequence, with approximately 10 nucleotide pairs per helical turn. Different organisms achieve different DNA compaction levels. The evolution has favoured the following three fundamental packaging (i.e. genome condensation) strategies in different kingdoms [53]:

- LC organisation of DNA and proteins (such as that observed in viruses), depending on the presence of multivalent ions and osmotic stress;

- DNA over- or under-winding, i. e. DNA supercoiling (such as that observed in bacteria);

- The building of architectures mediated by DNA-protein interactions (i.e. DNA-binding proteins), such as those observed in archaea (unicellular organisms without nucleus or membrane-bound structures, i.e. organelles) and eukaryotes (unicellular or multicellular organisms with a nucleus and membrane-bound structures).

These strategies may interplay and act synergistically, resulting in numerous possibilities. All of them have to deal with the elementary physical constraint that hinders compaction, i.e. the electrostatic repulsion due to the high line charge density of DNA [53]. Double-stranded DNA is a highly charged polyelectrolyte of two negative charges per base pair (bp). The bps are the building blocks of the double helix and contribute to the folded structure of both DNA and RNA (ribonucleic acid). Each elementary charge belongs to one phosphate backbone. These charges repel each other and act against the double helix bending. On the other hand, the stacking interaction between DNA bps also contributes to the stability of the double helix and, thus in turn, to its rigidity.

DNA molecules form dense LC phases both in vivo and in vitro. 
In vivo, during the cell cycle, DNA undergoes alternate condensation and decondensation processes. Its local concentration remains high due to the presence of macromolecules in the nucleus that produces crowding conditions. Further studies are warranted to understand the consequences of crowding conditions on the functional properties of the molecule.

In vitro, condensed DNA solutions can be obtained by multiple methods. They are always liquid crystalline, irrespective of the method used. LC phases have the following three properties that are required for DNA to function [54]: high local DNA concentration (to facilitate contact between the molecules), fluidity (to help the components to come into contact) and order (which is required in certain reactions such as homologous pairing). Self-organised DNA-based structures depend on the properties of DNA-DNA interactions. These structures are built by exploiting the programmable selectivity of DNA interactions and the modularity of their geometry and strength. Therefore, there is a wide variety of possible patterns in amorphous, liquid-crystalline and crystalline phases and in one, two or three dimensions. Locally, the DNA concentration can vary from 50 to $800 \mathrm{mg} / \mathrm{mL}$. In the same concentration range, linear DNA fragments in aqueous solution form multiple LC phases whose nature depends on the concentration. DNA condensation increases its activity in replication, recombination and transcription. When increasing the DNA concentration, the polymorphism sequence is typically (Fig. 3): isotropic solution; blue phases or precholesteric stages within a narrow range; CLC phase with a pitch typically ranges from 2 to $3 \mu \mathrm{m}$; and finally, when DNA molecules become densely packed, the CLC structure unwinds and a columnar hexagonal phase is formed. In the most concentrated solutions, DNA arrangements are crystalline. The ionic strength and the characteristics of the DNA affect the concentrations at which the different transitions occur.

So-called blue phases are composed of regions with double twist [55]. For some chiral LCs, a double twist may be energetically preferable to a one-dimensional twist. Double twist cylinders are known to be the building blocks of the three blue phases usually found in a narrow temperature range between the isotropic and the cholesteric phases in chiral thermotropic LCs. These phases differ one 
from another by the long-range ordering of the double twist cylinders [52]. Both blue phases and precholesteric stages are observed in DNA solutions between the isotropic and cholesteric phases with local double twist configurations - double twist cylinders and double twist helical cords respectively [52].
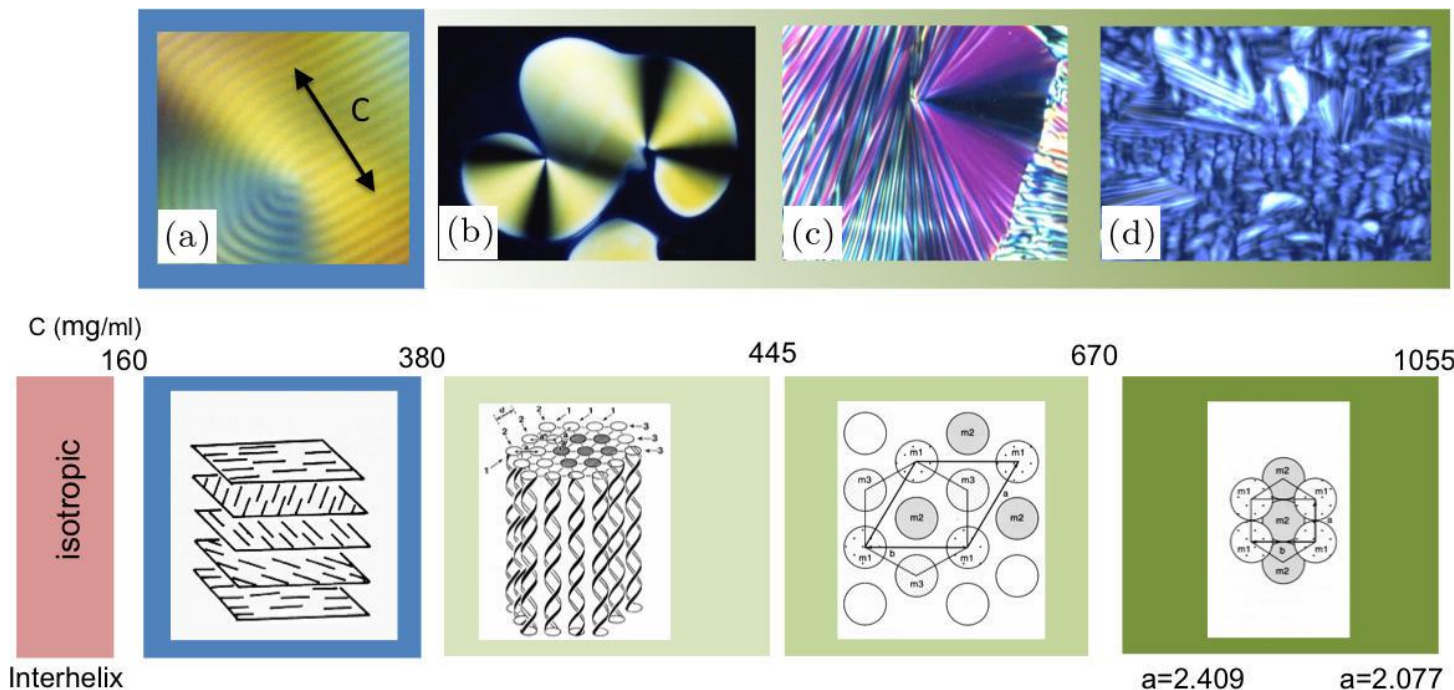

Distance 4.9

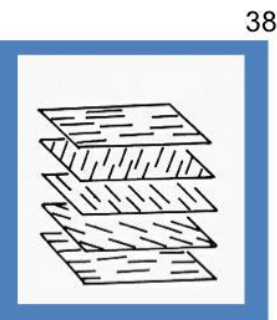

380

445

670

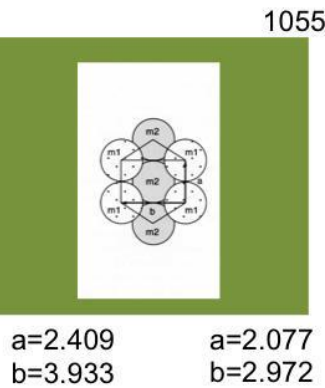

$(\mathrm{nm})$

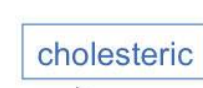

3.23 .15

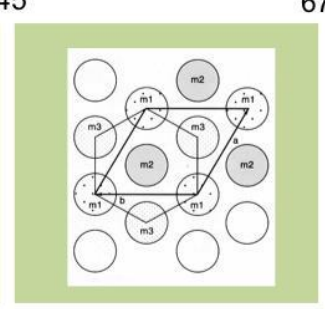

2.9

$2.37 b=3.933 \quad b=2.972$

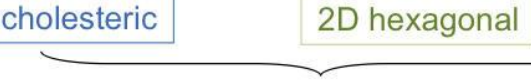

Liquid crystalline phases

3D crystals

Fig. 3. The typical sequence of liquid crystalline textures as observed by polarised light microscopy with corresponding structures for an increasing DNA (50-nm fragments) concentration [56] Copyright (c) The authors.

DNA is a highly charged anionic polyelectrolyte; therefore, several characteristics of the molecule change with the ionic concentration, such as the persistence length and the effective diameter of the DNA molecule. Both these parameters influence the LC behaviour of DNA molecules. The molecule length influences the preferred defect configurations, phase transitions and phase boundaries. It is 
difficult to obtain large amounts of well-defined long molecules, thus limiting the investigation of the role of the molecule length on the phase diagram.

The formation of chiral LC phases from DNA might have played a key role in the earliest development of life in the prebiotic era [57].

\subsection{DNA cholesterics}

The molecular chirality is responsible for the twist of the molecular director in the CLC phase. Molecules align in parallel and a slight displacement of some of them with respect to their neighbours creates oblique grooves along which other molecules can align, inducing the formation of a twist [58]. In this way, RH helices would give rise to a LH twist. Several theories on DNA cholesteric ordering have been developed on the basis of the helical nature of the DNA charge pattern [59]. Some geometrical models imply that the RH twist is favoured by DNA-DNA steric hindrance, while LH CLC phases originate from electrostatic interactions (Fig. 4). 
Review

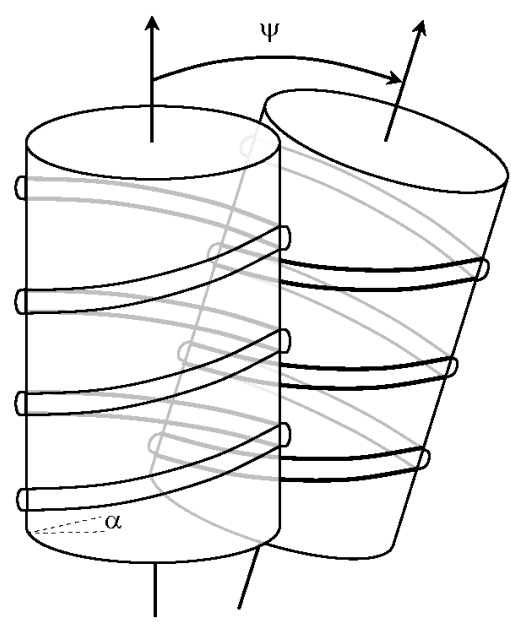

a) Steric interactions of uncharged helices: $\alpha<45^{\circ}, \psi>0$, right-handed cholesteric twist

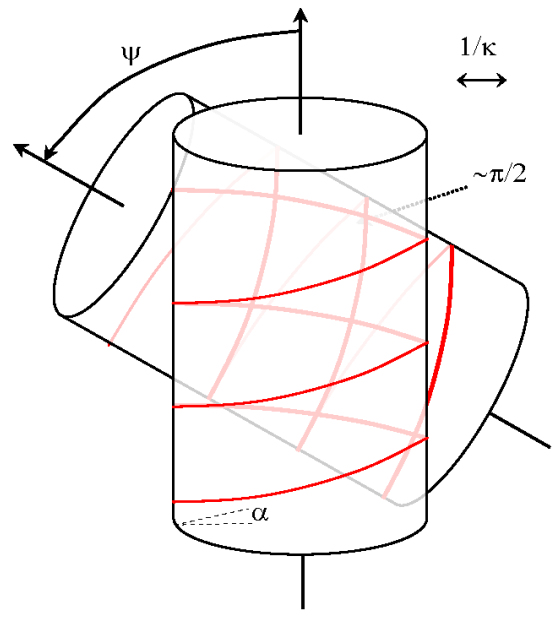

c) Electrostatic interactions of charged spirals: $\alpha<45^{\circ}, \psi<0$, left-handed twist

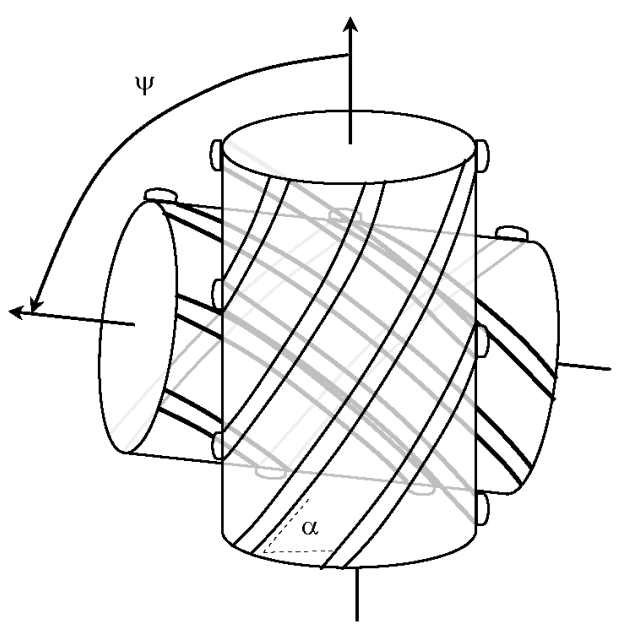

b) Steric interactions of uncharged helices: $\alpha>45^{\circ}, \psi<0$, left-handed twist

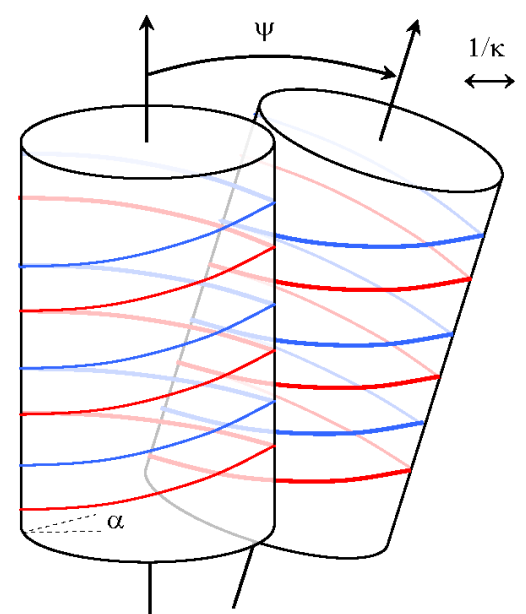

d) Electrostatic interactions of charged spirals with cations: $\alpha<45^{\circ}, \psi>0$, right-handed twist

Fig. 4. Scheme showing how steric (top) and electrostatic (bottom) interactions can affect the handedness of the cholesteric phase of densely packed $\mathrm{RH}$ helices with large diameters. The ridges on the contacting sides of the helices are drawn as thicker curves. The helix inclination angle is $\alpha$ and the mutual twist angle of helices is $\psi$. [60] Copyright (C) 2008, American Chemical Society.

CLC phase can be found in vivo in condensed forms of chromatin in bacteriophages, bacteria nucleoids, dinoflagellate chromosomes and the sperm nuclei of many vertebrates (such as human, 
horse, rabbit and whip scorpion) [58]. The cholesteric geometry is visible as a series of nested arcs (Fig. 5).
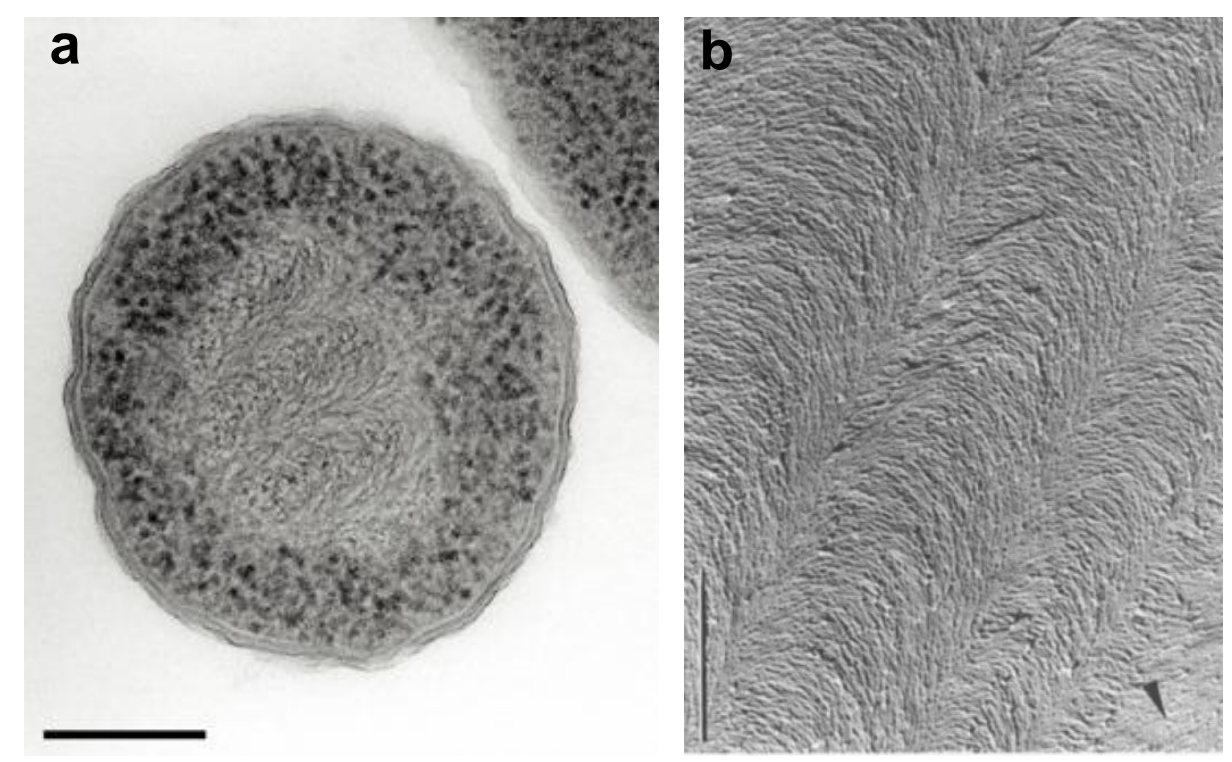

Fig. 5. Cholesteric geometry of DNA seen as a series of nested arcs using electron microscopy.

Oblique sections: (a) DNA-binding proteins from starved cells (Dps) of Escherichia coli. Dark particles at the cell periphery are phase-separated ribosomes. Scale bar: $150 \mathrm{~nm}$ [61]. Copyright (c) 2002, Rights Managed by Nature Publishing Group. (b) In vitro DNA sample $(225 \mathrm{mg} / \mathrm{mL}$ ) of dinoflagellate Prorocentrum micans. Scale bar: $1 \mu \mathrm{m}$. [62] Copyright (C 1989, Springer-Verlag.

Bouligand, by investigating the chromosomes of primitive unicellular algae dinoflagellates using optical and electron microscopy, found evidence of CLC arrangement of highly concentrated DNA in vivo [63]. The dinoflagellates have the largest known genomes among living organisms. A very high level of DNA condensation must be attained to sequester these genomes within the bounds of the nucleus, and this can be achieved through the CLC state. The DNA concentration in the dinoflagellate nucleus is up to 80 times more than a human cell, falling within the range observed for in vitro CLC DNA formation [64]. Furthermore, CLC order of DNA was found in other chromosomes, bacteria, 
viruses and sperm heads, where its concentration reaches extremely high values up to $800 \mathrm{mg} / \mathrm{mL}$, suggesting a correlation between the liquid crystalline packing and the biological activity, particularly with respect to protection from external stress or damage.

In nuclear DNA (i.e. DNA contained within a nucleus of eukaryotic organisms), a wide set of sequences with $\mathrm{n}$ between 8 and 20 bps were explored and both RH and LH CLC arrangements were found [65]. The handedness appears to be strongly dependent on the parameters such as oligonucleotide length, mode of terminal interaction, oligomer sequence or concentration, which reflects small changes in the helix-helix interactions.

Using the molecular theory and coarse-grained modelling, the relationship between the sequence of oligonucleotides and their organisation in the CLC phase was investigated [66]; hard-core interactions promoted an $\mathrm{RH}$ twist, whereas a change to an $\mathrm{LH}$ twist was produced by electrostatic interactions. The chirality of local interactions, which determines the geometry and stability of DNADNA crossovers, affects the physical properties and subsequently the topological state of supercoiled DNA. The local chirality plays a vital role in the organisation of DNA inside bacteriophages. Above a critical concentration, an LH CLC phase is formed by the solutions of double stranded B-DNA, with bps $>130$. Even the concentrated solutions of oligomers of double stranded nucleic acids with 6 to 20 bps exhibit the CLC phase. This behaviour, observed even in the absence of multivalent ions, was ascribed to end-to-end stacking interactions between short duplexes; these promote the formation of long linear aggregates having a sufficiently high length-to-width ratio to induce CLC ordering. LH and RH CLC phases were found depending on the sequence, length and nature of oligomer ends. This result is quite remarkable because the same handedness would be expected for perfect RH helices with the same periodicity and charge distribution. The following reasons may underlie the observed behaviour [66]: structural differences between the linear aggregates, such as those derived from the intrinsic curvature of duplexes or from defects in the molecular helix at the junction between the oligomers, and influence of the sequence on the flexibility of oligomers and of their aggregates or on 
the interactions of duplexes with counter ions and salts. The effects of these factors on helix-helix interactions are unknown. The molecular origin of the CLC organisation of nucleic acid duplexes remains controversial.

\subsection{Pitch}

Forces arising from the electrostatic interactions between helical distributions of charges (or hydration force equivalents) can be chiral only in the presence of azimuthal correlations [67]. In order to understand the physics of CLC phase, it is particularly important to establish the relationship between the azimuthal correlations and pitch. All the factors influencing electrostatic and steric DNA-DNA forces affect the pitch $[60,68]$. In vitro, the pitch typically varies from 0.2 to $>5 \mu \mathrm{m}$ with average values of $2.2-3 \mu \mathrm{m}$. In vivo, the pitch varies from approximately $50 \mathrm{~nm}$ to $0.45 \mu \mathrm{m}$ [58]; sperm nuclei have the smallest values $(50-70 \mathrm{~nm})$. The pitch varies with the species and physiological conditions affect the pitch within a given species. The different pitch values correspond to different degrees of DNA compaction, i.e. different local concentrations.

Long DNA CLC phases show pitch values of 2-4 $\mu$ m. Short DNA oligomers form a submicrometer pitch, depending on the ionic strength and temperature. The Kornyshev-Leikin [68] and TombolatoFerrarini [69] models show that the pitch decreases with the increasing ionic strength and increases with the increasing temperature. The behaviour of a long DNA molecule is correctly predicted by the TF model; however, it is missed by the KL model. The azimuthal frustration of helices with two different arrangements minimises the free energy in the latter model, supporting the possibility of an LH CLC phase [70].

Although the helicity sense obtained by this theory is opposite to that commonly reported in experiments, the pitch and its dependence on DNA lattice density are in qualitative agreement with the experimental data [60]. Other types of interactions might have led to this discrepancy, which 
might have been neglected in current investigations. To better understand the DNA CLC phases, attention should be focused on a combined theory of electrostatic and steric DNA-DNA forces.

\subsection{Defects}

Defects (disclinations) possibly play some important role in the in vivo chromatin activity [54]. They are rarely seen in cholesteric germs in vitro because they tend to move to the surface of the germs and get eliminated for energetic reasons. In the chromosomes of dinoflagellates, which are cholesteric germs in equilibrium with an isotropic state, defects are frequently observed. These defects can either be involved in specific biological functions as they correspond to particular molecular configurations or they can correspond to a geometrical solution of a local overcrowding, resulting from DNA replication.

\subsection{Outlook}

There is a lack of information regarding the role of diverse parameters on the determination of nature of the phases, the effect of the ionic environment and the characteristics of the DNA molecule (length, monodispersity vs. polydispersity and circularity vs. linearity). Further insights on LC organisations of the DNA can provide new perspectives for understanding the genetic material organisation and, consequently, the regulation of the functional activity of DNA. So far, there is no satisfactory model connecting the molecular chiral interactions and the cholesteric pitch. The relationship between the molecular chirality of DNA and the helicity handedness and pitch of the supramolecular organisation has not been completely understood.

\section{Chitin}

After cellulose, chitin is the second most abundant biopolymer. It is found in arthropods, molluscs, worms, mushrooms, algae and lichens. The mains sources of chitin are crabs and shrimps. Chitin has 
a wide range of applications, such as in the treatment of industrial pollutants, biosensors, antibacterial coatings and in the medical and pharmaceutical fields (it is used for the production of wound-dressing material, bone-filling material and control-released drugs), due to its biodegradability, nontoxicity, physiological inertness, antibacterial properties, hydrophilicity, gelforming properties and affinity for proteins [71]. For industrial applications, it is essential to obtain liquid-crystalline structures of chitin molecules as they fundamentally make up the organisation of a given material via a simple self-assembly process inherent to LCs.

Chitin has a structural role in the exoskeleton of arthropods, such as insects, crustaceans, arachnids and myriapods. The arthropods represent approximately $80 \%$ of the animal species. The other constituents of the exoskeleton are water, proteins and sometimes crystals of calcium and uric acid. Arthropods are adapted to all types of ecological niches in water, land and air. The cuticles of this phylum are majorly responsible for the evolutionary success of members. Cuticles cover the animal body by forming an interface with its environment and consist of three main layers, i.e. epicuticle, exocuticle and endocuticle, secreted by a single layer of epidermal cells. The epicuticle (outer skin) is usually a wax layer, which acts as a waterproofing barrier. The structure of the exoskeleton is determined by genetics and the prevailing conditions during its formation. The cholesteric structure is present in the exocuticle and endocuticle, which consists of a hard mineralised fibrous chitinprotein tissue. Emphasis should be given on the geometry of the cholesteric structure and the related physical properties by discussing known or supposed biological functions.

\subsection{Mechanical stability}

CLCs with a pitch gradient are omnipresent in the living matter [72]. The American lobster exoskeleton provides a representative example of a biomaterial with graded mechanical properties related to a graded cholesteric structure [73-76]. Fig. 6 shows the hierarchical organisation of the 
American lobster exoskeleton. Chitin is a polysaccharide composed of repeating units of N-acetyl-Dglucosamine. Approximately 18-25 molecular chains assemble in narrow and long crystalline units. Proteins are bound to the periphery of these parallel chitin crystals, which aggregate into fibrils. The cholesteric structure is the consequence of the helical stacking sequence of fibrous chitin-protein layers $[39,77-79]$.

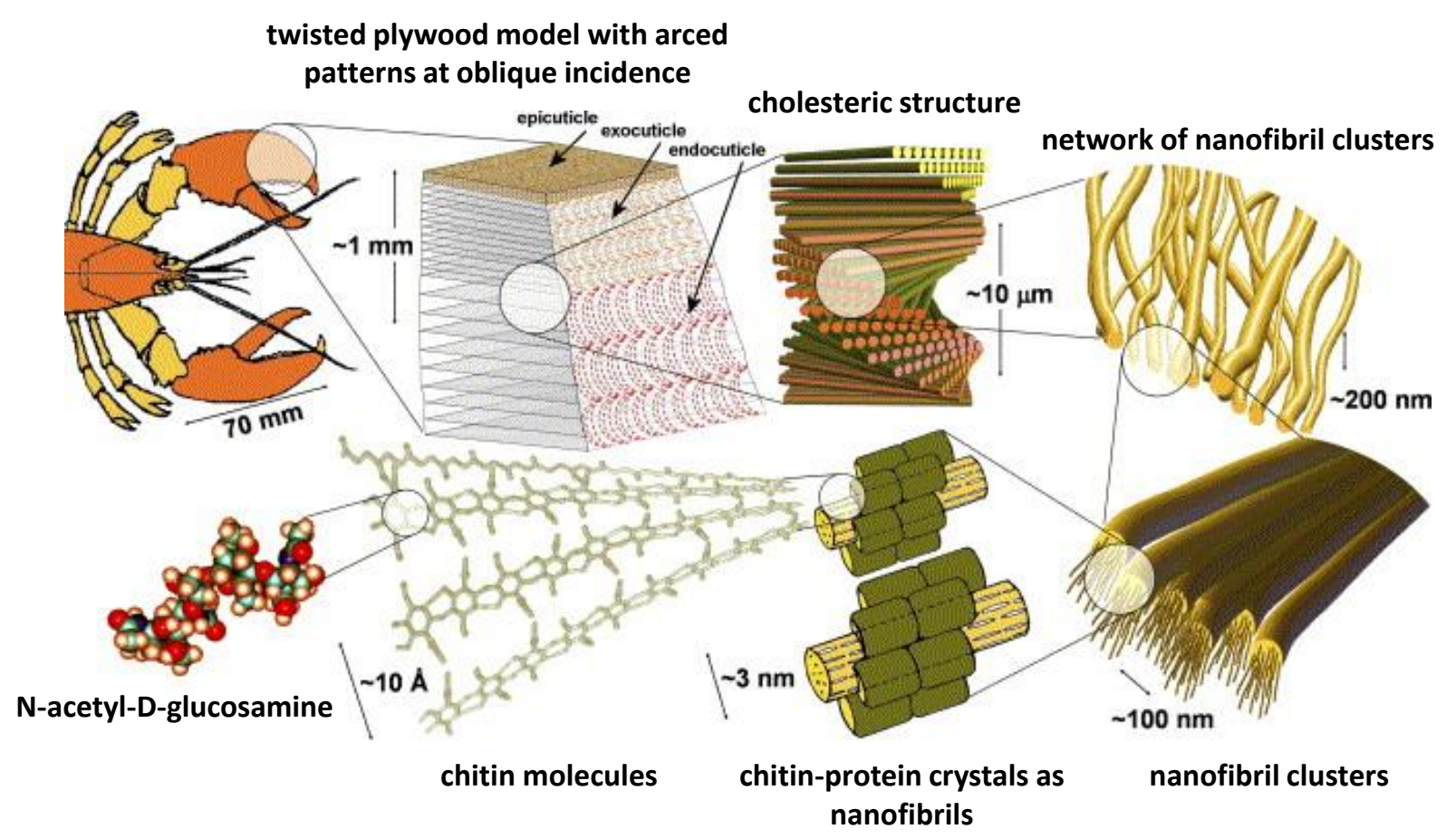

Fig. 6. The exoskeleton of Homarus americanus. The hierarchical organisation reveals six main levels.

From the bottom to top and from the left to the right: I. Chitin molecules, whose antiparallel alignment forms rod-like $\alpha$-chitin crystals. II. The arrangement of $18-25$ chitin molecules as crystalline units that are wrapped around by proteins, forming nanofibrils of approximately $2-5 \mathrm{~nm}$ diameter and $300 \mathrm{~nm}$ length. III. Clustering of these nanofibrils into long fibres of approximately 50$300 \mathrm{~nm}$ diameter. IV. Formation of a planar network of these clusters. The spacing between the strands is filled with proteins and minerals (calcite or amorphous calcium carbonate in crab exoskeletons). The chitin-protein layers form flat honeycomb-type arrays. V. Formation of 
cholesteric structure from these layers. VI. Fibrillar arced patterns viewed in a cross-section. Adapted from [73] Copyright @ 2005 Acta Materialia Inc. Published by Elsevier Ltd.

The SEM image of a cross-section (Fig. 7) reveals a pronounced change in the twisted structure at the exocuticle-endocuticle interface. When the exocuticle has a much finer structure than the one of the endocuticle, an abrupt mechanical discontinuity occurs at the same position as the change in the stacking density of the twisted layers [73]. The hardness increases within the exocuticle between the surface (130 MPa) and the region close to the exocuticle-endocuticle interface (270 MPa). In the endocuticle, both stiffness (3-4.5 GPa) and hardness (30-55 MPa) are much smaller than those in the exocuticle. A gradient in the calcium content between the exocuticle and endocuticle occurs [80], indicating more mineralisation of the exocuticle. This design-higher hardness of the exocuticle and wear resistance on the surface-is widely present in nature.

The cholesteric structure plays an important role in the mechanical behaviour of the exoskeleton. The excellent mechanical stability of the exocuticle-endocuticle interface, irrespective of the change in the mechanical properties, is attributed to the fact that the pattern changes across the interface only consist of stacking density changes in the chitin-protein layers. The gradients in stiffness and hardness through the cuticle thickness are qualitatively interpreted in terms of gradients in the honeycomb mechanics of the chitin-protein network. Honeycomb-type structures, as an array of interpenetrated fibres providing a very high density of interfaces, should provide a very high mechanical stability against fracture initiation and propagation. Similarly, the highly twisted structure of the honeycomb-type structures is responsible for enhanced resistance against crack propagation [74]. Ab initio and multiscale numerical simulations have confirmed that the cholesteric structure guarantees that the chitin-protein fibres reinforce the cuticle and significant amount of energy is dissipated during impact loadings [76]. 


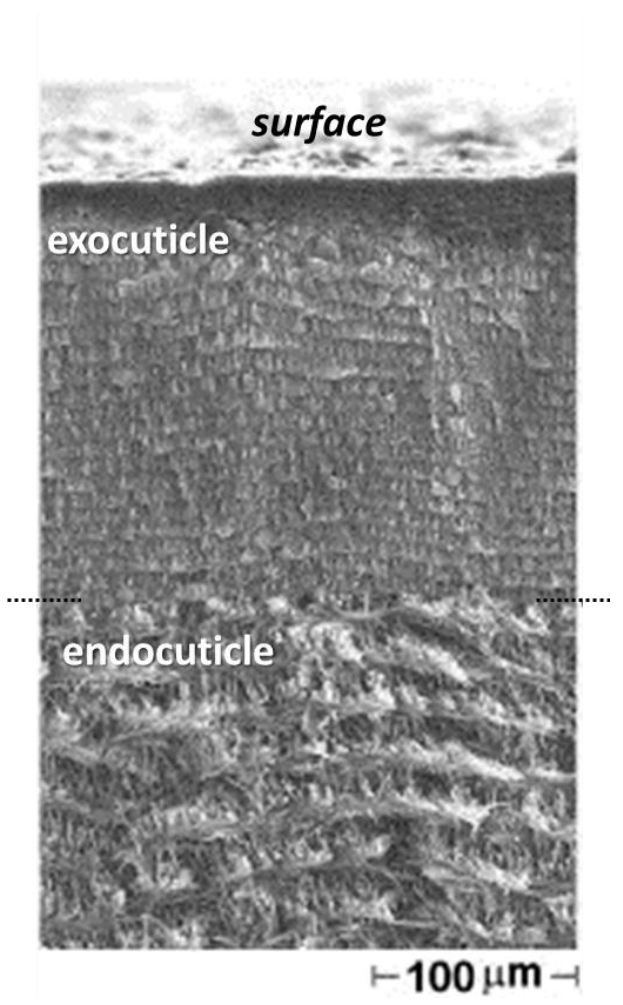

Fig. 7. SEM micrograph of the cross-section of Homarus americanus exoskeleton at the interface between the exocuticle and endocuticle, where a change occurs in the periodicity of the fingerprint texture and in its granular aspect. In the fingerprint texture, the distance between lines of equal contrast is related to the half-pitch and the helical axis is perpendicular to all the lines. [73] Copyright (C) 2005 Acta Materialia Inc. Published by Elsevier Ltd.

The mechanical properties in the longitudinal and transverse directions were measured in the sheep crab exoskeleton [80]. When tensile loading is applied in the transverse direction, a fracture tends to occur at the exocuticle-endocuticle interface with a flat cleavage appearance. When the endocuticle alone is solicited, the fracture morphology is irregular and the stress-strain curve shows a non-linear (irreversible) plastic deformation.

The hammer-like dactyl clubs of the stomatopod Odontodactylus scyllarus, who are known to smash its heavily shelled prey with high accelerations, exhibits several microstructural characteristics that 
permit the infliction of crippling impacts while minimising the internal damage [81]; a pitch-graded CLC structure dissipates the energy released by microcracks which propagate. By combining the propagator matrix formalism to represent the CLC structure with the Bloch-Floquet periodic boundary conditions to account for the graded pitch (from several $\mu \mathrm{m}$ to several tens of $\mu \mathrm{m}$ ), a dispersive response with bandgaps corresponding to propagation modes related to shear waves was identified [82]. Strikingly, these frequency bandgaps correspond to those generated from the stress pulse experienced by the dactyl club during the stomatopod's hunting activities.

In addition to possible inelastic and damage effects, the dactyl club can sustain high-intensity dynamical loads through a shear wave filtering capability introduced by the pitch-gradient CLC structure.

Cuttlebone, the sophisticated buoyancy device of cuttlefish, is made of superposed chambers with a complex internal arrangement of calcified pillars and organic membranes. In order to assemble the membranes, Sepia officinalis secretes a chitin-protein complex, which self-organises, 'layer' by 'layer', as a CLC [83]. It is argued that the twisted plywood is the solution to a mechanical adaptation for a better performance against the hydrostatic load. CLC organisation appears to be ubiquitous within coleoid cephalopods. Arced patterns have been observed in the pen of the squid Loligo [84] or in the septum (thin wall between the internal chambers of the shell of a cephalopod) of Spirula spirula [83].

In order to explain the formation of the interlamellar membranes of molluscan nacre [85], the CLC organisation is invoked. This constructional strategy could be traced even further back to at least the Upper Ordovician when the first nautiloid nacre was recorded (445 million of years).

Computational modelling by the finite difference time domain method provides an accurate prediction of the optical response in structure-gradient LC structures [86]. Complex pitch gradients in the cuticles have been studied using a geometric model and computational visualisation tool $[41,87]$. 
In summary, chitin-based materials in crustaceans or molluscs are anisotropic in structure and the mechanical properties have a recurrent role of the CLC organisation, which may often exhibit a pitch gradient.

\subsection{Optical information}

The role of optical information is of paramount importance in the evolution of most day-living animals [88]. Animals use coloration for sexual communication, cryptic behaviour or warning predators [89], relaying information about the species [90] or age when iridescence changes or deterioration occurs over time [91,92]. Iridescent coloration produces spectacular visual displays [9399]. The term iridescence is derived from Iris, the Greek goddess associated with the rainbow. It is currently used to describe metallic colours, spectral light dispersion and opal-like effects. In fact, iridescence is fundamentally related to a surface whose hue changes with the angle of view or illumination.

In 1911, Michelson discovered that the scarab beetle Plusiotis resplendens displayed CP reflection [100]. In 1924, Gaubert correlated it with the CP reflections in synthetic CLCs [101]. However, this topic of research was revived much later in the 1960s [102-104].

The cholesteric structures in living matter display unique optical signatures with selective light reflection property, vivid hues, strong angle-dependency of reflected colours and polarisationdependent reflection patterns. In nature, the 'tour de force' of cholesteric structures consists in producing a broad set of dramatic lighting effects from biological materials whose refractive indices vary in a narrow range; this behaviour is attributed to the helicoidal geometry and not the composition.

Single-pitch or graded-pitch cholesteric reflectors in insect cuticles are iridescent. However, some beetles do not have this characteristic. For silver metallic beetles, the cholesteric structure reflects a broader spectrum than the visible one; therefore, the human eye cannot detect this iridescence. For 
narrow-band reflectors, a diffuse reflection may arise from the irregularities in the cuticle (bumps, pits and indentations) resulting in the matte or dull appearance of the cuticle. The armour of insects plays a major role in their huge diversity (Fig. 8), especially for beetles because they have a thicker cuticle than most other insects [105]. There are several publications which review the iridescent colours in the insect world [106-110].
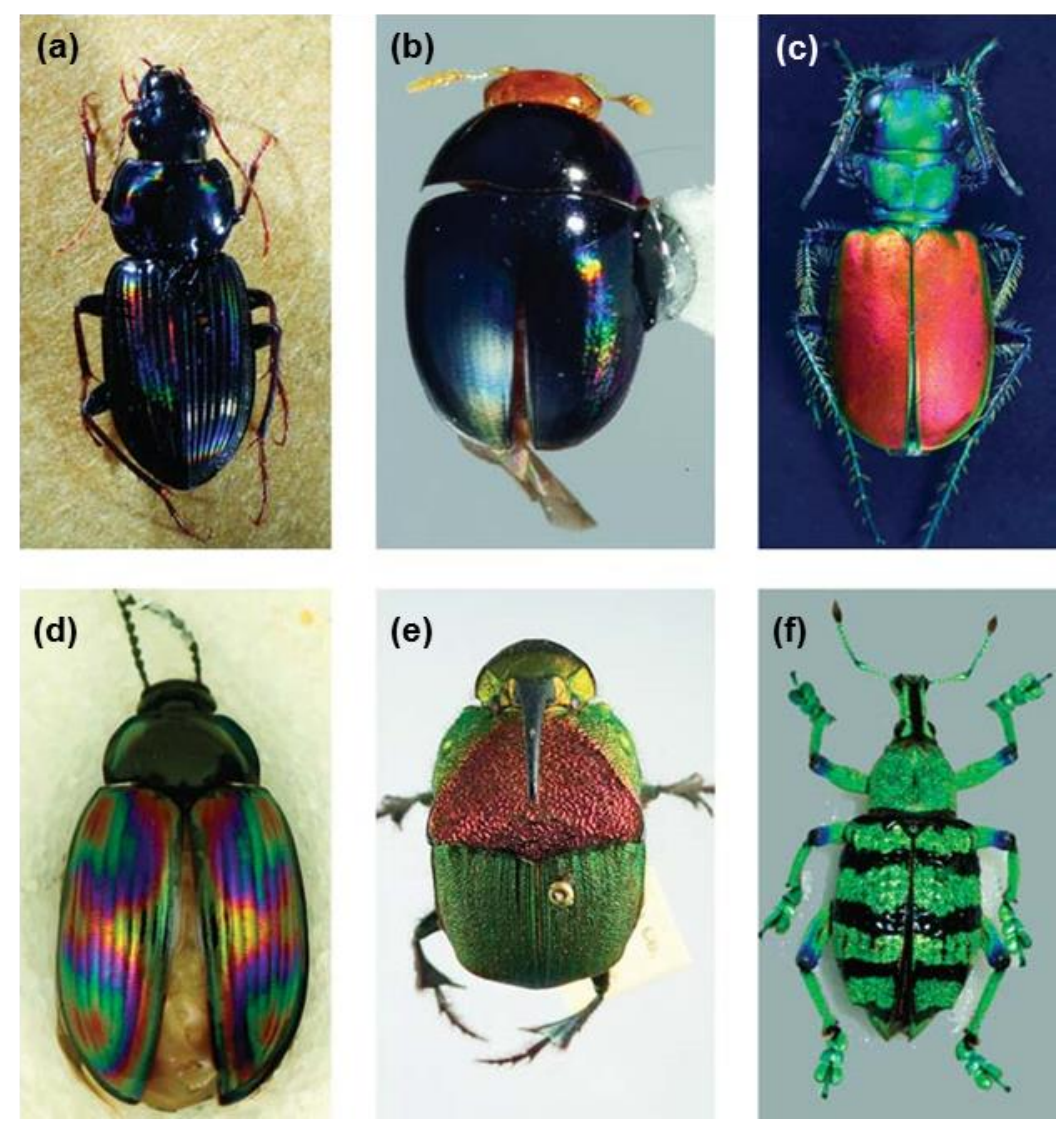

Fig. 8. Iridescent beetles. (a) Loxandrus rectus (Carabidae: Harpalinae), (b) Phalacridae sp., (c) Cicindela scutellaris scutellaris (Carabidae: Cicindelinae), (d) Amarygminae sp. (Tenebrionidae), (e) Phanaeus vindex (Scarabaeidae: Phanainae), (f) Eupholus sp. (Curculionidae: Entiminae). [108] Copyright (C) 2009, (C) 2008 The Royal Society.

5.2.1. Camouflage-Beetles from the genus Chrysina, also named jewel scarabs, show very vivid light reflections in a variety of colours, from bright green to metallic silver-gold, including broadband 
reflections [111-113]. For camouflage strategies, the organisms that reflect light similarly to a specular broadband mirror would match their background from any angle of observation; in other words, the colour of the broadband reflectors is less directionally dependent when a full range of wavelengths is reflected. In addition, the surrounding environment would be reflected from the mirrored surface so that the animal cannot be seen [105]. Camouflage may also be achieved in an environment with diffuse light to prevent a strong, direct reflection from the sun [114]. One of the most spectacular Chrysina beetles is Chrysina gloriosa (Fig. 9.a), which is found from southwestern North America to Central America in pine, pine-oak and juniper forests. C. gloriosa exhibits iridescence and selectively reflects the left CP light. Its exoskeleton includes alternate green and silver (mirror-like) stripes.
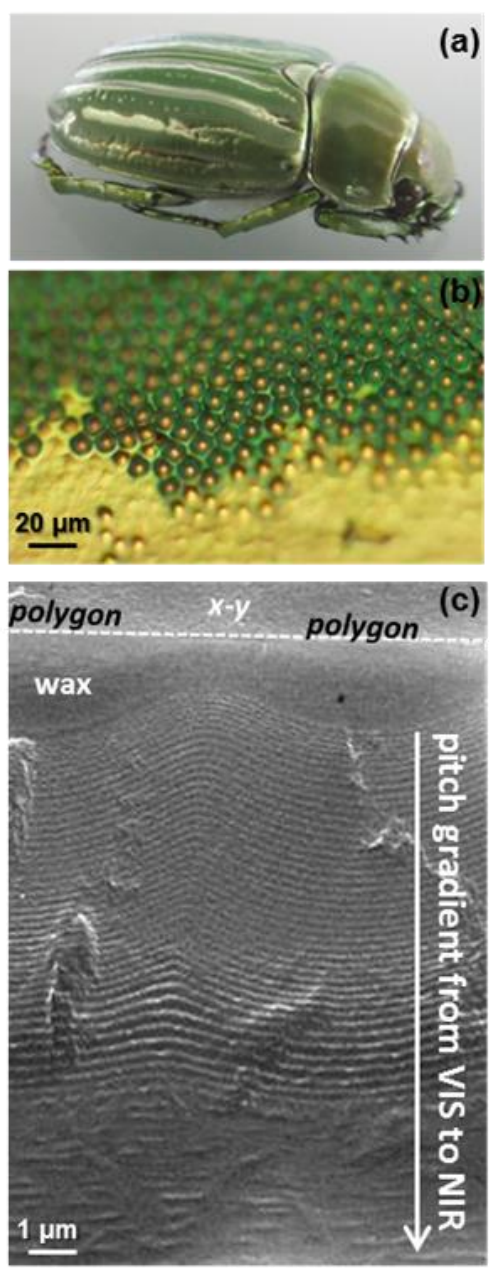
Fig. 9. (a) Chrysina gloriosa beetle. Its chitin-based cuticle is made of alternating green and silver stripes. (b) Optical micrograph (unpolarised light) at the interface between the green (top-polygonal texture) and silver (bottom) stripes. (c) Cholesteric fingerprint texture, as observed by scanning electron microscopy, in the cross-section of a green stripe. [115] (c) 2016 Acta Materialia Inc. Published by Elsevier Ltd

Since the foliage of the juniper tree is green with white flecks (resin spots), green-and-white (or silver)-striped insects are relatively cryptic in the juniper foliage with their frequent natural perch [116]. C. gloriosa belongs to a large group of insects with a tessellated exocuticle, in whole or in part, exhibiting an array of cells in the form of bumps, pits or indentations. Since the mid-2000s, several studies on these insects, such as Manuka beetles [117], June beetles [118], Plusiotis boucardi [119], Pyronata festiva [120], Chlorophila obscuripennis [121], several beetles from the genus Cicindela [108,122], Calidea panaethiopica [123], Chrysochroa fulgidissima [124], Chrysina aurora [125] and Anomala dimidata [97], have been undertaken. In the field of microlenses and micromirrors [126$128]$ and in photonics $[95,129]$, micro-textured exocuticles of these scarabs may inspire researchers and engineers to make their replicas as optical materials. The polygonal texture of $C$. gloriosa cuticle was compared to its equivalent in synthetic cholesteric oligomers and the fundamental differences were studied [115]. The cuticle has concave cells, whereas the artificial films have convex cells, which is contrary to expectation and assumption in the literature.

The bright glare from silver stripes might temporarily blind a potential predator, enabling C. gloriosa beetle to escape [130]. Since the silver stripes mirror the colour of its environment, C. gloriosa beetle may hide among the leaves when they are brown during the dry season. However, if dealing with a generic function, this hypothesis is not entirely satisfactory to other authors, e.g. Thomas et al. [116] observed that gold and silver species are found in evergreen tropical cloud forests. 
The green stripes have a polygonal texture (Fig. 9.b), and each polygonal cell contains a bright yellow core in a greenish cell with yellowish border according to bright field unpolarised microscopy. The reflectance exhibits, at a normal incidence, a broad halo from 500 to $600 \mathrm{~nm}$ with two peaks at 530 $\mathrm{nm}$ (green) and $580 \mathrm{~nm}$ (yellow) [111]. This kind of diffuse reflection, when an incident ray is reflected at many angles rather than at just one angle as in the case of specular reflection, arises from a combination of a continuous pitch gradient and irregularities on the cuticle surface below the flat wax layer (Fig. 9.c). Below the epicuticle (waxy layer), the cholesteric organisation presents two successive pitch gradients occurring in the IR spectrum in the endocuticle and in the visible spectrum in the exocuticle, producing the structural colour. The fingerprint texture in the endocuticle appears-as observed in the case of the Homarus americanus exoskeleton (Fig. 7)-to be less regular (stripes are interrupted) and grainy. The presence of a cholesteric grating with a large pitch might avoid overheating. This kind of thermal regulation could be offered to (many) arthropods (such as insects or beach-dwelling crabs), whose cuticle presents a pitch gradient in the IR range [72]. Dorsal colouration is associated with thermoregulation in diurnal beetles. Niche differentiation associated with thermoregulation is well documented in tiger beetles (Ref. [131] and references therein).

According to Pace, the TEM images of $C$. gloriosa cuticle showed a cellular pattern with concentric rings [132], which is similar to that found in the tubercle of crabs [133]. Fluorescence confocal microscopy images confirmed these patterns $[134,135]$. The polarising properties of $C$. gloriosa cuticle in the visible spectrum were investigated by using Mueller matrix spectroscopic ellipsometry $[136,137]$. Over the visible and near-IR spectra, the polygonal cells in the tessellated green stripes behave as multi-wavelength selective micromirrors [115]; these cells can be used in the future for fabricating multi-wavelength selective micromirrors or spatial wavelength-specific light modulators.

5.2.2. Communication-Humans have a trichromatic vision, while insects have a tetrachromatic or pentachromatic vision, depending on the species [138]. Their eyes and brains are able to perceive polarised light, which we humans cannot [139]. The ability of $C$. gloriosa to detect CP light has been 
evidenced [140]. C. gloriosa presents different flight orientations in accordance with linear and CP light stimuli of equal intensities and shows a discrimination between CP light and unpolarised light of different intensities. Circular polarisation sensitivity might allow C. gloriosa to communicate with conspecifics while remaining cryptic to predators with eye geometries not capable of CP light detection. Although linearly polarised light is quite common in nature, the production of CP light from unpolarised light appears limited to only a few groups of organisms including scarab beetles (Scarabaeidae, predominantly in subfamilies Rutelinae, Scarabaeinae and Cetoniinae [108]) and marine stomatopods $[141,142]$. It is still unknown whether the scarab beetles use the CP light as a recognition mechanism or for performing any other survival function. However, the rarity of CP light in nature presents itself as an opportunity for unique signal evolution. Perceiving polarised light might play a role in animal signalling, serve as a selective communication channel to specific polarisation-sensitive targets such as potential mates and can be used for navigation and orientation.

Another possible biological advantage of CP light for communication is that there is no preferential angle from which polarisation can be detected; animals can then send and receive signals regardless of their respective orientations (while the directionality of linearly polarised light represents a challenge; the orientation of the sender and receiver may have to be coordinated). In other cases, cholesteric colours may be brightest from certain directions and the body orientation could direct a visual signal to particular receivers [143].

The CP light reflected by the cuticle of scarab beetles is $\mathrm{LH}$. However, $\mathrm{RH}$ circular polarisations have been reported. They are very rare and restricted to single individuals such as $C$. resplendens in the Rutelinae [100,111,144,145]. Furthermore, Hegedüs et al. found examples of RH circular polarisations, but concluded that the situation was complicated [112]. Neville and Caveney reported that LH CP light was reflected by all the investigated species [104]. There is a mixed support to the observation of RH CP reflections. Therefore, it is difficult to conclude anything about RH CP light from different discussions found in the literature. Polarisation may occasionally occur in patterns (patches, 
stripes or edgings) and RH circular polarisations have been reported for a peculiar wavelength band; this discrepancy makes it difficult to draw any firm conclusions. The problem of spectrum-dependent handedness deserves detailed studies, requires elaborate equipment and suggests reproducing experiments on samples from not only same scarab species but also different climes. Thus, the research on the role of polarisation in light reflection by insect cuticles is still in its nascent phases.

The angle dependence of the cholesteric colour of the insect cuticle can slow or hinder the recognition process by predators or make the signal ineffective if predators approach from the directions relative to the cuticle surface where there is no apparent reflectance [146]. A high visual contrast may also confuse the predator leading to the escape of the prey [107]. Aposematism, a name given to antipredator adaptations, is commonly known in the context of warning colouration that may deter predators from attacking distasteful or toxic prey [147], which may sometimes be a deception. Although birds can exert selection on the dorsal colouration of tiger beetles [148], dorsal colours appear less significant for escaping to terrestrial predators because these beetles avoid lizards by running or flying. Despite the long history of interest in warning colouration, many questions remain unanswered regarding the tactical design features of warning signals that contribute to their effectiveness.

5.2.3. Evolutionary context-The complete role of light reflection by the cholesteric cuticle of insects still needs to be elucidated; better knowledge of physical properties and an evolutionary context is needed. The colour can be changed only by changing the pitch (or layer thickness if no twist) and not by changing of material; therefore, the selective pressure can be considered as lower in return. The cuticle of larvae is normally deposited in a cholesteric state $[149,150]$; therefore, polarised light reflection is simply brought in the same time. With regards to the evolution of visual function in any event, the way to evolve is to retain the twist from the larval cuticle formation in the adult cuticle, possibly leading to the evolution of cholesteric reflectors. 
The earliest known reflectors (diffraction gratings) in living matter are 515 million years (Ma) old [114]. The subsequent fossil record preserves multilayer reflectors, including cholesteric mirrors, because structural colouration is generally permanent and does not bleach like pigmental colours. Fossil beetle specimens ranging from 15-47 Ma in age exhibit several reflection colours [151] (Fig. 10). Reconstruction of the original colours of the fossils based on the structure of the reflector show that the preserved colours correspond to longer wavelengths; however, the conditions of fossilisation of these samples and their preservation must be exceptional. These fossilised beetles should have been rapidly buried by sediments before the breakdown by bacterias, and they should be preferably preserved in a fine-grained sediment [88].

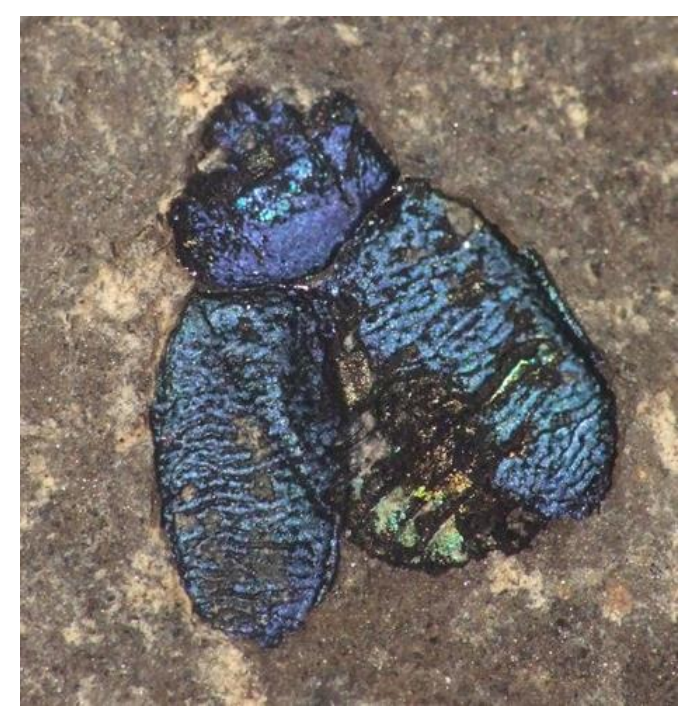

Fig. 10. Fossil of a 40 million-years-old leaf beetle (Chrysomelidae) found in Eckfeld (Germany), with blue elytra that are still reflective. [151] Copyright (C) 2012, This journal is @ 2011 The Royal Society.

Fossil records show that eyes evolved around 521 Ma ago [88]. The so-called 'Light Switch Theory' states that the introduction of vision to the behavioural system of animals caused the Cambrian explosion. This event introduced vision as a selection pressure in the evolution of animals, which led to the evolution of adapted optical devices. The evolution of the eye and probably active predators 
can explain why animals suddenly changed their appearance in the Lower Cambrian. Cambrian animals would have possessed efficient and coloured (cholesteric) reflectors to be visually adapted.

\subsection{Concluding remarks}

The cholesteric structure appears to play an important role in the evolution and the daily life of crustaceans and insects, with a benefit of mechanical strength and optical properties. The dispatch of cholesteric information including vivid reflection colours and polarisation, with angle dependence, possibly helps the animal for social signalling (recognition with conspecifics), sexual selection, aposematism (camouflage for avoiding predation) and thermoregulation. However, the cholesteric structure is not the only factor responsible for the structural colouration in insect cuticles [152]. The chitin fibres may assemble without twist like chirped layers with a nematic structure (parallel fibres) or as orthogonal plywood [153]. Such organisations may lead to an interferential network or a diffraction grating. Layers may sometimes be porous and filled with air or liquid (hydrochromic effects) [154].

In some beetles, uric acid plays a role in imparting the colour by enhancing the reflectivity [107]. In Plusiotis optima and Plusiotis resplendens, uric acid accounts for 0.6 and 0.7 volume fraction of the exocuticle, respectively [155]. Chitin-based structures can also be combined with pigments or lightemitting compounds; absorption colouration and bioluminescence are possible. Nevertheless, structural colouration has recently received more attention in the literature.

When evaluating the proposed function of a colour, it is important to analyse the visual system of the animal and its potential predators, the light conditions and the optical characteristics of the habitat (ground, foliage or sea). The knowledge of the phylogenetic and ecological context is also required to elucidate the role of cholesteric structures in an animal. For example, the environment plays a major role in the colour polymorphism exhibited by the southern African dung beetle, Gymnopleurus humanus [156]. The population samples of $G$. humanus were dominated by blue individuals in the 
cooler south, by cupreous individuals in the warmer north, and by locally co-occurring blue, green and cupreous individuals in intermediate situations. The differences in mean reflectance values between 24 populations were strongly correlated with the average annual temperatures at the study sites. The adaptability of physical CLC properties to thermal conditions can generate different exocuticle structures responsible for different light reflections. Colour polymorphism could be advantageous across a gradient from cooler to warmer climate due to the different thermal properties of different colours. Interestingly, it is hypothesised that the prevailing reflected colour balance in southern populations would shift in response to global climatic change. In this situation also, it could be argued that colour changes are easily accessible by changing the cholesteric pitch without the requirement of changing the material.

For a given cholesteric structure, it is difficult to affirm that the evolution has endowed the animal with optical features, increased mechanical strength or reduced weight. In some cases the cholesteric structure could be an artefact. It can be debated that the structural colouration may be an incidental consequence of the evolution of a periodic structure [157]. At the same time, a huge amount of literature directly addresses the critical importance of colouration in living organisms. The evolution of a colour-producing structure may be driven by several factors simultaneously, and the consequence would be the occurrence of a multifunctional material responding to several requirements, which may or may not be optimal for them. For example, the optimisation of both mechanical and optical functions may lead to a conflict.

In general, bio-inspired fabrication from cholesteric cuticles of insects can be applied in textiles, in cosmetics, for vehicle shells, in anti-counterfeiting technologies for banknote production, in microphotonics and as optical components for multifunctional materials [107]. 


\section{Collagen}

\subsection{Liquid crystalline nature of collagen}

Collagen accounts for one-third of the total body proteins and is present in almost all tissues [158]. It is the major part of the skin, bone, tendon and cornea, where collagen macromolecules organise into fibrillary networks. Type I collagen is predominant in connective tissues and plays a major role in morphogenesis. Type I collagen macromolecules are composed of three polypeptide chains that wind up into an RH triple helix (1.5 nm in diameter and $300 \mathrm{~nm}$ in length) which is known as tropocollagen (Fig. 11). They are first synthesised in a precursor form by cells as fibroblasts, the most common cells of connective tissues, or osteoblasts, the cells with a single nucleus that synthesise bone. Subsequently, they aggregate into individual fibrils in the extracellular matrix.

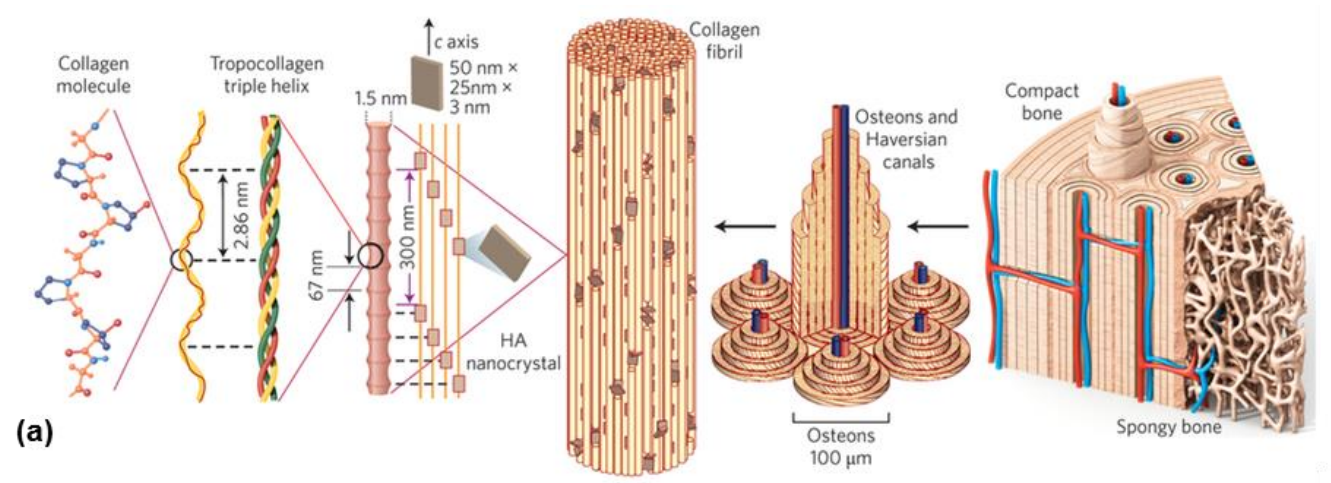

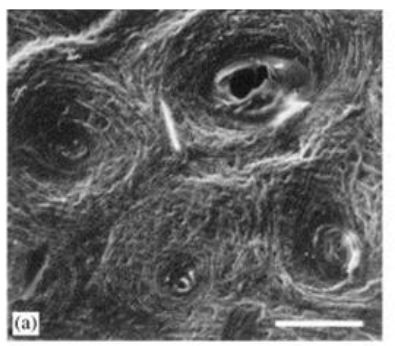

(b)

Fig. 11. (a) Hierarchical organisation of bone. Collagen fibrils are made from type I collagen macromolecules $\left(\sim 300 \mathrm{~nm}\right.$ long and $\sim 1.5 \mathrm{~nm}$ in diameter) and hydroxyapatite $(\mathrm{HA}) \mathrm{Ca}_{10}\left(\mathrm{PO}_{4}\right)_{6}(\mathrm{OH})_{2}$ nanocrystals (plate-shaped, $50 \mathrm{~nm} \times 25 \mathrm{~nm}$ in size and 1.5-4 nm thick) are distributed along the collagen fibrils. Compact bone is composed of osteons. Each osteon consists of lamellae arranged into coaxial cylinders and surround a central canal, the Haversian canal, which contains blood vessels. Lamellae consist of parallel collagen fibrils, whose orientation varies for one cylinder to the next. This geometrical construction results in a helical arrangement of the osteon. Therefore, the twisted 
plywood is cylindrical and not planar. Macroscale arrangements involve both compact bone at the surface and spongy bone (foam-like material with $\sim 100-\mu \mathrm{m}$ thick struts) in the interior [159]. Copyright (c) 2014, Rights Managed by Nature Publishing Group. (b) The SEM image of a transverse fracture of the human compact bone. Each osteon appears to be formed by concentric lamellae around the Haversian canal (bar $=100 \mu \mathrm{m}$ ) [160]. Copyright (c) 2003 Elsevier Science Ltd.

Collagen has essential functions at different levels, ranging from molecules to fibrils and suprafibrillar networks [161]. Tissue properties such as elasticity in the dermis, resistance to load in the bone, resistance to stretch or shear in tendons or transparency and resistance to pressure in the cornea depend on the molecular composition, size and the arrangement of fibrils and organisation of the fibrillary network [162]. As an implantable material, collagen is of major interest because it is highly biocompatible and biodegradable, shows low immunogenicity, favours cell adhesion and guides the cell growth and tissue repair [163].

Collagen macromolecules assemble into fibrils both in vitro (by raising the $\mathrm{pH}$ ) and in vivo (through enzymatic control). The passage from individual fibrils to ordered fibrillar arrays relies on the selfassembly processes driven by the LC organisation of collagen. The LC organisation of collagen has received much attention because it plays an important role in determining tissue form [164-169] and can orient the cell growth [170].

In compact bone osteons or in the cornea, a continuous twist occurs between individual collagen fibrils or between groups of fibrils [40,171,172]. Highly uniform CLC collagen films are capable of inducing contact guidance for osteoblasts, which are aligned with the orientation of bands in the cholesteric texture [161]. In the tendons, intervertebral disc or intestinal wall, crimp morphologies, in which a regular and planar undulation of fibrils occurs, resemble a precholesteric phase $[173,174]$. Molecular orientation in a precholesteric arrangement is oblique to the helical axis, whereas it is 
normal to the helical axis in a cholesteric structure. Such analogies have suggested that the cholesteric organisation plays a peculiar role in the determination of tissue form.

The LC nature of collagen was demonstrated in vitro in highly concentrated acetic acid solutions of type I collagen macromolecules, which possibly self-assemble into nematic, precholesteric and cholesteric phases [167]. At acidic pH, repulsions between the positively charged residues are large enough to prevent aggregation while maintaining an anisotropic fluid state.

\subsection{Collagen cholesterics}

The in vitro CLC organisation of collagen, with a pitch larger than $1 \mu \mathrm{m}$, was first reported with sonicated solutions of type I collagen [175]. The very high viscosity of the native samples hinders the formation of fingerprint patterns without previous sonication [162].

The in vitro collagen, when concentrated at $40-80 \mathrm{mg} / \mathrm{mL}$ in an acid solution and placed between a slide and coverslip, shows spontaneous anisotropic textures $[160,164]$. The following phases appear as the concentration of collagen progressively increases by solvent evaporation: isotropic phase, nematic phase, precholesteric domains characterised in polarised light by band texture (Fig. 12a) constituted by alternatively extinguished and illuminated bands ranging between 1 and $5 \mu \mathrm{m}$ in width (these patterns have been interpreted as the undulations of the molecular orientations within the preparation plane) and cholesteric phase exhibiting the typical fingerprint texture (Fig. 12b). The distance between two identical bands corresponds to $180^{\circ}$ rotation of the molecular orientation. Fingerprint textures can be observed by polarised optical microscopy as a function of the concentration by using a glass micro-chamber in which the evaporation is limited to one or two interfaces, and the system is continuously enriched with an input of dilute collagen [176]. Regular textures extending over the lengths of centimetres are obtained and a concentration gradient develops. The pitch decreases as the concentration increases. The solution was isotropic at concentrations of $5-50 \mathrm{mg} / \mathrm{mL}$, whereas cholesteric droplets appeared, floating in the isotropic 
phase, at higher concentrations, i.e., $50-400 \mathrm{mg} / \mathrm{mL}$, with long helical pitches. At concentrations of $400-800 \mathrm{mg} / \mathrm{mL}$ or more, the solutions were cholesteric, showing a much smaller helical pitch and so tight in some areas that the helical periodicity was not resolved by optical microscopy. To stabilise these solutions into gels, fibrillogenesis was induced by ammonia vapours. The images showed similarities with those obtained with thin sections of natural collagen matrices, for instance, in a compact bone. In the bone, the collagen fibrils showed a relatively constant diameter from 30 to 120 $\mathrm{nm}$, whereas the fibril diameter varied from $10 \mathrm{~nm}$ in the highly twisted regions to $500 \mathrm{~nm}$ in less twisted regions in these ammoniacal gels of collagen.

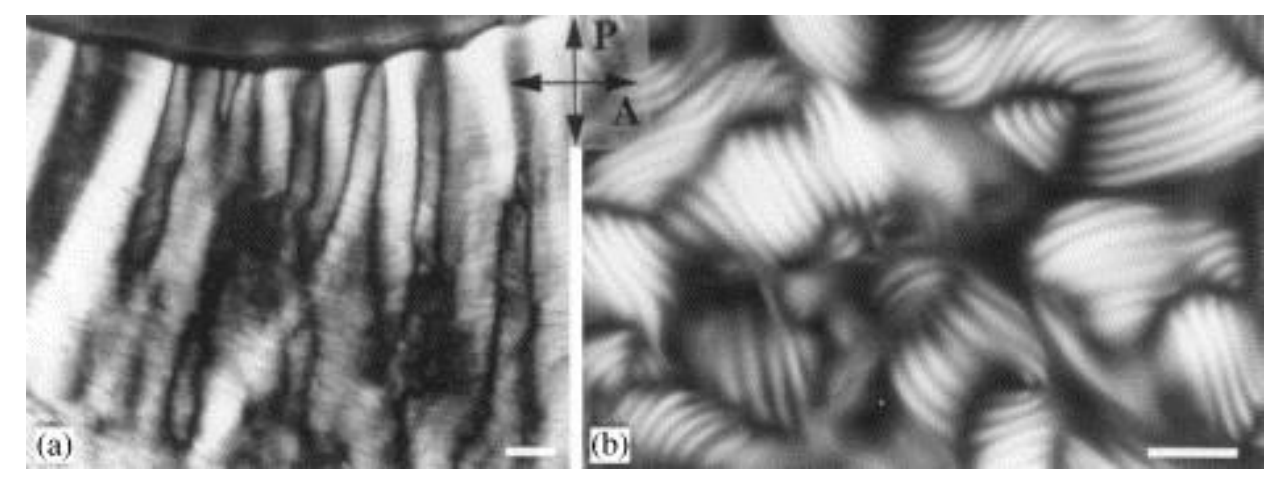

Fig. 12. Liquid crystal textures of collagen observed by polarised light microscopy between crossed polariser and analyser ( $P$ and $A)$. (a) Band texture in a precholesteric phase. Molecular directions undulate in the section plane and extinction occurs when they lie parallel to one of the polarisers. Bar: $10 \mu \mathrm{m}$. (b) Cholesteric fingerprint texture. Molecular directions regularly rotate along a direction normal to the lines. Bar: $10 \mu \mathrm{m}$. [160] Copyright (C 2003 Elsevier Science Ltd.

Thermodynamics, texture, structure and rheology of cholesteric collagen I solutions are discussed in Ref. [177].

6.2.1. Bone-Bone comprises organic and inorganic components in an advanced composite form that confers remarkable ability to withstand a high mechanical loading. Moreover, it comprises approximately $30 \%$ organics and $70 \%$ minerals by dry weight [178]. The toughness and stiffness are bestowed by the organic and mineral phases, respectively. The former is a matrix of proteins- 
mainly collagen-and other macromolecules including proteoglycans that are rich in acidic glycosaminoglycans (which polysaccharides dominate the organic-mineral interfaces) [179]. The structure of a compact bone consists of adjacent cylindrical units of about $0.2 \mathrm{~mm}$ in diameter called osteons (Fig. 11). Osteons are formed by concentric lamellae disposed around the Haversian canal containing blood vessels. The lamellae consist of collagen fibrils moving helically around the central canal with regular changes in the orientation of the fibrils.

Similar to the fish scales (discussed below), the bone is thus a collagen-mineral composite. Its strength comes primarily from its ability to absorb energy at small length scales through the mineral and protein phases; its anisotropic organisation at higher structural levels allows the development of the specific mechanical properties for peculiar functions. Two main osteon organizations may be found in a compact bone $[42,171]$. The first organization conforms to the classical description of osteons following an orthogonal (or a quasi-orthogonal) plywood model, i.e. with two principal orientations of fibrils. The second organization conforms to the twisted plywood model, where fibrils follow small and regular changes in their orientation; in this case, the structure is continuous. The passage between the orthogonal and twisted lamellae may be observed within the same osteon, with the arced patterns corresponding to the most recently secreted levels [171]. It is suggested that the twisted plywood appears when the collagen network is first produced by the cells, as it is always present in the newly secreted layers. The mechanical constraints further modulate the fibrillar arrangement before stabilisation of the collagen network.

Within the same context as that of the arthropod carapaces (Section 5.1), a plywood structure that is continuously twisted or exhibiting two directions of the preferred alignment is a resistant material [180]. The plywood structure may confer an enhanced resistance to the bone against fracture initiation and propagation in one or several directions. It provides several advantages over a perfect alignment: It increases the crack-extension energy per area, transports energy into a higher volume and leads to a more ductile fracture behaviour of the bone tissues [181]. It was reported that the 
fracture energy changes by two orders of magnitude depending on the collagen orientation; and the angle between the collagen orientation and the crack propagation direction is decisive in switching between different toughening mechanisms [181]. The structure-property relationship in the bone plywood is an evolving subject that requires supplementary investigations to be fully understood. A similar remark might be made for dentin (one of the four major components of teeth) whose toughness comes from its structure close to that of bone consisting of a cholesteric matrix of highly mineralised collagen fibrils [159].

Understanding how different structural features, acting at several length scales, interact simultaneously to generate the mechanical properties and biological responses is still a work in progress. Scaglione et al. [182] compared the in vivo cellular response with two osteoconductive materials that maximise the differences in the internal structure while displaying similar chemical compositions (a highly porous hydroxyapatite foam and a hydroxyapatite-collagen composite sponge). The pattern of the new bone tissue, deposited by bone-marrow-derived cells loaded on the two scaffolds, was assessed through a combined multimodal 3D optical microscope. Whenever a regular and geometrically ordered scaffold is present to the cells as a template for tissue regeneration, the lamellar bone tissue is formed and a cholesteric organisation of collagen fibrils is observed. A cholesteric scaffold design may contribute to drive properly the collagen fibre assembly to target in vivo bone regeneration $[183,184]$.

6.2.2. Tendon-A tendon connects muscle to bone and is essentially bundles of collagen fibres. A balance of repulsive and attractive pair interactions between collagen macromolecules determines the formation and swelling of fibres, which plays a crucial role in the tendon mechanics [67]. The twisted (rope like) organisation of tendons and ligaments provides them with the capacity to withstand large forces without stretching more than a few percent of their length making possible the movement. Cholesteric geometries are not clearly visible in the tendon. However, an unusual periodic change in the pattern of the bundles of collagen fibres occurs in tendons, which has been 
explained by a planar crimp of the collagen fibrils along the tendon axis $[158,185]$ (Fig. 13). This pattern allows for the extension of tendinous structures without the extension of collagen fibrils. This undulation does not occur in bone collagen, which is often subjected to compressive forces, but it occurs in the tissues that are subjected to tensile forces such as the tendon. The fact whether or not the crimp in the tendon might originate from similar mechanisms as those inducing the in vitro formation of the banded texture is not demonstrated [177].

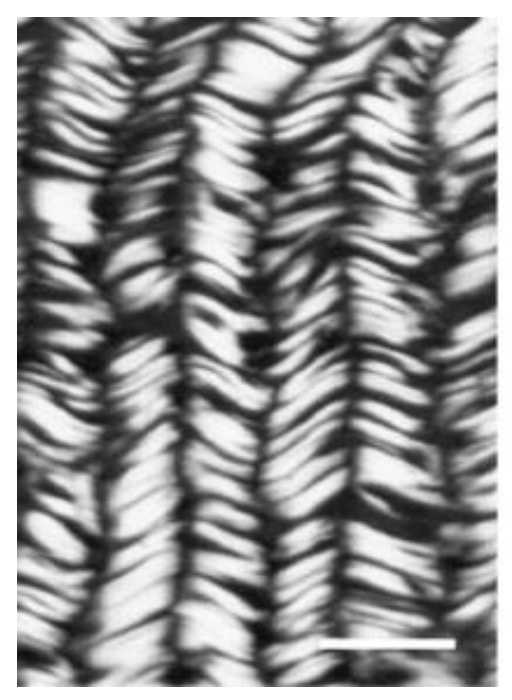

Fig. 13. The crimp patterns of collagen fibrils in a section of the rattail. Bar: $10 \mu \mathrm{m}$. [186] Copyright $(0$ 2008 Elsevier Ltd.

6.2.3. Cornea-The structure of collagen in the cornea is especially complex. It exhibits discontinuous rotation angles between the adjacent collagen bundles and a twist at a higher range [186]. The last part of the cornea consists of helicoidal layers of collagen fibres in fishes (carp and goldfish), amphibians (frogs), reptiles (turtle) and birds (domestic fowl, quail, pheasant and duck) [187]. The cholesteric structure, by providing equal stiffness in all directions, likely contributes to make and maintain, with the aid of intraocular pressure, a spherical shape to the cornea and thus reducing spherical aberrations. The corneal lenses are helicoidally constructed in the bird's (and insect's) corneas with the same sense of rotation in both eyes [188]. This means that the construction of 
fibrils in the left and right eyes is asymmetrical with respect to the bilateral symmetry of the body. Could this situation have any significance for the navigation and homing abilities, perhaps by the use of polarised light from the sky? There is no firm answer to this question.

In the dense solutions of collagen in $5 \mathrm{mM}$ acetic acid ( $\mathrm{pH} 3.5)$, the fibrils may assemble in a complex cornea-like organisation coupling together the smectic and cholesteric organisations [189]. This result is explained by the propensity of fibrils, which are in a repulsive regime, to form a cholesteric phase and an achiral (smectic or hexagonal) phase at the same time. The abrupt rotations between the different domains of fibres might result from such a frustration. A similar mechanism might exist in vivo. These results are of interest in the field of biomimetic corneal matrices.

6.2.4. Fish armour-The organisation of the collagen network in fish scales and scutes exhibits a diversity of the plywood structures: orthogonal, twisted, or double-twisted plywood (i.e. the orthogonal plywood where every second layer, instead of being strictly parallel to the first one, rotates by a small angle in a given sense so that the whole geometry is twisted) and many intermediate situations, in between discontinuous and continuous structures, depending on the species or the region under consideration in the fish armour. A series of arced patterns have been observed by the optical or electron microscopy in the fish scales such as coelacanths $[40,190]$, freshwater carp Cyprinus carpio communis [191], goldfish Carassius auratus [192,193] and in the dermal scutes of boxfish [194] (arc patterns were not recovered by Yang et al. [195]). In the latter case two cholesteric organisations were described: one with continuously rotating fibrils and the other with discrete steps of rotation [194]. The two geometric systems were separated by a 3D collagen lattice reminiscent to the array of double-twist cylinders in chiral LC phases called blue phases $[55,196]$. The cholesteric organisation can be evidenced by using small-angle X-ray scattering (SAXS), the same used for the teleost fish scales [197].

The cholesteric structure may specifically offer resistant armour against predators. Arapaima gigas is a freshwater fish found in the Amazon Basin, which can resist the appetite of piranhas through the 
strength and toughness of their scales. The cholesteric arrangement of collagen fibrils plays a crucial role in developing the unique protective properties of this fish [198]. It adapts to tensile loading by allowing the lamellae to rotate towards or away from the applied tensile stress, and thereby deforming in tension or compression, respectively. Most lamellae reorient towards the tensile axis and deform in tension through the stretching-sliding mechanisms, whereas other lamellae sympathetically rotate away from the tensile axis and compress, and thereby enhance the scale's ductility and toughness to prevent fracture. The changes in the angle of the fibrils with the tensile axis and the stretching of the fibrils are evidenced by the in situ synchrotron SAXS and explained by four principal mechanisms (Fig. 14).

a

Rotation through interfibrillar shear

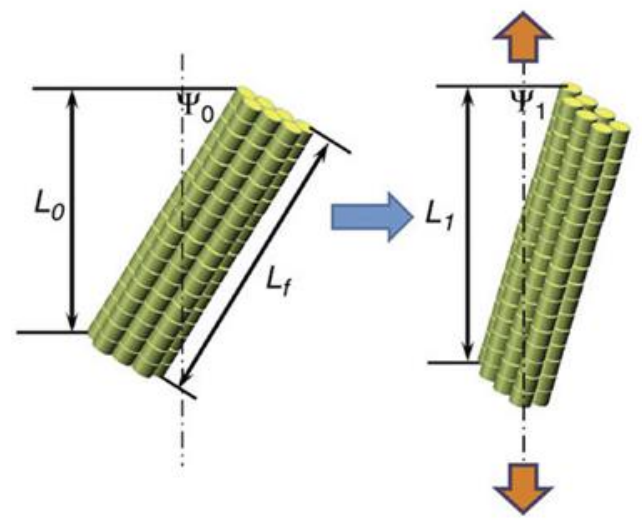

c Tensile opening interfibrillar gaps

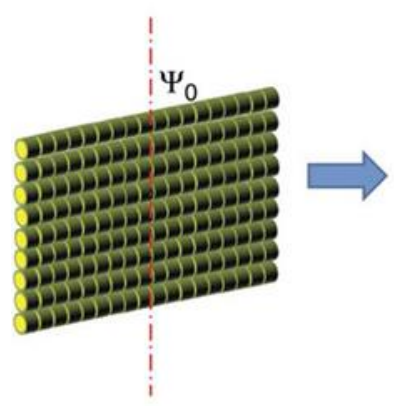

b

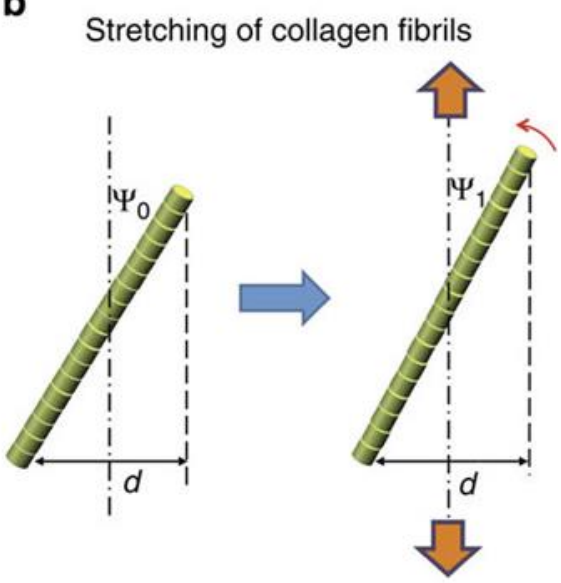

d Sympathetic lamella rotation

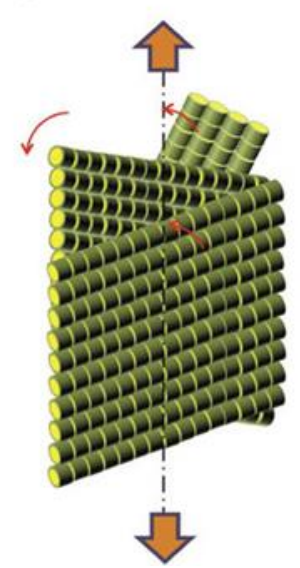

Fig. 14. Deformation and rotation phenomena in the cholesteric structure of the fish scale (Arapaima gigas) as explained through four principal mechanisms. (a) Interfibrillar sliding causes rotation 
towards the tensile axis, where fibrils at an original orientation from the tensile axis of $\psi_{0}$ reorient to $\psi_{1}$ with a corresponding increase in the projected length from $L_{0}$ before loading to $L_{1}$ under loading with respect to the fibril length, $L_{f}$. (b) The stretching of the lamellae could also cause the fibrils to rotate towards the tensile axis from $\psi_{0}$ to $\psi_{1}$, whereas the projected length $d$ is assumed to remain unchanged. Other mechanisms could be responsible for rotation away from the tensile axis. (c) Tensile separation of fibrils at an initial orientation of $\psi_{0}$ could force some fibrils to reorient towards the tensile axis $\left(\psi_{2}\right)$, whereas other fibrils rotate away from them $\left(\psi_{1}\right)$. (d) Sympathetic rotation of lamellae could occur, where lamellae rotating towards the tensile axis force other lamellae to reorient away from the tension. [198] Copyright (c) 2013, Rights Managed by Nature Publishing Group.

The light-reflecting structures of fishes are useful to communicate the information on relative positions, orientations and movements between neighbours, especially in a school of fish $[199,200]$. For example, the silvered patches on the tail or the pectoral fins may become much brighter or darker with movement, and the colours of the ventral flanks may change from bright red to blue with the viewing direction. Similarly to that happens in the insect world (Sections 5.2.1 and 5.2.2), it may be assumed that the optical properties unique to the cholesteric organisation (not found in noncontinuously twisted plywood structure)-the exceptionally large optical activity and the polarisation-selectivity rule-might provide unique benefits to a fish for camouflage (the silvery armour plays an important role in open water camouflage; broadband mirrors provide camouflage to fishes taking advantage of diffuse light conditions [201]) and communication and navigation inside a school of fish. The investigations on the specific role of cholesteric colours versus colours from achiral periodic structures like a simple stacking of platelets [202] are in a preliminary stage, in the world of sea animals. 


\subsection{Outlook}

The exact mechanisms that determine the tissue architecture in a compact bone, skin or cornea are still major open problems in morphogenesis. In vivo, the cholesteric organisation of fibrils in compact bone osteons and, in tendons, the crimp morphology-which is akin to a precholesteric phasesuggest that CLC organisation plays a crucial role in the determination of the tissue form. In vitro, collagen macromolecules in acid solution form nematic, precholesteric and cholesteric phases, but the relevance of it to the in vivo assembly mechanisms is unclear.

Many indirect cues suggest that an intermediate cholesteric phase could exist prior to fibril selfassembly (fibrillogenesis) and could, therefore, constitute a basic morphogenetic principle of the collagen patterning in tissues $[167,186]$. For example, cells produce collagen within the closed compartments (in the cell vesicles or the extracellular matrix) at very high concentrations, and the volume fraction of collagen in tissues and collagen LC phases is very similar. Advantageously the 'cholesteric-driven control' of fibrillogenesis could not require orchestrated cell movement but high cell density and high collagen concentration [203]. In the concentrated solutions of procollagen (precursor molecules of collagen), precholesteric arrangements are obtained at physiological $\mathrm{pH}$ and ionic strength in the form of large domains exhibiting regular precholesteric cords, but typical cholesteric textures are not observed.

The mechanism of the in vivo formation of collagen fibrils, the fixation of their diameter, the relationship between their compositions and the functional requirements in different tissues are still open questions. The differences in the long-scale organisation of collagen-twisted in bone, crimpy in tendon and orthogonal in cornea-are difficult to explain. 


\section{Cellulose}

Cellulose is produced by plants via the condensation and polymerisation of glucose, which is a product of photosynthesis. The long chains of anhydroglucose units joined via $\beta-1,4-$ glycosidic linkages $(\mathrm{C}-\mathrm{O}-\mathrm{C})$, are formed during this reaction. As wood contains considerable amounts of cellulose (Fig. 15), this polysaccharide is the most abundant biopolymer. Bacteria, slime moulds and a group of sea animals (tunicates) also have the ability to synthesise cellulose [204].

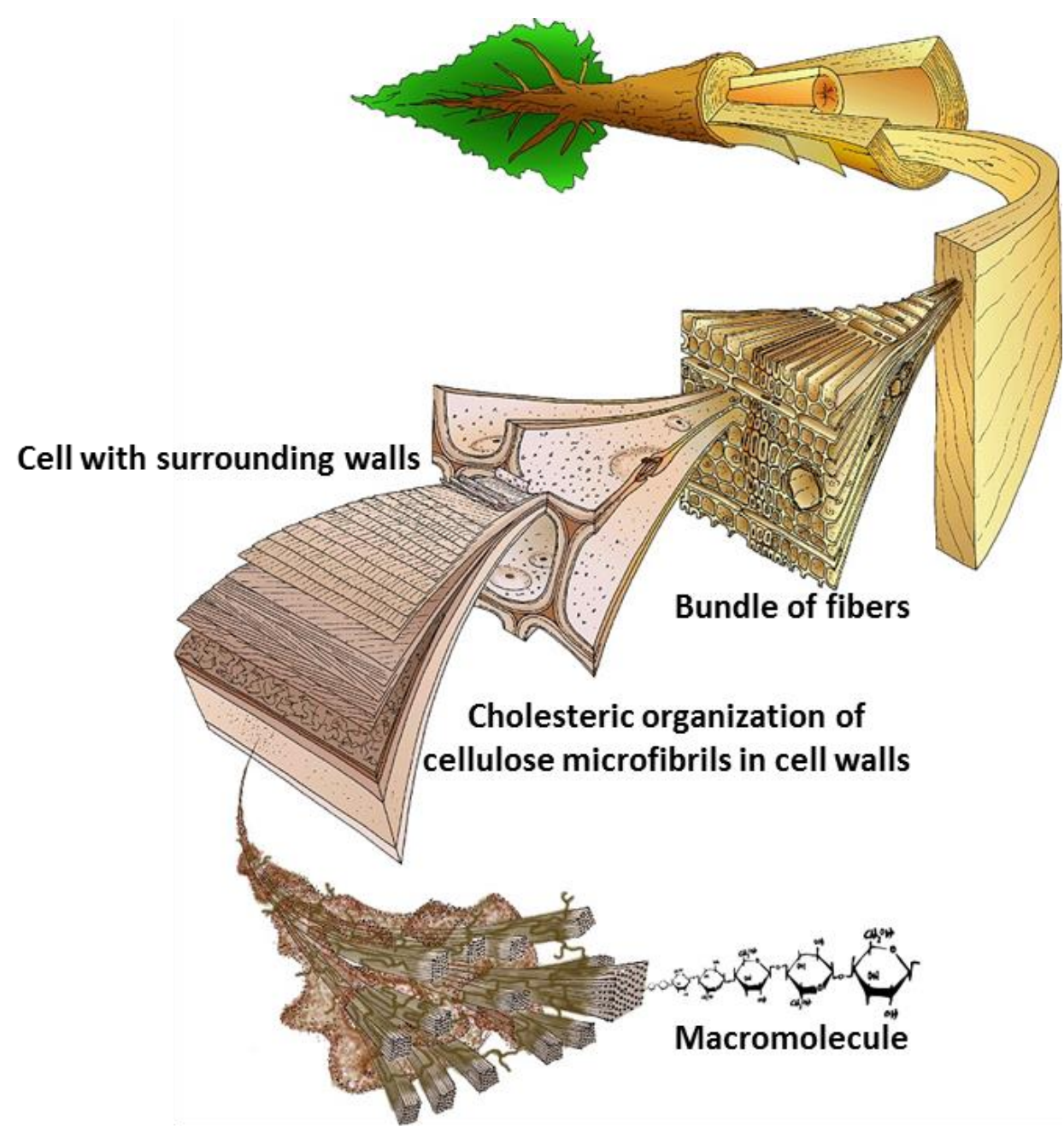

Cellulose nanofibrils

Fig. 15. The hierarchical structure of cellulose in wood. From an artwork by Mark Harrington, Copyright University of Canterbury, 1996. 


\subsection{In situ cholesterics}

7.1.1. The plant cell wall-In contrast to the animal cells, the plant cells possess a wall, which acts like an extracellular compartment (box) surrounding the cell. The thickness of plant cell walls generally lies in the range of $0.1-0.3 \mu \mathrm{m}$ and can exceed $1 \mu \mathrm{m}$ [205]. The walls form a continuous network through the whole plant. The growth and form are controlled by the oriented expansion of the walls. The driving force for cell expansion is osmotic. The cells grow by turgor-driven enlargement. The primary task of the wall is to provide a skeletal support to the plant. The wall shape depends on the types of cells. For example, the compression wood cells of spruce are cylinders of the circular or elliptical cross-section, whereas normal wood cells of spruce are often cylinders with super-elliptical cross-section [49]. The cell wall also plays a dominant role in cell morphogenesis, disease resistance, cell recognition and signalling, digestibility by herbivores and humans, and plant decay [206].

The wall is made of sequentially deposited layers of different thicknesses, chemical compositions and structural organisations. There are two types of walls: primary and secondary, which differ in function and in composition. The primary wall is the first layer to be laid down after the cell division and its formation coincides with the cell growth. It provides mechanical strength (it has to resist the internal turgor pressure of the cell) and must expand to allow the cell to grow and divide. It behaves like a fibrous composite ('fibreglass') with an ordered array of stiff cellulose microfibrils embedded in a less stiff matrix of polysaccharides and glycoproteins (hemicellulose, pectin and other macromolecules) (Fig. 16). Once the cell has ceased to grow, three layers of the secondary wall are laid over the primary wall in an inward direction. The central layer, called secondary layer S2, comprises about $80-90 \%$ (of the entire cell wall volume). The layers of the secondary wall are much thicker and stronger than the primary wall; they contain lignin. Lignification follows the organisation of microfibrils in the primary walls and provokes the hardening of the secondary walls. The secondary walls are not found in all cell types. 
Cellulose microfibrils are composed of approximately 36 hydrogen-bonded chains and each chain contains 500-14 000 glucose units. These cable-like structures are laid down by apposition on the inner surface of the growing wall, whereas pectin, hemicellulose and glycoproteins are secreted via the Golgi apparatus into the network of microfibrils.

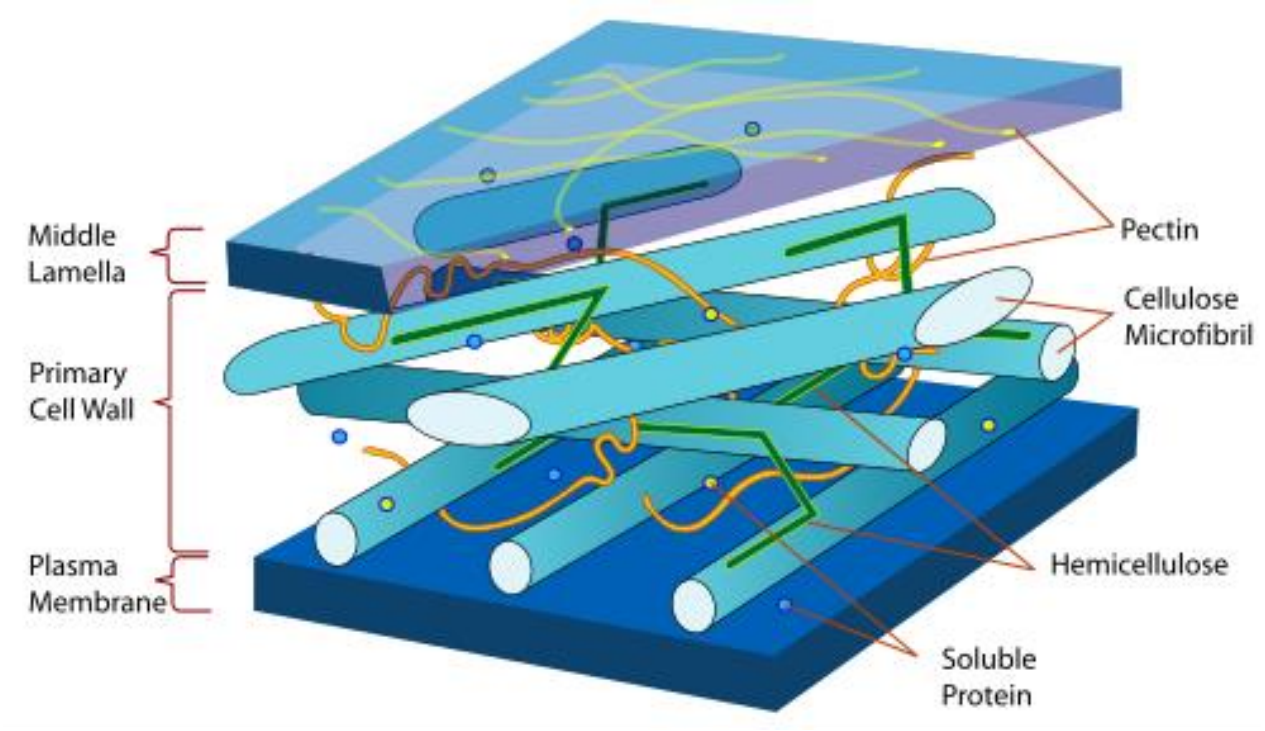

Fig. 16. Plant cell wall structure. The plasma membrane forms the innermost layer surrounding a cell. The primary wall is outside it. Cellulose microfibrils are the major components. They are represented by cylinders that, in this particular case, lie on the top of one another in a crisscross fashion. The middle lamella forms the outermost layer. It contains many pectin molecules and soluble proteins similar to those in the primary cell wall. Lignin is not shown here. Source: Wikimedia Commons (adapted from M. B. Sticklen, Nature Reviews Genetics, 2008, 9, 433-443).

Microfibrils may self-assemble in the cell wall with different kinds of organisations: axial (nematiclike), transverse, crisscrossed, so-called helical, and helicoidal (cholesteric-like) [207] (Fig. 17a). The cholesteric organisation (Fig. 17b) can be found both in the primary and secondary walls [206]. The walls may exhibit arc patterns that deviate from the monotonic helicoidal plywood as depicted in Fig. 
2, revealing different CLC structures with the graded pitch, random pitch, discontinued pitch, etc. [49], from which architectures could generate complex optical responses.
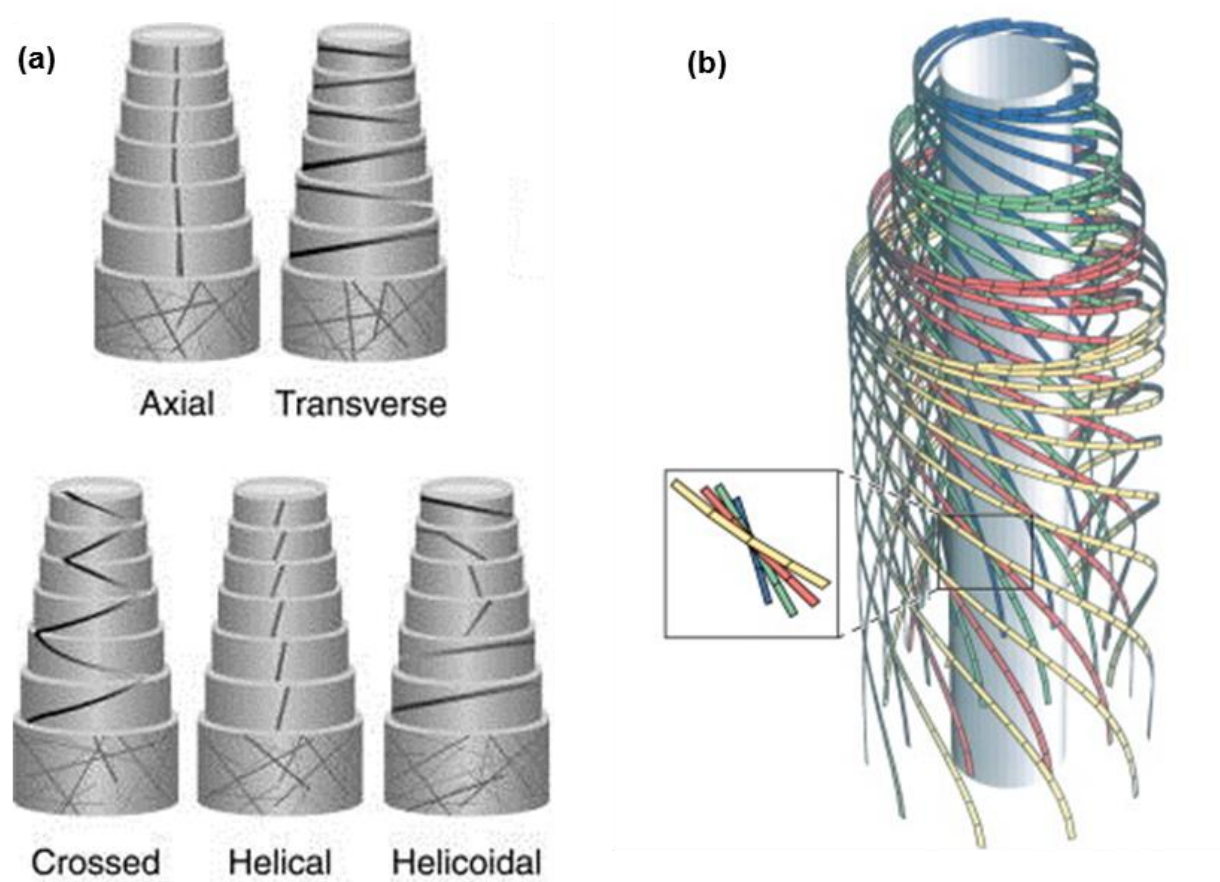

Fig. 17. (a) Basic organisations of cellulose microfibrils in the cell wall. The successive wall layers have been peeled off from the top to bottom to reveal the internal structure. (b) The focus is on the principal geometry of the helicoidal deposition of cellulose microfibrils. For representation purposes, the deposition is described as tapes that wind around a cylinder. A small number of microfibrils are drawn at a highly expanded scale. Four generations of microfibrils are spun. Each of them contributes locally to a single 'layer' in the cholesteric structure. The inset shows that the angle of deposition between the adjacent layers is nearly constant, which is the hallmark of the cholesteric organisation. [207] Copyright @ 2000 Elsevier Science Ltd.

The growth mechanisms of plant cells are not fully described. More information on the control of microfibrils orientation, inter alia, is required [208]. 
7.1.2. Early work-The cholesteric organisation is distributed throughout the plant taxa [209] and found in a range of cell types: spores, collenchyma, sclerenchyma, tracheids, sclereids and parenchyma [210-213]. In many supporting cells (sclerenchyma and wood cells), the CLC structure appears only temporarily; the process, which is inherent to growth, is irreversible and its regulation is determinant for the cell physiology [211].

The readers, for further information on in situ cholesteric cellulose reported till 1990, may refer to the must-read book "Biology of fibrous composites" by Neville [46]. The cholesteric cellulose concerns lower plants, such as mosses, horsetails, ferns, fungi and lichens (cholesteric chitin can also be found in cell walls of fungi and lichen), algae, coniferous gymnosperms, flowering plants, such as angiosperms including monocotyledons and dicotyledons (quince, hazel, pear, prune, cherry, walnut and olive), bacteria, cyanobacteria, and tunicates (Halocynthia papillosa). Neville's monography includes several tables classifying cholesteric structures found in different groups, genera and species, with references. For example, and beyond cellulose, Tables 2.1-2.6 [214] list arthropods other than insects and crustaceans (Scorpionida, Araneida), butterfly and moth eggshells, invertebrates excluding arthropodan phyla (Protista, Rotifera, Nematoda, Echinoderma and Mollusca), fishes and amphibia (eggshell or corneal collagen), reptiles (eggshell or corneal collagen), birds (corneal collagen), etc.

To visualise the cholesteric patterns, dedicated techniques for the preparation of specimens and electron microscopy are required; and, as mentioned by Neville, these patterns may remain undetected if the observation conditions are not correct [43].

The CLC structure provides better resistance to the plant in multiple directions against environmental stresses such as the wind [209]. Similarly to the case of chitin-based and collagen-based biomaterials, resistance to fracture is increased because the path of any crack is diverted by the change in orientation, which results in an increased capacity to dissipate energy [215]. Therefore, the CLC structure combines a balance of strength in all directions with flexibility. The cholesteric wall 
structure resists the turgor pressure equally in different directions [216], and similarly, the cholesteric collagen in the cornea of lower vertebrates resists the pressure of fluid within the eye (Section 6.2.3).

7.1.3. Iridescence in plants-Structural colour in general has been mainly studied in the animal kingdom, and largely ignored in plants [217], where research has focused on the analysis of pigments and the subtractive colouring they produce. Multilayer interferences, thin-film interferences, grating diffraction, scattering or light reflection by photonic crystals like cholesteric LCs may also be at the origin of colouration in plants $[218,219]$.

Iridescent plants are generally found in the shaded forests and at tropical latitudes. Iridescence found in leaves, fruits and petals can span to different colours of spectra that are perceptible to a variety of animals, including UV [217] and the visible range for humans [220]. The structures employed to achieve iridescent colours may (i) make plants attractive to pollinators by leaves and flowers and, by fruits, to birds and mammals, which then disperse the seeds (display function); e.g. the bumblebees can use iridescence as a cue to detect flowers [221,222]; (ii) deter herbivores (defence function), the changeability of colour with the viewing angle could corrupt the object identity, making it harder for insects to form a search image [223], and colouration could even be visible only to certain species of insects [224]; (iii) help in light management with a crucial role either in photoprotection or by focusing light on the chloroplasts (Ref. [225], and references therein), and the plant surface topography not only affects the visual appearance but also controls the amount of light coupled into the lower lying tissue [226] with the following consequences: the increased capture of photosynthetically important wavelengths and polarisation filtering that enhances the orientation of the photosynthetic apparatus within the cell and protects the shade-adapted plants against sun flecks. A diverse range of photosynthetic organisms from diatoms to algae and then to angiosperms produce a vivid iridescence over their surface, which suggests that iridescence has evolved multiple times and has some adaptive advantages for life in deep shade [223]. 
The recent publications on the physical properties of the in situ cholesteric cellulose are much rarer than those on cholesteric chitin. We devote this section to structural colour since most of them have remarkably focused on this subject.

7.1.4. Leaves-The leaves of Selaginella willdenowii produce UV-blue light iridescence. The underlying mechanism arises from the multilayer interference of two or more materials with different refractive indices $[223,227]$. The iridescence of Selaginella species might aid the capture of photosynthetically active wavelengths in low light conditions with the leaf iridescence acting as an anti-reflective coating. This coating would produce constructive interferences for certain wavelengths (by increasing the transmission of them), and other (non-transmitted) wavelengths would be strongly reflected because of destructive interferences [217].

The UV-blue colouration arising from a CLC structure is found in the leaves of Malaysian iridescent understory tropical fern species such as Danaea nodosa [225,228] (Fig. 18), Lindsaea lucida and Diplazium tomentosum $[224,225,228,229]$, where the cholesteric organisation is absent in the older leaves, which show no iridescence [217], and in the flowering plants such as Phyllagathis rotundifolia $[225,229]$.

Plant leaves are expected to be green because the chlorophyll pigments absorb visible light but little in the green range. The leaf colour other than green shows that wavelengths captured by chlorophyll are absorbed or reflected by other pigments. Consequently, less energy is captured for the photosynthesis and growth. Why blue plants living in a dark environment reflect light that could contribute to the photosynthetic efficiency [230]? The selectivity of light reflection by a cholesteric structure might provide photo-protection because these plants, adapted to low light conditions, suffer damages whenever encounter sunflecks. Some iridescent blue leaves may recover significantly more rapidly from light exposure than non-iridescent green leaves [217]. However, no difference was found between the iridescent and non-iridescent leaves of $D$. tomentosum [225]. 

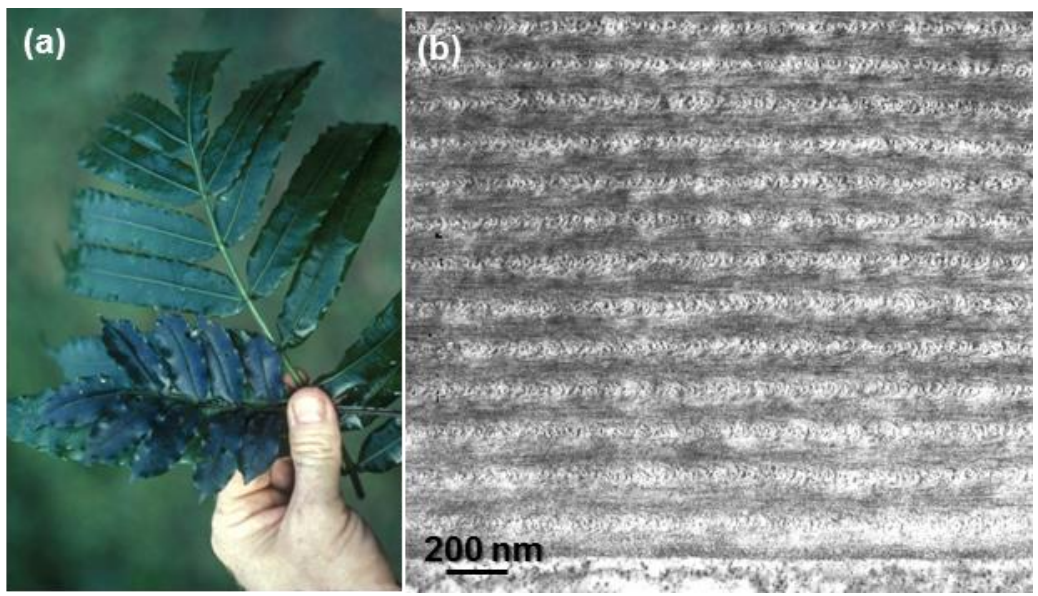

Fig. 18. (a) The photograph of juvenile (blue) and adult (green) leaves of $D$. nodosa. The adult leaves have lost iridescence. (b) The cholesteric structure as shown in a TEM cross-sectional view of the cell wall of a juvenile leaf. Reproduced with permission from D. W. Lee.

The Malaysian tropical rainforest understorey herb Mapania caudata (Fig. 19a and b) provides an unusual case of the iridescent cholesteric cellulose-enriched with silica nanoparticles [231]. Granular silica nanoparticles are organised inside the graded-pitch cholesteric organisation of microfibrils (Fig. $19 c$ and d) and contribute to the whole structure producing the blue iridescence. The diffuse reflection peak in the visible spectrum is quite broad from 400 to $700 \mathrm{~nm}$. The removal of silica from the walls eliminates the blue colour. Two partially overlapping periodicities might account for the blue structural colouration: the helicoidal periodicity of microfibrils and the periodicity for the layered aggregation of nanoparticles. The cholesteric colouration involving silica might not be limited to $M$. caudata. In addition to the cholesteric fingerprint texturation of platinum $[232,233]$ and gold [234] nanoparticles in synthetic cholesteric oligomers, this study remarkably presents the simultaneous nucleation and fingerprint patterning of bio-nanoparticles in a biopolymer. 


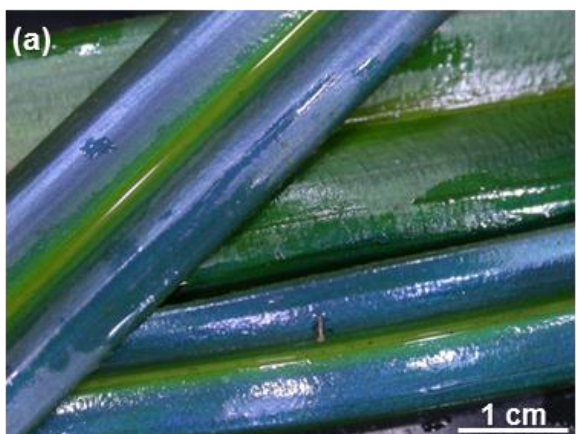

(c)

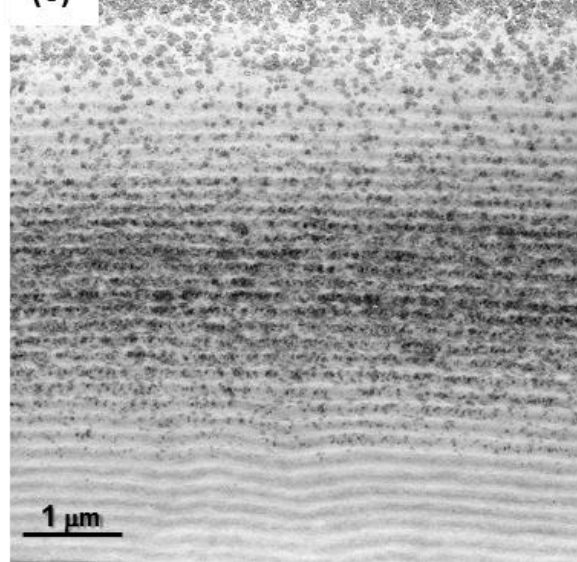

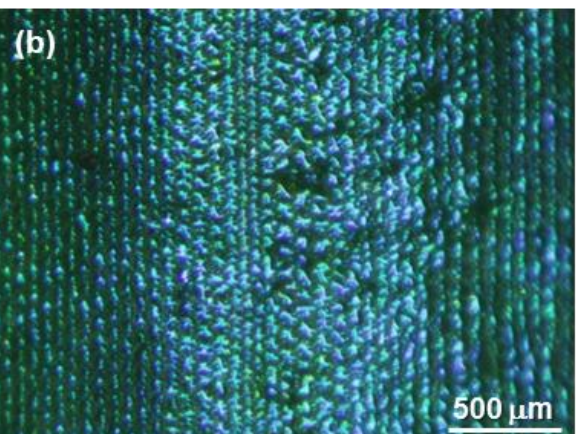

(d)

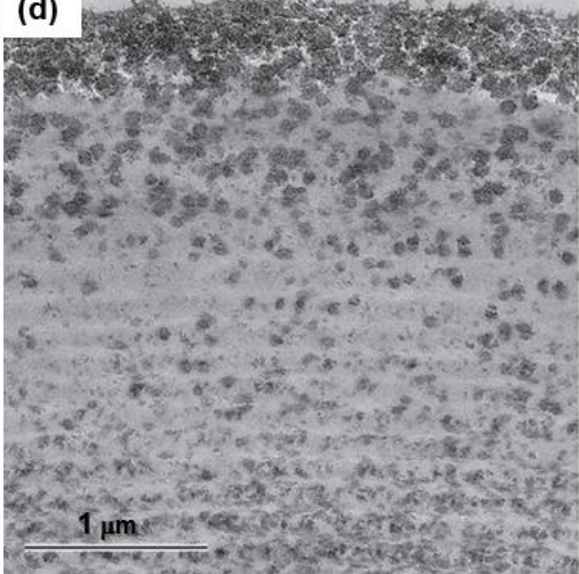

Fig. 19. Self-organisation of nanoparticles into the cholesteric cellulose of Mapania caudata leaves.

(a) The intense blue-green iridescent colour from the edge of leaf to midrib. (b) Light reflected by the surface of the leaf reveals the iridescence of individual epidermal cells. (c) A TEM image of the transverse cell wall showing the cholesteric fingerprint texture and a thicker granular layer near the surface. (d) Enlarged image showing the layering of granular nanoparticles inside the fingerprint texture near the surface. Reproduced with permission from D. W. Lee.

7.1.5. Fruits-The primary function of fruits and flower iridescence is likely to attract animals, particularly to those species whose visual systems are attuned to iridescence in the context of animal-animal communication [217].

The shiny, metallic, blue colour of the fruits of Pollia condensata (Fig. 20.a), an African forest understory species, arises from the cholesteric cellulose $[97,235]$. The epicarp (outermost skin) exhibits cellular motifs under a microscope. The pixelated iridescence of the fruit, with purple, blue, 
green and red speckles, is revealed by epi-illumination using circular polarisation filters (Fig. 20b and c). The TEM transverse section image of epicarp shows arc patterns (Fig. 20.d). The colour difference from cell to cell corresponds to different pitches. Each cell shows colour in a specific polarisation channel (Fig. 20.e), i.e. a specific twist handedness. P. condensata is a parental biological version of synthetic cholesteric gels in which RH and LH helicity senses coexist $[236,237]$. The property of double helicity, increasing the reflected intensity at a given wavelength in the Bragg band, added to the existence of different colours makes the $P$. condensata fruit the most brilliant land-based biological organism to date.
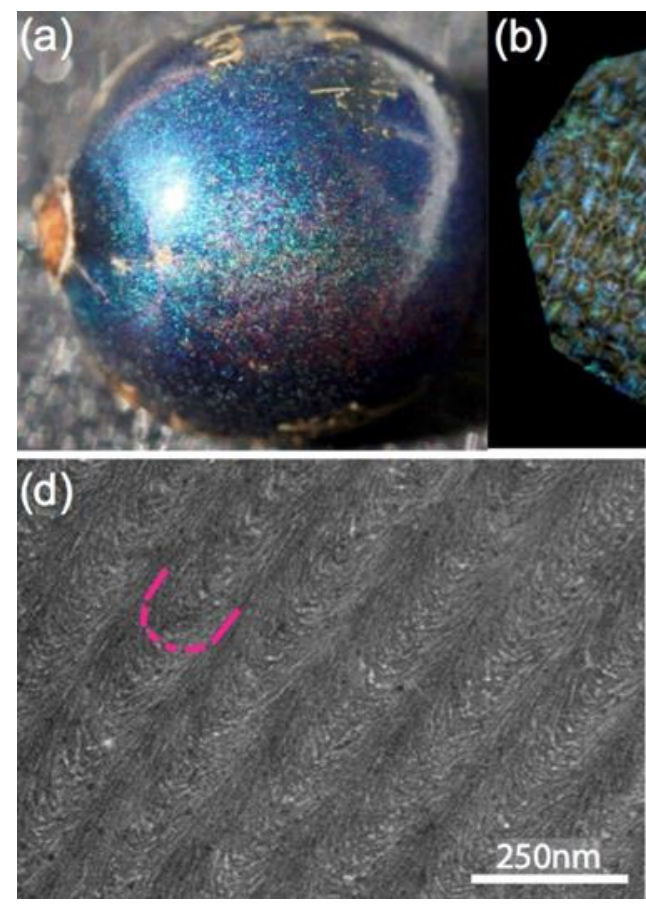
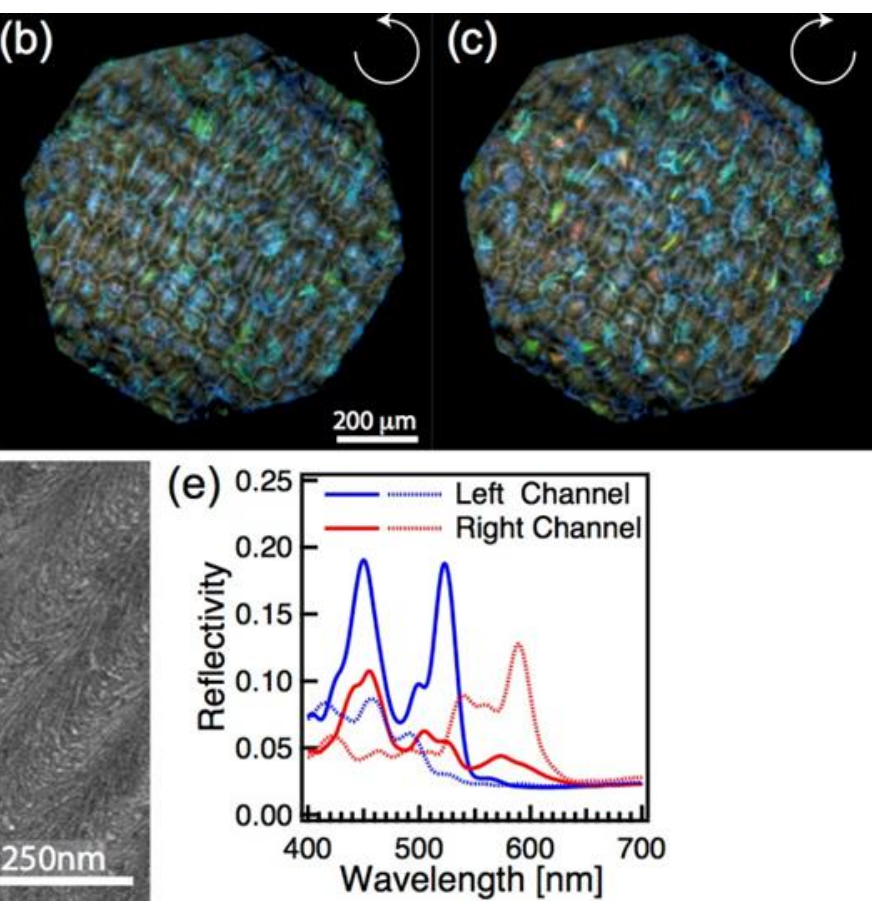

Fig. 20. (a) Pollia condensata fruit. The diameter is about $5 \mathrm{~mm}$. (b, c) Optical micrographs in epiillumination (unpolarised incident light) of the single area of epicarp by using left-handed (b) and right-handed (c) circular polarisers. The pointillist colouration originates from individually coloured cellular motifs. (d) Cholesteric structure is revealed in a cross-sectional TEM view of the epicarp; the pink line enhances an arced pattern. (e) Reflection spectra for two different cells (continuous and dotted lines) collected by the left- and right-handed circular polarisation channels. [97] Copyright (C) 2014 The Authors. Published by Elsevier Ltd. 
Although more than 50-year old, the fruit shown in Fig. 20a appears like a fresh one. By mimicking the appearance of a fresh nutritious fruit, some plants like $P$. condensata may have evolved to mislead their seed dispersers, without offering them any nutritious reward [238]. This strategy could avoid the energy cost of producing the fresh pulp. The structural colours, in contrast to the pigmental colours, give to the fruit a brilliant and intense appearance that is maintained even after it falls from the plant, increasing the probability of attracting an animal. Alternatively to the promise of fresh fruits, $P$. condensata might also attract birds for the research of shiny objects to decorate nests or arenas to attract potential mates [239].

7.1.6. Mechanism of the helicoidal formation of the cell wall-In a study by Murugesan and Rey [215], a model based on the Landau-de Gennes theory was used to simulate the dynamic selfassembly of a lyotropic CLC and to understand the mechanism of the helicoidal formation of the cell wall. This mechanism is still a matter of debate $[240,241]$. (i) One hypothesis is that the cellulose selfassembly is guided by hemicellulose [209,242-244]. Cellulose is crystalline, strong and resistant to hydrolysis, whereas hemicellulose is amorphous, shows weak strength and may be hydrolysed. The unbranched homopolymers like cellulose crystallise with backbone chains closely packed to form parallel crystallites. The branched heteropolymers like hemicellulose show a pipe-cleaner structure: flexible side chains (which can contain different sugar monomers such as xylose, mannose, galactose, rhamnose and arabinose) are attached to a stiff backbone that may be composed of glucose (as in xyloglucans) or xylose (as in gluronoxylans). Such a structure offers the possibility to have rotatory movements in hemicellulose molecules, not in cellulose molecules, and to adopt a twisted organisation due to their chirality (the presence of asymmetric carbons). Since hemicellulose molecules are hydrogen bonded to the periphery of cellulose microfibrils (Fig. 16), they may entrain cellulose microfibrils into the CLC structure. In this model, the handedness of the material is determined by the intrinsic chirality of the molecules that compose the cell wall. (ii) In the other 
model, the helicoidal structure of cellulose microfibrils may be determined by the rotation of microtubules in the underlying cell $[241,245]$. Chan [237] focused on the relationship between the growth and the orientation of microtubules and cellulose microfibrils. The microtubules provide a template for cellulose-synthesising particles that glide along the plasma membrane extruding cellulose microfibrils into the wall [246]. Microtubules can change the position during the cell growth and rotate in both the clockwise and anticlockwise directions. The mechanism that determines the direction of the microtubule rotation is unknown. It could lead to both the $\mathrm{LH}$ and RH CLC structures because the helicoidal arrangement would be independent of the chirality of the microfibrils. According to Vignolini et al. [235], this mechanism could explain why both helicity senses coexist in $P$. condensata. However, with this scenario, no change would happen in the direction of microtubule rotation during the growth of a single cellular motif. More clarification is expected on the origin of cholesteric domains with both helicities in P. condensata.

7.1.7. Outlook - Is the production of colour a primary function of a periodic and chiral structure or a by-product of a structure that performs a different (non-optical) function? The same question was also raised for chitin and collagen. However, limited information is available about the developmental mechanisms and the genetic controls used by plants or animals in producing cholesteric structures.

Light plays a major role in the plant life. The columns of cells in plant seedlings (oats, corn, mung bean) can act like a bundle of fibre optics [247]. Laser experiments have shown that plants can transmit light up to the tips of root hairs even when they are bent. Do cholesteric cell walls play a role in the internal light reflection? In the plant fibre optics, the light may coordinate various aspects of the physiology of the growing plants.

Although much is known about the chemistry of plant cell walls, a lot yet to be unravelled about the control of their morphology. The relationship between the cholesteric organisation and other components requires to be further exemplified. 
Structural colours are probably quite frequent in the plant kingdom but we have only a fraction of the knowledge about their distribution, development and function. The reason why not so many plant tissues with cholesteric-based coloration are known, in contrast to insects, might simply be that nobody has yet looked for them [224]. Many iridescent plants might be awaiting an exploration [248] that could reveal novel mechanisms of colour production. A multitude of plants for which the structural origin of the colouration effects has not yet been identified or characterised has been compiled by Gebeshuber and Lee [218]. The enormous morphological diversity of more than 300000 angiosperm species has to be kept in mind. It demands a mutual interaction between the scientists belonging to different horizons to understand the significance of chiro-optical phenomena in plants.

As Kutschera wrote the cholesteric organisation of cellulose looks like an example of 'complex design in biological systems without an intelligent designer' [244]. More experimental work is required to support further this concept of the generation of ordered structures from disordered cable-like biopolymers in the extracellular compartments of living organisms like plants.

\subsection{Ex situ cholesterics}

A number of review papers have compiled the information available on the structures, properties and applications of cellulose-based nanomaterials $[240,249-258]$. In this section, our prime attention is on the cholesteric structures artificially produced from natural cellulose nanocrystals (CNCs). Being promising optical materials and templates $[259,260]$, they resulted an avalanche of publications from several research groups, in particular from 2003-2004.

7.2.1. Nanocrystals suspensions-CNCs are produced by the sulphuric acid based hydrolysis of natural cellulose such as wood or cotton pulp, bacteria and tunicates ([249] and references therein). A cellulose microfibril contains both amorphous and crystalline parts. The acid degrades the amorphous regions, leaving CNCs as rod-like particles. CNCs were also referred to as cellulose microcrystals (in the early literature), nanocrystalline cellulose and cellulose whiskers (or 
nanowhiskers). CNCs resemble whiskers because of the tapering at the ends of the crystals consequent to the hydrolysis. Another consequence is that the surface of CNCs becomes negatively charged by the sulphate groups, which serve both for the stabilisation of colloidal suspensions of CNCs and the formation of a CLC phase [261]. CNCs have a high aspect ratio-typically 3-50 nm wide and 50-1000 nm long [262]. Their dimensions depend on the origin of cellulose. Cotton CNCs have typical dimensions of 100 to $300 \mathrm{~nm}$ in length and 8 to $10 \mathrm{~nm}$ in diameter, while tunicate CNCs range from $100 \mathrm{~nm}$ to few micrometers in the length and 10 to $20 \mathrm{~nm}$ in diameter [263].

At very low concentrations, CNCs randomly suspend in water and form an isotropic phase. A nematic or cholesteric organisation of CNCs above a critical concentration is the result of favourable excluded volume interactions leading to higher packing entropy than in the isotropic phase [264]. The CLC phase is the most commonly observed LC phase in the CNC suspensions. In 1992, Revol, Derek G. Gray et al. discovered that CNCs (from wood pulp, cotton pulp, ramie, bacteria) in aqueous suspension might form CLC phases [261]. The cholesteric structure of the suspensions can be preserved by the slow evaporation of water, which means that solid iridescent films with optical properties similar to CLCs can be prepared. The final structure strongly depends on the drying conditions $[261,265,266]$.

Fig. 21.a shows the fingerprint texture of a eucalyptus suspension [267]. The pitch decreases with an increasing cellulose concentration and the rod length. At the same volume fraction than the short rods, the long rods tend to align in a nematic state instead of a cholesteric state. Fig. 21.b shows the fingerprint texture of a bacterial suspension for comparison [268]. A monodomain texture is promoted. This situation is due to a larger aspect ratio, the rectangular shape of the cross-section of bacterial CNCs (typically $54 \mathrm{~nm} \times 10 \mathrm{~nm}$ vs. $5 \mathrm{~nm} \times 5 \mathrm{~nm}$ for wood), and a lower surface charge density. 

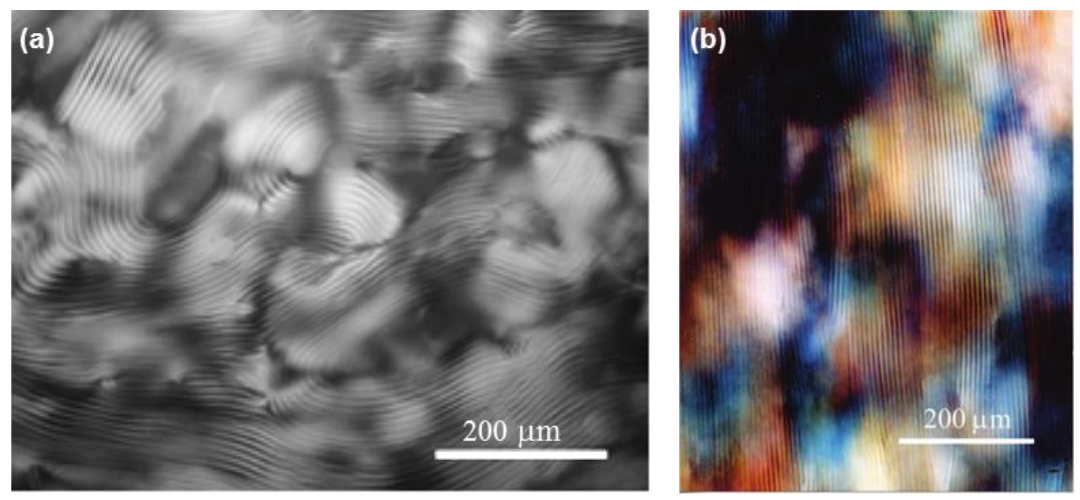

Fig. 21. Cholesteric fingerprint texture of cellulose nanocrystals from: (a) Eucalyptus in suspension in water (cellulose concentration $=10$ wt.\%) [267]. Copyright @ 2005, American Chemical Society. (b) Bacteria in suspension in water (cellulose concentration = 3 wt.\%) [268]. Copyright @ 2009, American Chemical Society.

Although the case of synthetic cellulose is beyond the scope of this review, it has to be noted that CLC phases appear in concentrated solutions of many cellulose derivatives such as ethyl cellulose, hydroxypropylcellulose (HPC), acetoxypropylcellulose, and other esters of propyl cellulose (propanoate, butanoate, benzoate) [269]. Both LH and RH structures have been observed [269], but to date only LH CLCs have been observed for CNC suspensions. Much higher concentrations of cellulosic derivative are needed to form the CLC phase in comparison to native CNCs (typically 7 wt.\% for CNCs vs. 50-75 wt.\% for HPC and 40 wt.\% for ethyl cellulose) [270,271].

7.2.2. Pitch tuning-The size, shape, dispersity or charge of CNCs, type of electrolyte, conditions of film preparation and external stimuli can affect liquid crystallinity, pitch and domain size.

Pitch can vary from less than $1 \mu \mathrm{m}$ to $50 \mu \mathrm{m}$ (and even beyond) and depends on the shape anisotropy of the CNCs, polydispersity in length and width [272,273]-longer CNCs give longer pitch $[265,268]-$, concentration that drives the minimisation of excluded volume [273], ionic strength of the CNCs-solvent suspension which regulates the charges on CNCs $[265,275,276]$, drying 
temperature [276] and application of a shear alignment [277]. The glass formation after the quenching (drying) is a non-equilibrium process, which is delicate to control, thus strong pitch variations may occur (Fig. 22) in the quenched state with time and from one region to another. A competition between glass formation and LC self-assembly governs the formation of the targeted helical structure. Both processes are promoted by the high aspect ratio of CNC rods. The fundamental issues related to this sensitive balance have yet to be fully understood; they have been discussed by Lagerwall et al. [278]. The kinetic arrest, leading to the glass formation, in the later stages of evaporation is of importance while producing uniform films and reproducibly controlling the pitch [279].

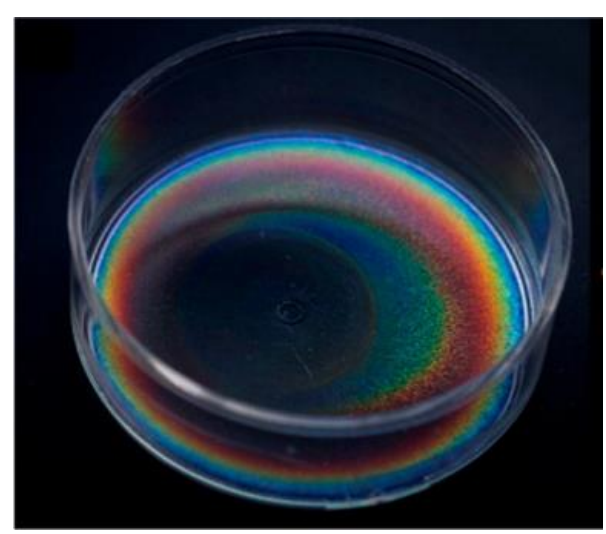

Fig. 22. Dry cholesteric film in a Petri dish formed from a 4 wt.\% eucalyptus CNCs-water suspension. The rainbow-like variation of colour is related to the pitch gradient. It comes from the gradient in the concentration and thickness consequent to the slow drying at an ambient temperature. Both CNC concentration and film thickness decrease from the edge of the dish towards the centre. When the water has completely evaporated the colour variation is locked into a solid film [273]. Creative Commons Attribution (CC-BY).

The CNCs extracted from filter paper [275], wood pulp [267] and bacterial cellulose [268] showed a decrease in the pitch in suspensions with an increasing CNC concentration. Although the origin of 
twist in lyotropic CLCs [280] is still debateable, it is generally accepted that the proximity between chiral particles decreases the pitch, whereas an increasing inter-particle distance increases it. The film colour can be shifted toward shorter wavelengths by increasing the concentration prior to film casting [265] or toward longer wavelengths by the ultrasonication of the suspension [281]. The added electrolyte partially masks the negative charges of the sulphate ester groups, reducing interparticle electrostatic repulsions and shortening the pitch in a predictable manner.

Vacuum-assisted drying can play some role in the film colour [282]. The films that are prepared at ambient conditions generally show a polydomain structure but applying a magnetic field during the drying can induce homogeneity in the size and orientation of domains $[266,283]$. The drying of suspension with the control of time and in the presence of $0.2 \mathrm{~T}$ magnetic field increases the pitch [284]. The colour can be changed by applying electric field [285] and could also be affected by humidity, so the films might be used as moisture sensors [286,287].

7.2.3. Origin of twist and other questions to be answered-The CLC phase formation in CNC suspensions can be explained by the phase equilibrium theories related to colloidal LCs such as the Onsager theory [264] or its extended version - the Stroobants, Lekkerkerker, and Odijk (SLO) theory [288]. However, the explanations for this formation remain speculative, as the electrostaticallystabilised CNC suspensions contain only pure water and crystallites with charged surface groups. The question is, 'What is the source of chiral interactions?' On the basis of in situ small angle neutron scattering measurements in CNC suspensions under magnetic field and shear alignment, Orts et al. [277] confirmed that CNCs are screw-like rods. Araki and Kuga [289] showed that the CNCs from bacterial cellulose (produced by Acetobacter xylinum in Nata de coco gel) form a nematic phase in an electrolyte-free suspension and a CLC phase consecutive to the addition of a trace electrolyte $(<1$ $\mathrm{mM} \mathrm{NaCl}$ ). This phenomenon was explained by morphological changes from a plain cylindrical configuration to a twisted rod, an outcome of surface charge masking (Fig. 23). In conditions of extreme deionisation, the charge double-layer may alter the screw-like character of the crystalloids 
from some sources of cellulose and lead to the formation of a nematic phase. The authors concluded that the twisted particle geometry is the most likely mechanism of the formation of the CLC phase. In other words, the chiral interactions would arise from the shape of the rods and not from the chiral nature of cellulose chains. It has to be kept in mind that the films of CNCs bear chirality on three different scales: on the molecular level because of the asymmetric carbon atoms of each D-glucose unit; on the nanoscale because of the screw-shape morphology of the individual crystals; and on the mesoscopic scale with the LH CLC structure. A chronological and detailed review of different contributions about the origin of twist in cellulosic materials has been discussed by Conley et al. [290].

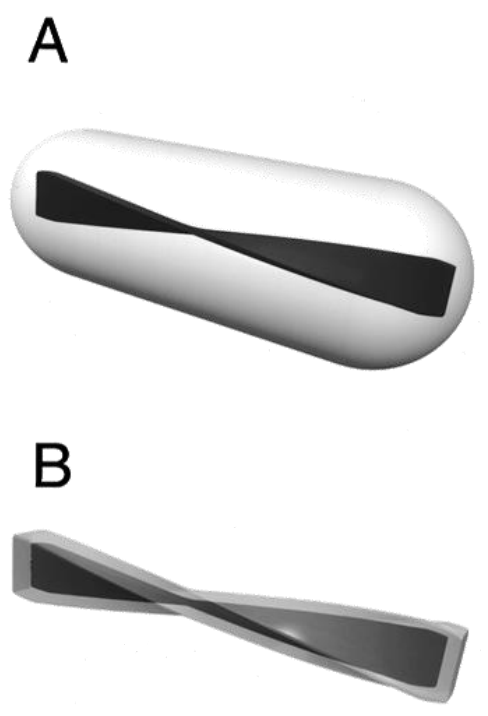

Fig. 23. Schematic illustration of cellulose nanocrystals with surface charge showing the change in effective particle shape. (a) In water, repulsion by surface charge extends to a long range. The particle (nanocrystal) appears as an achiral rod. (b) The addition of $\mathrm{NaCl}$ decreases the repulsion range and the particle appears as a twisted rod [289]. Copyright (C 2001, American Chemical Society.

In addition to the controversies regarding the self-organisation of CNCs in aqueous suspensions, the attribution of colour to Bragg's band has been challenged on the basis of observations of pitch that is 
too long for the reflection to take place in the visible range [291]; and a surprising dependence of the phase sequence and pitch variation with the ionic strength has been observed in some systems [268]. The open questions about the stumbling blocks in the progress in the field of CNCs-based materials and their applications are discussed by Lagerwall et al. [278]. The exact role of factors influencing the optical properties of CLC films prepared from CNC suspensions remains to be a qualitative one and the interplay between the chiral interactions and kinetic factors during film formation is still poorly understood [260].

7.2.4. Potential applications-Cellulose-based products are widespread but are still primarily used for low-tech applications such as banknotes, information storage and packaging [292]. There is a growing interest in applying cellulose to advanced technologies as it is a widely available and renewable resource. The cholesteric design of cellulose may help in transforming it into an advanced material. The solid films with the attractive optical properties of cholesteric structures render them as promising candidates for novel applications $[255,263,278,284,292]$ such as in anti-counterfeiting components in security papers (banknotes, passports, certificates) - since optical features cannot be reproduced by photocopying or usual printing-, polarising mirrors, mirrorless lasing lasers, intelligent packaging materials, printed paper electronic devices, additives for paints, inks and cosmetic products and optical encryption.

The films made from CNCs may be problematic in certain applications due to their inherent susceptibility to re-dispersion in water, and it is yet challenging to produce uniform planar textures leading to highly reflective films with high pitch reproducibility. 


\section{Viruses}

There is a debate as to whether viruses can be considered as living organisms [293-295]. A virus cannot grow or multiply on its own (it can replicate inside the living cells of other organisms) but at the same time, it contains genes, which give it an ability to mutate and evolve.

The filamentous viruses like tobacco mosaic virus (TMV), M13 and $f d$ are present as rod-like particles. As for CNCs, the suspensions of rod-like viruses may exhibit LC phases. TMV was the first virus to be isolated and purified [296]. Onsager showed theoretically that the anisotropic phase of TMV suspensions is a nematic phase for purely entropic reasons [264].

Since the year 2000, the experimental studies on LC phases in virus suspensions have mainly focused on $f d$ suspensions [297]. $F d$ virus is a micrometer-length semi-flexible polyelectrolyte with a diameter of $6.6 \mathrm{~nm}$. It contains single stranded DNA helicoidally wrapped by proteins, making it a chiral particle with a helical charge distribution. Isotropic, cholesteric [298], smectic A and smectic C [299] phases are displayed by increasing rod concentration ([300] and references therein). A set of characteristics, such as rich polymorphism including CLC phase, high monodispersity, surface properties ([301] and references therein), and ease for technical investigations (e.g. optical microscopy) due to the large size of $f d$ particles, have made them highly valuable systems to explore the complex relationship between the chirality of individual bricks and the chirality of their self-assembly [302]. While TMV [296] and pf1 [297] viruses have a helical structure extremely similar to $f d$, they exhibit a nematic phase. This behaviour is not understood. A reversible temperaturedriven transition between the cholesteric and nematic states is possible in M13 virus suspensions by heating it above $40^{\circ} \mathrm{C}$ and incubating for several days [303].

Various chemical modifications of $f d$ virus capsid (protein shell of the virus) have shown that the particle interactions due to surface charges, in addition to particle chirality, play an important role in the origin of the twist [301]. When $f d$ virus is grafted with the neutral polymer polyethylene glycol 
(PEG), the $f d$-PEG suspensions yet exhibit a CLC phase, which means that chiral interactions between the rods are not hampered [302]. Slight differences in the surface properties of rod-like viruses with very similar molecular structures can strongly change the self-assembly behaviour.

The origin of twist in the cholesteric phase of virus suspensions is an open question.

\section{Silk}

Silk is produced by spiders, the larvae of Bombyx mori mulberry silkworm and numerous other arthropods [304]. Silk fibre is mainly composed of fibroin proteins.

A CLC phase in fibroin was observed in the early duct portion of the major silk-producing gland in Nephila clavipes spider and Bombyx mori [305]. The investigations were performed by cryogenically quenching the animals during the spinning process. The morphology of the material within the silk gland was studied by TEM, electron diffraction, and atomic force microscopy. Until this study, only a nematic texture was reported in silk solutions $[306,307]$, as the consequence of rod-like aggregates of globular or coiled protein chains [307]. However, these ex situ observations may differ from the structure present in the gland under natural spinning conditions, and a material in a cholesteric state at equilibrium may untwist to a nematic state while flowing [308]. Fibroin may form chiral secondary structures, which could explain the CLC organisation [305]. A band texture assigned to a CLC phase was also observed in a film formed by an aqueous solution of pure fibroin prepared from Bombyx mori cocoon at the interface with hexane [309].

Apart from these early investigations [305,309], there have been no further studies exploring cholesteric silk. The discussion on the liquid crystallinity of silk has mainly focused on the nematic state [310,311]. Owing to the liquid crystallinity of spinning dope (material from which silk is spun), spiders can draw it during the extrusion into a hardened fibre using minimal forces [312]. Liquid 
crystallinity reduces the fibre formation energy budget by minimising a viscous drag. This process involves an unusual internal drawdown within the spider's spinneret followed by a conventional external drawdown after the dope has left the spinneret. A better understanding of this process, including the detailed LC behaviour and properties of silk, may help industrial production of silkbased fibres with unique properties under benign conditions. Spider silk has indeed outstanding mechanical properties while being spun at close to an ambient temperature and pressure, and simply with water as solvent. Viscoelastic modelling of silk spinning process sheds some light on the textural transitions in the duct of spiders and silkworms [313]. The concerted structuring action of capillary confinement, strong anchoring, and nematic flow leads to the predictions that agree with experimental textural transitions [314].

\section{Cholesterol ester deposition in atherosclerosis}

Atherosclerosis - the primary cause of heart disease and stroke-is characterised by the progressive accumulation of lipids and fibrous plaques in large arteries [315]. The lipid composition of the normal young aortic intima (the innermost layer of the aorta) mainly includes phospholipids. Free cholesterol is also present but cholesterol esters are either absent or present in trace amounts [316]. During the development of atherosclerosis, cholesterol esters become increasingly abundant. In the more advanced cases, cholesterol and its esters predominate. The relationship between phospholipids, cholesterol, cholesterol esters and water could be displayed by a quaternary phase diagram [316], which helps define the states of lipids in relation to the environment of the intima. Cholesterol esters of long chain fatty acids may exhibit at body temperature isotropic, cholesteric, lamellar (smecticlike), and crystal phases [317-319], according to the type of esters and relative concentration.

The knowledge of LC phases in the lesions of arterial wall may allow predicting the possible reversibility of atherosclerosis disease. The fluid lipid phases-isotropic phase and LC phases-may 
be removed metabolically while the crystallised lipids may be more problematic and require surgery. The reversibility of lipid lesions might depend partly on the lipid phases present and on the composition of these phases. However, it remains unclear that how to promote isotropic and LC phases and the stability of LC phases, at the detriment of crystalline deposits. How to promote the presence of the CLC phase at the detriment of (more ordered) lamellar phases?

Except for a few studies in 1970s and 1980s, we could not find any recent studies on LC phases involved in arterial diseases. It seems that little attention has been paid to the physical states of cholesterol esters in last few decades.

\section{Summary and concluding remarks}

The cholesteric organisation is a recurring design in the animal and plant kingdoms. Its biological importance suggests the convergent evolution of an optimised left-handed helicoidal structure. Nucleic acids, polysaccharides, proteins and lipids have a predominant cholesteric organisation in the living matter. These are four major types of molecules essential to life. Cholesteric organisation is mainly found in:

- DNA and chromatin;

- polysaccharide fibres in polysaccharide matrix (plant cell wall) or in protein matrix (arthropod cuticle);

- protein fibres in polysaccharide matrix (bone) or in protein matrix (eggshells: fish, brine shrimp, moth [320]).

The multifunctionality of biological CLCs is objectified by the combination of maximising packing efficiency and reduction in the energy costs incurred in the processing, with mechanical and optical 
properties. In summary, we gather and categorise the roles and possible functions brought by the CLC structure:

- Packing efficiency:

$\checkmark$ Cholesteric structure offers a high local DNA concentration, which is required for DNA to function.

$\checkmark$ Cholesteric defects could correspond to a geometrical solution of a local overcrowding consecutive to the replication of the DNA molecule.

$\checkmark \quad$ Highly uniform cholesteric collagen films are capable of inducing contact guidance for osteoblasts in bone.

- Morphogenesis:

$\checkmark$ A cholesteric structure can exist prior to collagen fibrillogenesis and offer a basic morphogenetic scaffold for collagen patterning in tissues. Cholesteric organisation of collagen may play a peculiar role in the determination of tissue form.

$\checkmark$ A cholesteric scaffold may contribute to the properly driven collagen fibre assembly to target in vivo bone regeneration.

\section{- Mechanical stability:}

The cholesteric structure:

$\checkmark$ guarantees that the chitin-protein fibres reinforce the cuticle and is suitable to dissipate significant amounts of energy during the impact loadings with the benefit of a reduced weight; in cephalopods, the cholesteric structure looks like the solution to a mechanical adaptation against the hydrostatic load; 
$\checkmark$ adapts to tensile loading by allowing the 'layers' to rotate towards or away from the applied tensile stress and prevents fracture and its propagation; cholesteric collagen lends to sea animals a specifically resistant armour against predators;

$\checkmark$ provides the plant better resistance against environmental stresses, by combining a balance of strength in all directions with flexibility;

$\checkmark$ may offer resistance of plant cell wall to turgor pressure equally in different directions.

Cholesteric collagen may offer resistance to:

$\checkmark \quad$ load in bone: cholesteric structure may confer an enhanced resistance against fracture initiation and propagation in one or several directions;

$\checkmark$ stretch or shear in tendons and ligaments: cholesteric organisation provides them with the capacity to withstand large forces without stretching more than a few percent of their length, making movement possible;

$\checkmark$ pressure in the cornea, by providing equal stiffness in all directions, which maintains the spherical shape of the cornea and so reduces spherical aberrations.

\section{- Optical information:}

Unique optical signatures of CLC structure may help:

$\checkmark$ animals in sexual communication and selection, social signalling (recognition with conspecifics or intra-species communication), warning against predators, camouflage to avoid predation, communication and navigation within a fish school;

$\checkmark$ plants to maintain attractiveness to animals (for iridescent fruits), since structural colours, unlike the pigmental colours, do not fade with time (cf. cholesteric fossils of beetles) or indicate aging while it happens that iridescence changes over time (in adult fern leaves). 


\section{- Radiation protection:}

$\checkmark$ IR thermoregulation for diurnal beetles and beach-dwelling crabs;

photo-protection against sun-flecks for plants adapted to low light conditions.

- Evolutionary context: The biological CLCs offer a set of optical features using the materials whose refractive indices vary in a narrow range. The reason, rather than in the composition, lies in the helicoidal geometry. Since colour can be changed only by changing the pitch, the selective pressure of evolution can be considered as lower in return.

Open questions have been mentioned and discussed in appropriate contexts throughout the article and thus will not be repeated in this section. However, as concluding remarks, we would like to recall a selective set of considerations of possible interest for current and future investigations. (i) It would be of great interest to explore why a similar organisation is found in distant biological materials, differing in their chemical composition, function and phylogenetic positions. Arced patterns are found in several diverse tissues of animal and plant groups, mainly extracellular matrices, connective and skeletal tissues, and in several intracellular differentiations. (ii) The CLC organisation is involved in most physical aspects of biological morphogenesis with specific defects and textures whose investigation has to be pursued in details at a small scale, probably with updated or novel imaging techniques. The problem is the comprehension of the differentiation of biological CLCS as what comes from liquid crystallinity of the initial secretion and what is controlled by cells. (iii) It might also be interesting to make models of CLC structures for biomimicry. CLCs are rarely considered in applied biology, although there are considerable perspectives. New mineralised biocomposites with a CLC organisation of the organic part could serve as implants. The investigation of nucleation and growth of mineral phases in the confined environment of matrices mimicking cholesteric organisations has to be continued, which could give rise to interesting problems of physics in confined geometry with inorganic-organic interfaces. Several issues for future investigations, of which some are relevant, have been compiled elsewhere [72,162,180,321-326]. 


\section{Acknowledgements}

I gratefully acknowledge Prof. Derek G. Gray (McGill University, Montreal, Canada) and Prof. Young-Hwa Goo (Albany Medical College, New York, USA) for fruitful discussions on cholesteric cellulose and atherosclerosis, respectively.

\section{References}

[1] G. H. Brown and W. G. Shaw, Chem. Rev., 1957, 57, 1049-1157.

[2] G. W. Gray, Molecular Structure and Properties of Liquid Crystals, Academic Press, London and New York, 1962.

[3] J. A. Castellano, Liquid Gold-The Story of Liquid Crystal Displays and the Creation of an Industry, World Scientific, Singapore, 2005, p. 48.

[4] T. J. Sluckin, D. A. Dunmur, and H. Stegemeyer, Crystals that flow-Classic papers from the history of liquid crystals, Taylor \& Francis, 2004.

[5] D. Dunmur and T. Sluckin, Soap, science, \& flat-screen TVs-A history of liquid crystals, Oxford University Press, 2011.

[6] M. Mitov, ChemPhysChem, 2014, 15, 1245-1250.

[7] A. Figueiredo Neto and S. R. A. Salinas, The Physics of Lyotropic Liquid Crystals, Oxford Science Publications, 2005.

[8] Thermotropic Liquid Crystals, ed. A. Ramamoorthy, Springer, New York, 2010.

[9] V. Luzzati, in Biological membranes, ed. D. Chapman, vol. 1, Academic Press, New York, 1968, p. 71.

[10] T. A. Waigh ,P. Perry ,C. Riekel, M. J. Gidley and A. M. Donald, Macromol., 1998, 31, 79807984. 
[11] V. Grassert and V. Vill, Liq. Cryst. Today, 1994, 4, 4-5.

[12] O. Lehmann, Die neue welt der flüssigen kristalle, Akademische Verlagsgesellschaft m.b.H., Leipzig, 1911.

[13] Y. Bouligand, in Liquid Crystal Order in Polymers, ed. A. Blumstein, Academic Press, New York, 1978, pp. 269-274.

[14] D. W. L. Hukins and J. Woodhead-Galloway, Mol. Cryst. Liq. Cryst., 1977, 41, 33-39.

[15] I. Hamley, Soft Matter, 2010, 6, 1863-1871.

[16] F. Reinitzer, Liq. Cryst. 1989, 5, 7-18 (translation from the German of the original paper published in Monatshefte für Chemie 1888, 9, 421-441).

[17] R. Virchow, Virchows Archiv., 1854, 6, 571.

[18] C. Mettenheimer, Corr. blatt d. Vereins gem. Arbeit z. Förd. d. wiss. Heilkunde, 1857, 24, 331.

[19] A. Trokhymchuk, Cond. Matt. Phys., 2010, 13, 37002: 1-4.

[20] E. Haeckl, in foreword of Crystal Souls-Studies of Inorganic Life (1917), translated by A. L. Mackay, Forma, 1999, 14, 1-240.

[21] G. Friedel, Ann. de Phys., XVIII, 273-474, 1922.

[22] O. D. Lavrentovich and M. Kleman, in Chirality in Liquid Crystals, Eds. H.-S. Kitzerow \& C. Bahr, Springer, New York, 2001, pp. 115-158.

[23] R. Smith, D. R. Sabatino and T. J. Praisner, Exp. in Fluids, 2001, 30, 190.

[24] Y. Han, K. Pacheco, C. W. M. Bastiaansen, D. J. Broer and R. P. Sijbesma, J. Am. Chem. Soc., 2010, 132, 2961-2967.

[25] J. Stasiek, A. Stasiek, M. Jewartowski and M. W. Collins, Optics \& Laser Tech., 2006, 38, 243256.

[26] A. Saha, Y. Tanaka, Y. Han, C. M. W. Bastiaansen, D. J. Broer and R. P. Sijbesma, Chem. Commun., 2012, 48, 4579-4581.

[27] H. Hirschmann and V. Reiffenrath, in Handbook of Liquid Crystals, Vol. 2A (Eds. D. Demus, J. Goodby, G. W. Gray, H.-W. Spiess, V. Vill), Wiley-VCH, Weinheim, Germany, 1998, p. 199. 
[28] N. Tamaoki, Adv. Mat., 2001, 13, 1135.

[29] J. Chen and C. T. Liu, IEEE Access, 2013, 1, 150-158.

[30] S.-T. Wu and D.-K. Yang, Reflective Liquid Crystal Displays, John Wiley \& Sons Ltd., Chichester, England, 2001.

[31] I. P. Ilchishin and E. A. Tikhonov, Progr. in Quant. Elec., 2015, 41, 1-22

[32] H. Khandelwal, R. C. G. M. Loonen, J. L. M. Hensen, M. G. Debije and A. P. H. J. Schenning, Scientif. Reports, 2015, 5, 11773.

[33] L. Y. Zhang, Y. Z. Gao, P. Song, X. J. Wu, X. Yuan, B. F. He, X. W. Chen, W. Hu, R. W. Guo, H. J. Ding, J. M. Xiao and H. Yang, Chin. Phys. B, 2016, 25, 096101.

[34] T. Engels and W. von Rybinski, J. of Mat. Chem., 1998, 8, 1313.

[35] D. Coates, Liq. Cryst., 2015, 42, 653-665.

[36] R. Balamurugan and J.-H. Liu, Reac. Func. Polym., 2016, 105, 9-34.

[37] F. Y. Biga, F. I. Luks, J. W. McMurdy and G. P. Crawford, in Liquid Crystals - Frontiers in Biomedical Applications, Eds. S. J. Woltman, G. D. Jay and G. P. Crawford, World Scientific, 2007, pp. 81-147.

[38] Y. Bouligand, C. R. Acad. Sci. Hebd. Seances Acad. Sci. D, 1965, 261, 4864-4867.

[39] Y. Bouligand, Tissue \& Cell, 1972, 4, 189-217.

[40] M.-M. Giraud-Guille, Int. Rev. of Cytology, 1996, 166, 59-101.

[41] O. F. Aguilar Gutierrez and A. D. Rey, Soft Matter, 2014, 10, 9446-9453.

[42] O. F. Aguilar Gutierrez and A. D. Rey, Soft Matter, 2016, 12, 1184-1191.

[43] M.-M. Giraud-Guille, Tissue \& Cell, 1986, 18, 603-620.

[44] L. Besseau and M.-M. Giraud Guille, J. Mol. Biol., 1995, 251, 197-202.

[45] G. De Luca and A. D. Rey, Eur. Phys. J. E, 2003, 12, 291-302.

[46] A. C. Neville, Biology of fibrous composites-Development beyond the cell membrane, Cambridge University Press, 1993.

[47] A. D. Rey, Soft Matter, 2010, 6, 3402-3429. 
[48] A. D. Rey, E. Herrera-Valencia and Y. K. Murugesan, Liq. Cryst., 2014, 41, 430.

[49] Y. K. Murugesan, D. Pasini and A. D. Rey, J. Renew. Mater., 2015, 3, 56-72.

[50] V. Luzzati and A. Nicolaieff, J. Mol. Biol., 1959, 1, 127-133.

[51] C. Robinson, Tetrahedron, 1961, 13, 219-234.

[52] F. Livolant and A. Leforestier, Prog. Polym. Sci., 1996, 21, 1115-1164.

[53] P. Carrivain, A. Cournac, C. Lavelle, A. Lesne, J. Mozziconacci, F. Paillusson, L. Signon, J.-M. Victor and M. Barbi, Soft Matter 8, 9285-9301 (2012).

[54] A. Leforestier and F. Livolant, Biophys. J., 1993, 65, 56-72.

[55] P. P. Crooker, in Chirality in Liquid Crystals, Eds. H.-S. Kitzerow \& C. Bahr, Springer, New York, 2001, pp. 186-222.

[56] M. de Frutos, A. Leforestier and F. Livolant, Biophys. Rev. and Lett., 2014, 9, 81-104.

[57] T. P. Fraccia, G. Zanchetta, V. Rimoldi, N. A. Clark and T. Bellini, Orig. Life Evol. Biosph., 2015, 45, 51-68.

[58] F. Livolant, Physica A, 1991, 176, 117-137.

[59] A. G. Cherstvy, Phys. Chem. Chem. Phys., 2011, 13, 9942-9968.

[60] A. G. Cherstvy, J. Phys. Chem. B, 2008, 112, 12585-12595.

[61] A. Minksy, E. Shimoni and D. Frenkiel-Krispin, Nature Rev. Molec. Cell Biol., 2002, 3, 50-60.

[62] R. L. Rill, F. Livolant, H. C. Aldrich and M. W. Davidson, Chromosoma, 1989, 98, 280-286.

[63] Y. Bouligand, Tissue \& Cell, 1972, 4, 189-217.

[64] M. H. Chow, K. T. H. Yan, M. J. Bennett and J. T. Y. Wong, Eukaryotic Cell, 2010, 9, 1577-1587.

[65] G. Zanchetta, F. Giavazzi, M. Nakata et al., Proc. Natl. Acad. Sci. USA, 2010, 107, 17497-17502.

[66] E. Frezza, F. Tombolato and A. Ferrarini, Soft Matter, 2011, 7, 9291-9296.

[67] A. B. Harris, R. D. Kamien and T. C. Lubensky, Phys. Rev. Lett., 1997, 78, 1476-1479.

[68] A. Kornyshev, D. J. Lee, S. Leikin and A. Wynveen, Rev. Mod. Phys., 2007, 79, 943-996.

[69] F. Tombolato and A. Ferrarini, J. Chem. Phys., 2005, 122, 054908.

[70] T. Bellini, R. Cerbino and G. Zanchetta, Top. Curr. Chem., 2011, 318, 225-279. 
[71] M. Rinaudo, Prog. Polym. Sci., 2006, 31, 603-632.

[72] M. Mitov, Adv. Mater., 2012, 24, 6260-6276.

[73] D. Raabe, C. Sachs and P. Romano, Acta Materialia, 2005, 53, 4281-4292.

[74] D. Raabe,P. Romano, C. Sachs, A. Al-Sawalmih, H.-G. Brokmeier, S.-B. Yi, G. Servos and H.G. Hartwig, J. Cryst. Growth, 2005, 283, 1-7.

[75] P. Romano, H. Fabritius, D. Raabe, Acta Biomater., 2007, 3, 301-309.

[76] S. Nikolov, M. Petrov, L. Lymperakis, M. Friak, C. Sachs, H.-O. Fabritius, D. Raabe and J. Neugebauer, Adv. Mater., 2010, 22, 519-526.

[77] M. M. Giraud-Guille, Tissue \& Cell, 1984, 16, 75

[78] M. M. Giraud-Guille, J. Struct. Biol., 1990, 103, 232.

[79] M. M. Giraud-Guille, Curr. Opin. Solid State Mater. Sci., 1998, 3, 221.

[80] P.-Y. Chen, A. Y.-M. Lin, J. McKittrick and M. A. Meyers, Acta Biomater., 2008, 4, 587-596.

[81] J. C. Weaver, G. W. Milliron, A. Miserez, K. Evans-Lutterodt, S. Herrera, I. Gallana, W. J. Mershon, B. Swanson, P. Zavattieri, E. DiMasi and D. Kisailus, Science, 2012, 336, 1275-1280.

[82] N. Guarín-Zapata, J. Gomez, N. Yaraghi, D. Kisailus and P. D. Zavattieri, Acta Biomater., 2015, 23, 11-20.

[83] A. G. Checa, J. H. E. Cartwright, I. Sanchez-Alamzo, J. P. Andrade and F. Ruiz-Raya, Scientific Reports, 2015, 5, 11513.

[84] S. Hunt and A. El Sherief, Tissue \& Cell, 1990, 22, 191-197.

[85] J. H. E. Cartwright and A.G. Checa, J. R. Soc. Interface, 2007, 4, 491-504.

[86] K. Hwang and A. D. Rey, Appl. Optics, 2005, 44, 4513-4522.

[87] O. F. Aguilar Gutierrez and A. D. Rey, Colloids Interface Sci. Commun., 2014, 3, 18-22.

[88] A. R. Parker, Optics \& Laser Tech., 2011, 43, 323-329.

[89] M. Théry and D. Gomez, Adv. Insect. Physiol., 2010, 38, 267-353.

[90] R. E. Silberglied and O. R. Taylor, Behav. Ecol. and Sociobiol., 1978, 3, 203-243.

[91] D. J. Kemp, Evol. Ecol. Res., 2006, 8, 515-527. 
[92] P. P. Bitton and R. D. Dawson, J. Avian Biol., 2008, 39, 446-452.

[93] S. Kinoshita, Structural Colors in the Realm of Nature, World Scientific Singapore, 2008.

[94] S.M. Doucet and M. G. Meadows, J. R. Soc. Interface, 2009, 6, S115-S132.

[95] L. P. Biro and J.-P. Vigneron, Laser Photonics Rev., 2011, 5, 27-51.

[96] K. Yu, T. Fan, S. Lou and D. Zhang, Prog. Mat. Sci., 2013, 58, 825-873.

[97] B. D. Wilts, H.M. Whitney, B. J. Glover, Ullrich Steiner and S. Vignolini, Mat. Today: Proc., 2014, 1S, 177-185.

[98] D. G. Stavenga, Mat. Today: Proc., 2014, 1S, 109 - 121.

[99] Y. Fu, C. A. Tippets, E. U. Donev and R. Lopez, WIREs Nanomed. Nanobiotechnol., 2016, 8, 758775.

[100] A. A. Michelson, Phil. Mag., 1911, 21, 554-567.

[101] P. Gaubert, C. R. Acad. Sci., 1924, 179, 1148-1150.

[102] C. Robinson, Mol. Cryst. Liq. Cryst., 1966, 1, 467-494.

[103] Y. Bouligand, J. Microscopie, 1967, 6, 41a.

[104] A. C. Neville and S. Caveney, Biol. Rev. Cambridge Phil. Soc., 1969, 44, 531-562.

[105] A. R. Parker, D. Mckenzie and M. Large, J. Exp. Biol., 1998, 201, 1307.

[106] S. Berthier, Iridescences, Springer New York, 2007.

[107] T. Lenau and M. Barfoed, Adv. Eng. Mat., 2008, 10, 299-314.

[108] A. E. Seago, P. Brady, J.-P. Vigneron and T. D. Schultz, J. R. Soc. Interface, 2009, 6, S165-S184.

[109] M. Srinivasarao, M. Crne, V. Sharma and J. O. Park, Scarab Beetle Iridescence, in Yearbook of Science and Technology 2011, McGraw-Hill, 2011.

[110] H. Arwin, R. Magnusson, J. Landin and K. Järrendahl, Phil. Mag., 2012, 92, 1583-1599.

[111] H. Goldstein, Appl. Optics, 2006, 45, 7944-7950.

[112] R. Hegedüs. G. Szél and G. Horváth, Vis. Res., 2006, 46, 2786-2797.

[113] D. E. Azofeifa, M. Hernandez-Jimenez, E. Libby, A. Solis, C. Barboza-Aguilar and W. E. Vargas, J. Quant. Spectrosc. Radiat., 2015, 160, 63-74. 
[114] A. R. Parker, J. R. Soc. Interface, 2005, 2, 1.

[115] G. Agez, C. Bayon and M. Mitov, Acta Biomater., 2017, 48, 357-367

[116] D. B. Thomas, A. Seago and D. C. Robacker, Amer. Entomol., 2007, 53, 224-230.

[117] L. de Silva, I. Hodkinson, P. Murray, Q. H. Wu, M. Arnold, J. Leader and A. McNaughton, Electromag., 2005, 25, 391-408.

[118] K. Buhl, Z. Roth, P. Srinivasan, R. Rumpf and E. Johnson, Proc. SPIE, 2008, 7057, 1-8.

[119] S. A. Jewell, P. Vukusic and N. W. Roberts, N. J. of Phys., 2007, 9, 1-10.

[120] A. Crowe, Which New Zealand Insect?, Penguin, New Zealand, 2002.

[121] Liu, H. Yin, B. Dong, Y. Qing, L. Zhao, S. Meyer, X. Liu, J. Zi and B. Chen, Phys. Rev. E, 2008, 77, 012901.

[122] T. D. Schultz and M. A. Rankin, J. Exp. Biol., 1985, 117, 87-110.

[123] J. P. Vigneron, M. Ouedraogo, J.-F. Colomer and M. Rassart, Phys. Rev. E, 2009, 79, 021907.

[124] D. G. Stavenga, B. D. Wilts, H. L. Leertouwer and T. Hariyama, Phil. Trans. B, 2011, 366, 709723.

[125] M. Hernandez-Jimenez, D. E. Azofeifa, E. Libby, C. Barboza-Aguilar, A. Solis, L. Arce-Marenco, I. Garcia-Aguilar, A. Hernandez and W. E. Vargas, Opt. Mat. Expr., 2014, 4, 2632-2645.

[126] G. Agez, R. Bitar and M. Mitov, Soft Matter, 2011, 7, 2841-2847.

[127] C. Bayon, G. Agez and M. Mitov, Lab Chip, 2014, 14, 2063-2071.

[128] C. Bayon, G. Agez and M. Mitov, Optics Lett., 2015, 40, 4763-4766.

[129] I. Musevic, Liq. Cryst. Rev., 2016, 4, 1-34.

[130] H.E. Hinton, Proc. \& Trans. Brit. Entomol. Soc.,1973, 6, 43-54.

[131] T. R. Brosius and L. G. Higley, PeerJ, 2013, 1, e169.

[132] A. Pace, Science, 1972, 176, 678-680.

[133] Y. Bouligand, J. Phys. Colloq., 1969, 30, 90-103.

[134] V. Sharma, M. Crne, J. O. Park and M. Srinivasarao, Science, 2009, 325, 449-451.

[135] V. Sharma, M. Crne, J. O. Park and M. Srinivasarao, Mat. Today: Proc., 2014, 1S, $161-171$. 
[136] L. Fernandez del Rio, A. Arwin and K. Järrendahl, Thin Solid Films, 2014, 571, 410-415.

[137] L. Fernandez del Rio, A. Arwin and K. Järrendahl, Mat. Today: Proc., 2014, 1S, 172-176.

[138] M. Srinivasarao, Chem. Rev., 1999, 99, 1935-1961.

[139] R. Wehner, Scientific American, 1976, 23,106-115.

[140] P. Brady and M. Cummings, Amer. Nat., 2010, 175, 614-620.

[141] T.-H. Chiou, S. Kelinlogel, T. Cronin, R. Caldwell, B. Loeffler, A. Siddiqi, A. Goldizen and J. Marshall, Curr. Biol., 2008, 18, 429-434.

[142] Y. L. Gagnon, R. M. Templin, M. J. How and N. J. Marshall, Curr. Biol., 2015, 25, 3074-3078.

[143] K. Vulinec, Florida Entomol., 1997, 80, 132-141.

[144] D. Pye, Biol. J. Linnean Soc., 2010, 100, 585-596.

[145] H. Arwin, T. Berlind, B. Johs and K. Järrendahl, Optics Expr., 2013, 21, 22645-22656.

[146] R. L. Rutowski, A. C. Nahm and J. M. Macedonia, Funct. Ecol., 2010, 24, 767-775.

[147] V. Pegram, H. A. Han and R. L. Rutowski, Ethology, 2015, 121, 861-873

[148] T. D. Schultz, Coleop. Bull., 2001, 55, 153-163.

[149] A. C. Neville, in Insect Ultrastructure, ed. A. C. Neville, Blackwell, Oxford, 1970, 17-39.

[150] R. Crowson, The biology of the Coleoptera, Academic Press London, 1981.

[151] E. McNamara, D. E. G. Briggs, P. J. Orr, H. Noh and H. Cao, Proc. R. Soc. B, 2012, 279, 11141121.

[152] J. Sun, B. Bhushan and J. Tong, RSC Advances, 2013, 3, 14862-14889.

[153] Ref. [46], pp. 25-27.

[154] J. P. Vigneron, J. M. Pasteels, D. M. Windsor, Z. Vertesy, M. Rassart, Th. Seldrum, J. Dumont, O. Deparis, V. Lousse, L. P. Biro, D. Ertz and V. Welch, Phys. Rev. E, 2007, 76, 031907.

[155] S. Caveney, Proc. Roy. Soc. Lond. B., 1971, 178, 205.

[156] A. L. V. Davis, D. J. Brink, C. H. Scholtz, L. C. Prinsloo and C. M. Deschodt, Ecol. Entomol., 2008, 33, 771-779.

[157] V. L. Welch and J.-P. Vigneron, Opt. Quant. Electron, 2007, 39, 295-303. 
[158] S. C. Cowin, J. Biomech. Eng., 2000, 122, 553-569.

[159] U. G. K. Wegst, H. Bai, E. Saiz, A. P. Tomsia and R. O. Ritchie, Nature Mater., 2015, 14, 23-36.

[160] M. M. Giraud-Guille, L. Besseau and R. Martin, J. Biomech., 2003, 36, 1571-1579.

[161] M. Tang, S. Ding, X. Min, Y. Jiao, L. Li, H. Li and C. Zhou, Mat. Sci. Eng. C, 2016, 58, 977-985.

[162] M. M. Giraud-Guille, E. Belamie, G. Mosser, C. Helary, F. Gobeaux and S. Vigier, C. R. Chimie, $2008,11,245-252$.

[163] M.M. Giraud Guille, C. Helary, S. Vigier and N. Nassif, Soft Matter, 2010, 6, 4963-4967.

[164] M.M. Giraud-Guille, J. Mol. Biol., 1992, 224, 861-873.

[165] L. Besseau and M.M. Giraud-Guille, J. Mol. Biol., 1995, 251, 197-202.

[166] M.M. Giraud-Guille, L. Besseau, C. Chopin, P. Durand and D. Herbage, Biomater., 2000, 21, 899-906.

[167] R. Martin, J. Farjanel, D. Eichenberger, A. Colige, E. Kessler, D.J. Hulmes and M.-M. GiraudGuille, J. Mol. Biol., 2000, 301, 11-17.

[168] D. Eglin, G. Mosser, M.-M. Giraud-Guille, J. Livage and T. Coradin, Soft Matter, 2005, 1, 129131.

[169] M.M. Giraud Guille, G. Mosser, C. Helary and D. Eglin, Micron, 2005, 36, 602-608.

[170] J.E. Kirkwood and G.G. Fuller, Langmuir, 2009, 25, 3200-3206.

[171] M. M. Giraud-Guille, Calcif. Tissue Int., 1988, 42, 167-180

[172] Ref. [46], pp. 138-141.

[173] E. Baer, J. J. Cassidy and A. Hiltner, in Biomimetics, Design and Processing of Materials, eds. M. Sarikaya and I. A. Aksay, American Institute of Physics Press, New York, 1995, 13-34.

[174] M. M. Giraud-Guille and L. Besseau, Connect. Tissue Res., 1998, 37, 183-193.

[175] M.-M. Giraud-Guille, Biol. Cell., 1989, 67, 97.

[176] G. Mosser, A. Anglo, C. Helary, Y. Bouligand and M. M. Giraud-Guille, Matrix Biol., 2006, 25, 313. 
[177] F. Gobeaux, E. Belamie, G. Mosser, P. Davidson, P. Panine and M.-M. Giraud-Guille, Langmuir, 2007, 23, 6411-6417.

[178] A. J. Salgado, O. P. Coutinho and R. L. Reis, Macromol. Biosci., 2004, 4, 743-765

[179] R. Wise, S. Maltsev, M. E. Davies, M. J. Duer, C. Jaeger, N. Loveridge, R. C. Murray and D. G. Reid, Chem. Mater., 2007, 19, 5055-5057.

[180] Y. Bouligand, C. R. Chimie, 2008, 11, 281-296.

[181] H. Peterlik, P. Roschger, K. Klaushoffer and P. Fratzl, Nature Mater., 2006, 5, 52-55.

[182] S. Scaglione, P. Giannoni, P. Bianchini, M. Sandri and R. Marotta, G. Firpo, U. Valbusa, A. Tampieri, A. Diaspro, P. Bianco and R. Quarto, Scientif. Reports, 2012, 2, 00274.

[183] Y. Wang, T. Azaïs, M. Robin, A. Vallée, C. Catania, P. Legriel, G. Pehau-Arnaudet, F. Babonneau, M. M Giraud-Guille and N. Nassif, Nature Mater., 2012, 11, 724-733.

[184] B. Wingender, P. Bradley, N. Saxena, J. W. Rubertiand and L. Gower, Matrix Biol., 2016, 52-54, 384-396.

[185] V. L. C. Feitosa, F. P. Reis, M. A. M. Esquisatto, P. P. Joazeiro, B. C. Vidal and E. R. Pimentel, Micron, 2006, 37, 518-525.

[186] M. M. Giraud-Guille, G. Mosser and E. Belamie, Curr. Opin. Colloid Sci., 2008, 13, 303-313.

[187] Ref. [46], pp. 95-96.

[188] Ref. [46], p. 36.

[189] P. De Sa Peixoto, A. Deniset-Besseau, M. Schmutz, A.Anglo, C. Illoul, M.-C. Schanne-Kleinb and G. Mosser, Soft Matter, 2013, 9, 11241.

[190] M.M. Giraud-Guille, J. Castanet, F. J. Meunier and Y. Bouligand, Tissue \& Cell, 1978, 10, 671686.

[191] Ravneet, M. L. Sharma and H.P.S. Kang, J. Biomim., Biomater. and Tissue Engin., 2009, 4, 1320.

[192] N. Komatsu, N. Ogawa, K. Limura, K. Ura and Y. Takagi, Fisheries Science, 2014, 80, 1249-1256. 
[193] Z. Fang, Y. Wang, Q. Fenga, A. Kienzle and W. E.G. Müller, Mat. Sci. and Eng., 2014, C43, 145152

[194] L. Besseau and Y. Bouligand, Tissue \& Cell, 1998, 30, 251-260.

[195] W. Yang, S. E. Naleway, M. M. Porter, M. A. Meyers and J. McKittrick, Acta Biomater., 2015, 23, 1-10.

[196] H.-S. Kitzerow, ChemPhysChem, 2006, 7, 63-66.

[197] A. Bigi, M. Burghammer, R. Falconi, M. H. J. Koch, S. Panzavolta and C. Riekel, J. of Struct. Biol., 2001, 136, 137-143.

[198] E. A. Zimmermann, B. Gludovatz, E. Schaible, N.K.N. Dave, W. Yang, M. A. Meyers and R. O. Ritchie, Nature Commun., 2013, 4, 2634.

[199] E. J. Denton, Phil. Trans. R. Soc. Lond. B, 1970, 258, 285-313.

[200] M. Rowe and E. J. Denton, Phil. Trans. R. Soc. Lond. B, 1997, 352, 531-549.

[201] J. Denton, in Light and life in the sea, Eds. P. J. Herring, A. K. Cambell, M. Whitfield \& L. Maddock, Cambridge University Press, Cambridge, 1990, pp. 127-148.

[202] S. Zhao, P. C. Brady , M. Gao, R. I. Etheredge, G. W. Kattawar and M. E. Cummings, J. R. Soc. Interf., 2015, 12, 20141390.

[203] X. Guo, A. E. K. Hutcheon, S. A. Melotti, J. D. Zieske, V. Trinkaus-Randall and J. W. Ruberti, Invest. Ophthalmology \& Visual Sci., 2007, 48, 4050-4060.

[204] A. G. Matthysse, K. Deschet, M. Williams, M. Marry, A. R. White and W. C. Smith, Proc. Nat. Acad. Sci. USA, 2004, 101, 986-991.

[205] L. Dupuy, J. Mackenzie and J. Haseloff, Proc. Nat. Acad. Sci. USA, 2010, 107, 2711-2716.

[206] Ref. [46], p. 65.

[207] A. M. C. Emons and B.M. Mulder, Trends in Plant Sci., 2000, 5, 35-40.

[208] L. H. Thomas, V. T. Forsyth, A. Šturcová, C. J. Kennedy, R. P. May, C. M. Altaner, D. C. Apperley, T. J. Wess and M. C. Jarvis, Plant Physiol., 2013, 161, 465-476.

[209] A. C. Neville, BioEssays, 1985, 3, 4-8. 
[210] A. C. Neville, Planta, 1984, 162, 370-384.

[211] D. Reis, Mol. Cryst. Liq. Cryst., 1987, 153, 43-53.

[212] J. C. Roland, D. Reis, B. Vian, B. Satiat-Jeunemaitre and M. Mosiniak, Protoplasma, 1987, 140, 75-91.

[213] B. Vian, J. C. Roland and D. Reis, Int. J. Plant Sci., 1993, 154, 1-9.

[214] Ref. [46], pp. 28-29 and 42-45.

[215] Y. K. Murugesan and A. D. Rey, Polymers, 2010, 2, 766-785.

[216] Ref. [46], p. 97.

[217] J. Glover and H. M. Whitney, Annals of Botany, 2010, 105, 505-511.

[218] I. C. Gebeshuber and D. W. Lee, in Springer Encyclopedia of Nanotechnology, Eds. B. Bushan and M. Nosonovsky, Springer, Heidelberg, 2012, pp. 1790-1803.

[219] S. Vignolini, E. Moyroud, B. J. Glover and U. Steiner, J. Roy. Soc. Interface, 2013, 10, 20130394.

[220] P. Vukusic and D. G. Stavenga, J. Roy. Soc. Interface, 2009, 6, S133-S148.

[221] M. Whitney, M. Kolle, P. Andrew, L. Chittka, U. Steiner and B. J. Glover, Science, 2009, 323, 130-133.

[222] M. Whitney, M. Kolle, R. Alvarez-Fernandez R, U. Steiner and B. J. Glover, Commun. Integr. Biol., 2009, 2, 230-232.

[223] R. Thomas, M. Kolle, H. M. Whitney, B. J. Glover and U. Steiner, J. Roy. Soc. Interface, 2010, 7, 1699-1707.

[224] S. M. Diah, S. B. Karman and I. C. Gebeshuber, J. Nanomater., 2014, 878409.

[225] D. W. Lee, Nature's Palette: The Science of Plant Color, The University of Chicago Press, Chicago, Illinois, USA, 2007.

[226] J. Glover, J. Exp. Bot., 2000, 51, 497-505.

[227] C. Hébant and D. W Lee, Am. J. Bot., 1984, 71, 216-219.

[228] M. Graham, D. W. Lee and K. Norstog, Am. J. Bot., 1993, 80, 198-203.

[229] S. Gould and D. W. Lee, Am. J. Bot., 1996, 83, 45-50. 
[230] D. W. Lee, Amer. Scient., 1997, 85, 56-63.

[231] G. Strout, S. D. Russell, D. P. Pulsifer, S. Erten, A. Lakhtakia and D. W. Lee, Ann. Bot., 2013, 112, 1141-1148.

[232] M. Mitov, C. Portet, C. Bourgerette, E. Snoeck and M. Verelst, Nature Mater., 2002, 1, $229-231$.

[233] M. Mitov, C. Bourgerette and F. de Guerville, J. Phys. : Condens. Matter, 2004, 16, S1981S1988.

[234] R. Bitar, G. Agez and M. Mitov, Soft Matter, 2011, 7, 8198-8206.

[235] S. Vignolini, P. J. Rudall, A. V. Rowland, A. Reed, E. Moyroud, R. B. Faden, J. J. Baumberg, B. J. Glover and U. Steiner, Proc. Nat. Acad. Sci. USA, 2012, 109, 15712-15715.

[236] M. Mitov and N. Dessaud, Nature Mater., 2006, 5, 361-364.

[237] M. Mitov and N. Dessaud, Liq. Cryst., 2007, 34, 183-193.

[238] M. Galetti, in Seed dispersal and frugivory: Ecology, Evolution and Conservation, Eds. D. Levey, W. Silva and M. Galetti, CABI Publishing, Wallingford, Oxfordshire, UK, 2002, Chap. 12.

[239] E. Cazetta, L. S. Zumstein, T. A. Melo and M. Galetti, Rev. Bras. Bot., 2008, 31, 303-308.

[240] Y. Habibi, L. A. Lucia and O. J. Rojas, Chem. Rev., 2010, 110, 3479-3500.

[241] J. Chan, J. Microsc., 2012, 247, 23-32.

[242] A. C. Neville, J. Theor. Biol., 1988, 131, 243-254.

[243] Ref. [46], pp. 85-123.

[244] U. Kutschera, Ann. Bot., 2008, 101, 615-621.

[245] J. Chan, E. Crowell, M. Eder, G. Calder, S. Bunnewell, K. Findlay, S. Vernhettes, H. Höfte and C. Lloyd, J. Cell Sci., 2010, 123, 3490-3495.

[246] I. B. Heath, J. Theor. Biol., 1974, 48, $445-449$.

[247] F. Mandoli and W. R. Briggs, Photochem. Photobiol., 1984, 39, 419-424.

[248] S. McPherson, Plantsman, 2010, 9, 120-125.

[249] J. Eichhorn, Soft Matter, 2011, 7, 303-315 
[250] D. Klemm, F. Kramer, S. Moritz, T. Lindström, M. Ankerfors, D. Gray and A. Dorris, Angew. Chemie Int. Ed., 2011, 50, 5438-5466.

[251] R. J. Moon, A. Martini, J. Nairn, J. Simonsen and J. Youngblood, Chem. Soc. Rev., 2011, 40, 3941-3994.

[252] A. Dufresne, Nanocellulose, Walter de Gruyter, Berlin, Germany, 2012.

[253] A. Salas, T. Nypelö, C. Rodriguez-Abreu, C. Carrillo and O. J. Rojas, Curr. Opin. in Colloid \& Interface Sci., 2014, 19, 383-396

[254] M. Mariano, N. El Kissi and A. Dufresne, J. Pol. Sci., Part B: Polym. Phys., 2014, 52, 791-806.

[255] M. Giese, L. K. Blusch, M. K. Khan and M. J. MacLachlan, Angew. Chem. Int. Ed., 2015, 54, 28882910.

[256] R. J. Moon, G. T. Schueneman and J. Simonsen, JOM, 2016, 68, 2383-2394.

[257] J. Y. Zhu, W. Luo, P. N. Ciesielski, Z. Fang, J. Y. Zhu, G. Henriksson, M. E. Himmel and L. Hu, Chem. Rev., 2016, 116, 9305-9374

[258] T. Abitbol, A. Rivkin, Y. Cao, Y. Nevo, E. Abraham, T. Ben-Shalom, S. Lapidot and O. Shoseyov, Curr. Opin. in Biotech., 2016, 39, 76-88.

[259] A. G. Dumanli, G. Kamita, J. Landman, H. M. van der Kooij, B. J. Glover, J. J. Baumberg, U. Steiner and S. Vignolini, Adv. Optical Mater., 2014, 2, 646-650.

[260] D. G. Gray, Nanomater., 2016, 6, 1-9.

[261] J.-F. Revol, H. Bradford, J. Giasson, R.H. Marchessault and D. G. Gray, Int. J. Biol. Macromol., $1992,14,170-172$.

[262] B. L. Peng, N. Dhar, H. L. Liu and K. C. Tam, Can. J. Chem. Eng., 2011, 89, 1191- 1206.

[263] M. M. de Souza Lima and R. Borsali, Macromol. Rapid Commun., 2004, 25, 771-787.

[264] L. Onsager, Ann. N.Y. Acad. Sci., 1949, 51, 627.

[265] J.-F. Revol, L. Godbout and D. G. Gray, J. Pulp Paper Sci., 1998, 24, 146.

[266] C. D. Edgar and D. G. Gray, Cellulose, 2001, 8, 5.

[267] S. Beck-Candanedo, M. Roman and D. G. Gray, Biomacromol., 2005, 6, 1048-1054. 
[268] A. Hirai, O. Inui, F. Horii and M. Tsuji, Langmuir, 2009, 25, 497-502.

[269] D. G. Gray, Carbohydr. Polym., 1994, 25, 277-284

[270] R. S. Werbowyj and D. G. Gray, Macromolecules, 1980, 13, 69- 73.

[271] L. Yan, Q. Zhu and T. Ikeda, J. Appl. Polym. Sci., 2001, 82, 2770 -2774.

[272] S. Elazzouzi-Hafraoui, Y. Nishiyama, J.-L. Putaux, L. Heux, F. Dubreuil and C. Rochas, Biomacromol., 2008, 9, 57-65.

[273] A. G. Dumanli, H. M. van der Kooij, G. Kamita, E. Reisner, J. J. Baumberg, U. Steiner and S. Vignolini, ACS Appl. Mater. Interfaces, 2014, 6, 12302-12306.

[274] J. F. Revol, L. Godbout, X. M. Dong, D. G. Gray, H. Chanzy and G. Maret, Liq. Cryst., 1994, 16, $127-134$

[275] X. M. Dong, T. Kimura, J. F. Revol and D. G. Gray, Langmuir, 1996, 12, 2076.

[276] S. Beck, J. Bouchard, G. Chauve and R. Berry, Cellulose, 2013, 20, $1401-1411$.

[277] J. Orts, L. Godbout, R. H. Marchessault and J.-F. Revol, Macromolecules, 1998, 31, 5717-5725.

[278] J. P. F. Lagerwall, C. Schütz, M. Salajkova, J. Noh, J. H. Park, G. Scalia and L. Bergström, NPG Asia Materials, 2014, 6, e80; doi:10.1038/am.2013.69.

[279] C. Honorato-Rios, A. Kuhnhold, J. Bruckner, R. Dannert, T. Schilling and J. P. F. Lagerwall, Front. Mater., 2016, 3, 1-13.

[280] E. Figgemeier and K. Hiltrop, Liq. Cryst., 1999, 26, 1301-1305.

[281] S. Beck, J. Bouchard and R. Berry, Biomacromol., 2011, 12, 167-172.

[282] Q. Chen, P.Liu, F. Nan, L. Zhou and J. Zhang, Biomacromol., 2014, 15, 4343-4350

[283] M. Dong and D. G. Gray, Langmuir, 1997, 13, 3029-3034.

[284] J. Pan, W. Hamad and S. K. Straus, Macromol., 2010, 43, 3851-3858.

[285] Y. Nishio, T. Kai, N. Kimura, K. Oshima and H. Suzuki, Macromol., 1998, 31, 2384.

[286] P. Zhang, V. P. Chodavarapu, A. G. Kirk and M. P. Andrews, Sens. Actuators B, 2013, 176, $692-$ 697.

[287] T. Wu, J. Li, J. Li, S. Ye, J. Wei and J.Guo, J. Mater. Chem. C, 2016, 4, 9687-9696. 
[288] A. Stroobants, H. N. W. Lekkerkerker and T. Odijk, Macromol., 1986, 19, 2232.

[289] J. Araki and S. Kuga, Langmuir, 2001, 17, 4493-4496.

[290] K. Conley, L. Godbout, M.A. Whitehead and T. G.M. van de Ven, Carbohydrate Polym., 2016, 135, 285-299.

[291] J. Majoinen, E. Kontturi, O. Ikkala and D. G. Gray, Cellulose, 2012, 19, 1599-1605.

[292] M. Giese, L. K. Blusch, M. K. Khan, W. Y. Hamad and M. J. MacLachlan, Angew. Chem. Int. Ed., $2014,53,8880-8884$.

[293] D. Moreira and P. López-García, Nature Reviews Microbiology, 2009, 7, 306-311.

[294] N. R. Hegde, M. S. Maddur, S. V. Kaveri and J. Bayry, Nature Reviews Microbiology, 2009, 7, 615-617.

[295] S. Luketa, Protistology, 2012, 7, 218-237.

[296] F.C. Bawden, N.W. Pirie, J. D. Bernal and I. Fankuchen, Nature, 1936, 138, 1051-1052.

[297] Z. Dogic and S. Fraden, Langmuir, 2000, 16, 7820-7824.

[298] J. Lapointe and D. A. Marvin, Mol. Cryst. Liq. Cryst., 1973, 19, 269-78.

[299] Z. Dogic and S. Fraden, Phys. Rev. Lett., 1997, 78, 2417-2420.

[300] Z. Dogic and S. Fraden, Curr. Opin. Coll. \& Interf.Sci., 2006, 11, 47-55.

[301] Z. Zhang and E. Grelet, Soft Matter, 2013, 9, 1015.

[302] E. Grelet and S. Fraden, Phys. Rev. Lett., 2003, 90, 198302.

[303] S. Liu, T. Zan, S. Chen, X. Pei,H. Li and Z. Zhang, Langmuir, 2015, 31, 6995-7005.

[304] C. L. Craig, Spiderwebs and Silk, Oxford University Press, Oxford, 2003.

[305] J. Willcox, S. P. Gido, W. Muller and D. L. Kaplan, Macromol., 1996, 29, 5106-5110.

[306] K. Kerkam, C. Viney, D. Kaplan and S. Lombardi, Nature, 1991, 349, 596-598.

[307] C. Viney, A. E. Huber, D. L. Dunaway, K. Kerkam and S. T. Case, in Silk Polymers: Materials Science and Biotechnology, Eds. D. Kaplan, W. W. Adams, B. Farmer \& C. Viney, American Chemical Society, Washington, 1994.

[308] G. Kiss and R. S. Porter, J. Polym .Sci.: Polym. Phys. Ed., 1980, 18, 361-388. 
[309] R. Valluzzi, S .J. He, S. P. Gido and D. Kaplan, Int. J. Biol. Macromol., 1999, 24, 227-236.

[310] D. P. Knight and F. Vollrath, Proc. R. Soc. Lond. B, 1999, 266, 519-523.

[311] T. Asakura, K. Umemura,Y. Nakazawa,H. Hirose, J. Higham and D. Knight, Biomacromol., 2007, 8, 175-181.

[312] F. Vollrath and D. P. Knight, Nature, 2001, 410, 541-548.

[313] A. D. Rey and E. E. Herrera-Valencia, Biopolymers, 2012, 97, 374-396.

[314] A. D. Rey, Soft Matter, 2010, 6, 3402-3429.

[315] J. Lusis, Nature, 2000, 407, 233-241.

[316] D. M. Small and G. G. Shipley, Science, 1974, 185, 222-229.

[317] D. M. Small, in Surface Chemistry of Biological Systems, ed. M. Blank, Plenum Press, New York, 1970, p. 55.

[318] M. Hillman and D. M. Engelman, J. Clin. Invest., 1976, 58, 1008-1018.

[319] F. A. A. Sayeed and H. Schott, J. Colloid Interface Sci., 1986, 109, 140-149.

[320] Not addressed here in the absence of recent investigations and identified perspectives. Early studies can be found in Ref. [46] pp. 53-56 and 61-62.

[321] Y. Bouligand, C. R. Palevol., 2004, 3, 617-628.

[322] F. Livolant, S. Mangenot, A. Leforestier, A. Bertin, M. de Frutos, E. Raspaud and D. Durand, Phil.Trans. R. Soc. A, 2006, 364, 2615-2633.

[323] J. Woltman, G. D. Jay and G. P. Crawford, Nature Mater., 2007, 6, 929-938.

[324] A. R. Parker and H. E. Townley, Nature Nanotech., 2007, 2, 347-353.

[325] D. Deamer, Chem. Soc. Rev., 2012, 41, 5375-5379.

[326] K. Yu, T. Fan, S. Lou and D. Zhang, Progr. Mat. Sci., 2013, 58, 825-873. 